\title{
Palaeont ology
}

Rezbstered Charity no 2 thes

\section{A NEW PHYLOGENETIC HYPOTHESIS OF TURTLES WITH IMPLICATIONS FOR THE TIMING AND NUMBER OF EVOLUTIONARY TRANSITIONS TO MARINE LIFESTYLES IN THE GROUP}

\begin{tabular}{|c|c|}
\hline Journal: & Palaeontology \\
\hline Manuscript ID & PALA-02-18-4165-OA.R2 \\
\hline Manuscript Type: & Original Article \\
\hline Date Submitted by the Author: & 17-May-2018 \\
\hline Complete List of Authors: & $\begin{array}{l}\text { Evers, Serjoscha; University of Oxford, Department of Earth Sciences } \\
\text { Benson, Roger; University of Oxford, Department of Earth Sciences }\end{array}$ \\
\hline Key words: & $\begin{array}{l}\text { phylogeny, Chelonioidea, sea turtles, marine adaptation, evolutionary } \\
\text { transition, diversification }\end{array}$ \\
\hline
\end{tabular}

\section{SCHOLARONE \\ Manuscripts}




\section{A NEW PHYLOGENETIC HYPOTHESIS OF TURTLES WITH IMPLICATIONS FOR THE TIMING AND NUMBER OF EVOLUTIONARY TRANSITIONS TO MARINE LIFESTYLES IN THE GROUP}

by SERJOSCHA W. EVERS ${ }^{1}$ and ROGER B. J. BENSON ${ }^{1}$

${ }^{1}$ Department of Earth Sciences, University of Oxford, South Parks Road, OX1 3AN, UK; serjoscha.evers@earth.ox.ac.uk; roger.benson@earth.ox.ac.uk

\section{ABSTRACT}

Evolutionary transitions to marine habitats occurred frequently among Mesozoic reptiles. Only one such clade survives to the present: sea turtles (Chelonioidea). Other marine turtles originated during the Mesozoic, but uncertain affinities of key fossils have obscured the number of transitions to marine life, and the timing of the origin of marine adaptation in chelonioids. Phylogenetic studies support either a highly-inclusive chelonioid total-group including fossil marine clades from the Jurassic and Cretaceous (e.g. protostegids, thalassochelydians, sandownids), or a less inclusive chelonioid totalgroup, excluding those clades. Under this paradigm, these clades belong outside of Cryptodira, and represent at least one additional evolutionary transition to marine life in turtles. We present a new phylogenetic hypothesis informed by high resolution computed tomographic data of living and fossil taxa. Besides a well-supported Chelonioidea, which includes protostegids, we recover a previously unknown clade of stem-group turtles, Angolachelonia, which includes the Late Jurassic thalassochelydians, and the Cretaceous-Palaeogene sandownids. Accounting for the Triassic Odontochelys, 
our results indicate three independent evolutionary transitions to marine life in nonpleurodiran turtles (plus an additional two-three in pleurodires). Among all independent origins of marine habits, a pelagic ecology only evolved once, among chelonioids. All turtle groups that independently invaded marine habitats in the Jurassic-Cretaceous (chelonioids, angolachelonians, bothremydid pleurodires) survived the Cretaceous-Palaeogene mass extinction event. This highlights extensive survival of marine turtles compared to other marine reptiles. Furthermore, deeply-nested clades such as chelonioids are found by the mid Early Cretaceous, suggesting a rapid diversification crown-group turtles during the Early Cretaceous.

Key words: phylogeny, Chelonioidea, sea turtles, marine adaptation, evolutionary transition, diversification.

Turtles are a major group of reptiles and show high ecological diversity, inhabiting marine, freshwater, and terrestrial environments. The ancestral ecology for crown-turtles is inferred to be aquatic (Joyce \& Gauthier 2004), and there is evidence for variation between terrestrial and aquatic habitats among stem-group turtles (Joyce \& Gauthier 2004; Scheyer \& Sander 2007; Li et al. 2008; Reisz \& Head 2008; Scheyer et al. 2014; Cerda et al. 2016; Joyce 2017). As an ecologically diverse extant group with an excellent fossil record, turtles provide information on the evolutionary dynamics of ecological transitions in vertebrates, and in particular the secondary reversion to marine life. This transition is not well understood in reptiles, despite its occurrence in at least eighteen lineages among many higher groups (mesosaurs, thalattosaurs, ichthyosaurs, sauropterygians, crocodiliforms, rhynchocephalians, squamates, turtles) (Motani 2009; 
Benson 2013; Bardet et al. 2014). In part, this lack of understanding results from the extinction of most marine reptile groups by the end of the Mesozoic, or mid-Cenozoic.

Within turtles alone, multiple lineages independently adapted to marine life from as early as the Triassic (Gaffney et al. 2006; Li et al. 2008; Mateus et al. 2009; Anquetin et al. 2015; Ferreira et al. 2015). Of these, only chelonioids (sea turtles) survive to the present. Previous phylogenetic hypotheses imply at least four and as many as eight independent transitions to marine life in turtles, throughout their entire evolutionary history (e.g. Joyce 2007; Li et al. 2008; Mateus et al. 2009; Rabi et al. 2012; Anquetin et al. 2015). However, deep uncertainty regarding the phylogenetic affinities of several extinct groups renders the precise number highly uncertain. This lack of consensus on turtle phylogeny also affects our understanding of wider macroevolutionary dynamics, such as the mode and rate of morphological evolution during ecological transitions.

Extant turtles provide genetic (=molecular) data that help to constrain their phylogenetic relationships, and allow the estimation of divergence ages for subclades (e.g. Joyce et al. 2013). Morphological and molecular phylogenies have resulted in different hypotheses for the interrelationships of extant turtles (for instance regarding the monophyly and content of Chelydroidea: Shaffer et al. 1997; Parham et al. 2006; Joyce et al. 2013; Joyce 2016). Although morphological evidence has subsequently been found to support some of the propositions of molecular studies (e.g. Knauss et al. 2011 for the example of Chelydroidea), not all conflicting relationships among crown-turtles have yet been reconciled. At present, it is common for morphological studies of turtle phylogeny to use a backbone constraint informed by the results of molecular studies (Danilov \& Parham 2008; Cadena \& Parham 2015; Zhou \& Rabi 2015).

Nevertheless, analysis of morphological data remains important, because the placement of fossil taxa has to be established for a reliable tree calibration in molecular 
clock analyses (Near et al. 2005; Parham et al. 2012; Joyce et al. 2013). Additionally, the consideration of fossils is fundamental to understanding the patterns of morphological and ecological evolution during deep divergences, and in entirely extinct groups. This is maybe best documented by the evolutionary transition from fish to tetrapods (e.g. Ahlberg \& Milner 1994; Ahlberg et al. 1996; Carroll 1996; Ahlberg \& Johanson 1998; Long \& Gordon 2004; Clack 2009), and by the dinosaurian origins of birds (Ostrom 1975; Gauthier 1986).

Several Mesozoic turtle groups exemplify the difficulties associated with robustly fitting fossil taxa into the turtle tree. These include the marine thalassochelydians, sandownids and protostegids, as well as the freshwater xinjiangchelyids, sinemydids and macrobaenids. Most of these groups have been alternatively proposed to be stemgroup turtles, stem-group cryptodires, or within the crown-group of cryptodires as stem- or crown-group chelonioids, although this is in part caused by the instability of the position of pleurodires across studies (Sterli 2010). Because the placements of these groups influence reconstructions of morphological changes during deep evolutionary divergences, they have implications for the relative phylogenetic placements of other clades. Furthermore, different phylogenetic hypotheses give rise to distinct conclusions regarding: (1) the number of times that marine ecologies have evolved within turtles; (2) the timing of secondarily marine adaptation in the chelonioid total-group; and (3) inferences of character state changes and polarities, which influence hypotheses of morphological evolution on the stem-group of cryptodires, and among turtles more widely. Clearly, resolving the phylogeny of key fossil groups can have substantive implications for our understanding of the evolution of turtles as a whole. We present a new phylogenetic analysis that helps to clarify these issues. 
Independent origins of marine life in turtles

Adaptation to marine life evolved independently in stem-group turtles and in both cryptodires and pleurodires. The stem-group turtle Odontochelys semitestacea from the middle Late Triassic (220 Ma) is generally interpreted as the oldest marine turtle based on its depositional environment (Li et al. 2008; Reisz \& Head 2008; Lyson et al. 2010). Furthermore, Odontochelys has limb proportions characteristic of aquatic turtles, contrasting with other Triassic stem-turtles (Joyce \& Gauthier 2004; Li et al. 2008).

Among pleurodires, marine taxa have been identified in two phylogenetically distinct lineages, documenting at least two independent instances of adaptation to marine life: the Cretaceous-Oligocene (and possibly Miocene) Bothremydidae (Gaffney et al. 2006; Rabi et al. 2012), and the Eocene-Pleistocene Stereogyina (Sánchez-Villagra et al. 2000; Winkler \& Sánchez-Villagra 2006; Gaffney et al. 2011; Ferreira et al. 2015). Bothremydid phylogeny suggests that there could be two independent origins of marine habits in that group, as the marine Taphrosphyini and the marine Bothremydina do not form a monophyletic group with respect to freshwater bothremydids (Gaffney et al. 2006; Rabi et al. 2012).

The number of independent lineages of marine turtles within the total group of cryptodires is less well understood. Chelonioidea, which includes all extant sea turtles, represents one unambiguous evolutionary origin of secondarily marine ecologies within the crown of cryptodires. Chelonioids form a clade of highly marine-adapted forms that are characterized by the presence of flippers, salt glands, incipient to well developed secondary palates, and a range of modifications of the shell, all of which represent adaptations to a marine lifestyle, and are observed in at least some fossil chelonioids (Mlynarski 1976; Zangerl 1980; Hirayama 1994). Undisputed marine stem-group 
chelonioids are also known from that time (Toxochelys spp.: Coniacian-Campanian, Nicholls 1988; Joyce et al. 2013), but the phylogenetic position of some putative crowngroup chelonioids from the Cretaceous (e.g. Allopleuron hofmanni from the Late Maastrichtian, Gray 1831) have been uncertain. The only non-marine turtles that have repeatedly been recovered as stem-group chelonioids are various 'macrobaenids' (usually including Judithemys sukhanovi from the Campanian of Canada; Parham \& Hutchinson 2003) and 'sinemydids' (Brinkman \& Wu 1999; Danilov \& Parham 2008; Sterli 2010; Pérez-García 2012; Cadena \& Parham 2015), but most authors argue against this (e.g. Zhou \& Rabi 2015).

Other marine turtles have been recognized, especially from the Late Jurassic and Early Cretaceous. Depending on their phylogenetic position, these groups, the protostegids, thalassochelydians and sandownids, could represent additional, independent origins of marine adaptation (Fig. 1). Protostegids are known from the Barremian-Campanian (e.g. Zangerl 1953; Collins 1970; Hirayama 1994, 1998; Hooks 1998; Kear \& Lee 2006; Cadena \& Parham 2015). Thalassochelydians include 'plesiochelyids', 'eurysternids', 'thalassemydids', Solnhofia parsoni, and Jurassichelon oleronensis from the Late Jurassic (e.g.; Gaffney 1975a, b; Rieppel 1980; Joyce 2000; Anquetin \& Joyce 2014; Anquetin et al. 2014a, b, 2015, 2017). Sandownids are known from the Cretaceous and Palaeogene (Aptian-Danian; Meylan et al. 2000; Mateus et al. 2009; Cadena 2015). Many distinct phylogenetic hypotheses have been proposed, not only for these groups, but also for their members. In the following, we provide brief summaries on all relevant groups, including evidence for their inferred ecologies and previously proposed phylogenetic relationships. 
Protostegids are a group of Cretaceous marine turtles with a cosmopolitan distribution (e.g. Zangerl 1953; Collins 1970; Hirayama 1998; Kear \& Lee 2006; Cadena \& Parham 2015). They include the gigantic forms Archelon ischryos (Wieland 1896) and Protostega gigas (Cope 1871a) from the Campanian of North America, as well as early representatives such as Santanachelys gaffneyi from the Late Aptian or Early Albian of Brazil (Hirayama 1998) and Desmatochelys padillai form the Late Barremian or Early Aptian of Colombia (Cadena \& Parham 2015). These taxa have been found in a monophyletic group in most phylogenetic studies so far (Hirayama 1994, 1998; Hooks 1998; Kear \& Lee 2006; Cadena \& Parham 2015; but see Gentry et al. 2018). They share unambiguous adaptations to a pelagic marine lifestyle with chelonioids, including the modification of hands into flippers and the reduction of the shell, and also an enlarged fenestra interorbitale indicative of salt glands (e.g. Wieland 1896, 1906; Case 1897; Hirayama 1998). Many studies have found protostegids on the stem-lineage of Dermochelys (the extant leatherback turtle; Hirayama 1994, Kear \& Lee 2006; Bardet et al. 2013; Cadena \& Parham 2015; Gentry et al. 2018), with a few exceptions (Joyce 2007; Anquetin 2012; and studies expanding these matrices; see below).

Thalassochelydians (sensu Anquetin et al. 2017) are an assemblage of Late Jurassic turtles from central and western Europe (Anquetin \& Chapman 2016; Anquetin et al. 2017), and possibly Argentina (Fernández and de la Fuente 1988; de la Fuente and Fernández 2011). They are exclusively found in marine depositional environments, with 'plesiochelyids' and 'thalassemydids' found in sediments indicating open-marine carbonate platform environments, and 'eurysternids' such as Solnhofia parsoni coming from more marginal marine settings (Anquetin et al. 2017). Plesiochelyids have been found as a monophyletic group by almost all phylogenetic studies (e.g. Sterli 2010; Sterli 
\& de la Fuente 2013; Anquetin et al. 2015; but see Anquetin 2012), but the monophyly of the more inclusive Thalassochelydia (including Solnhofia parsoni, Jurassichelon oleronensis, and plesiochelyids) has only recently been demonstrated (Anquetin et al. 2015; but see below). The marine habits of these taxa are supported by their oxygen isotope signatures, which indicate brackish environments for 'eurysternids', and fully marine environments for 'plesiochelyids' (Billon-Bruyat et al. 2005). Unlike chelonioids and protostegids, thalassochelydian limbs do not take the form of flippers, although their manus is notably elongated, indicating adaptation to aquatic locomotion (Anquetin et al. 2017). Furthermore, an expanded fenestra interorbitale indicates the presence of salt glands, and the presence of shell fontanelles provides morphological evidence consistent with a marine lifestyle (Anquetin et al. 2017). The shell bone histology is also consistent with an aquatic lifestyle (Scheyer et al. 2014).

Sandownids are a secondarily marine group of putative stem-group cryptodires currently known from four taxa ranging in age from the Aptian (Sandownia harrisi: Meylan et al. 2000) or possibly Late Barremian (Leyvachelys cipadi: Cadena 2015) to the Paleocene (Brachyopsemys tingitana: Tong \& Meylan 2013). These taxa have been recovered as a clade by all phylogenetic studies that included more than one of them (Mateus et al. 2009; Tong \& Meylan 2013; Cadena 2015). Their fossils come from shallow marine deposits, and distinctive morphological adaptations such as their extensive secondary palate indicative of a durophagous diet have been interpreted as marine adaptations (Mateus et al. 2009; Tong \& Meylan 2013; Cadena 2015). Informative shell and postcranial material is only known from Leyvachelys cipadi. Leyvachelys lacks features found in pelagic marine turtles (cheloniids, dermochelyids, and protostegids) as it has an unflattened and unexpanded humerus and metacarpal, a strongly ossified contact between the plastron and carapace, and lacks shell fontanelles 
(Cadena 2015). Sandownids are therefore thought to have lived in littoral habitats (Cadena 2015).

Previous phylogenetic work

Extant chelonioids include cheloniids (hard-shelled sea turtles) and the leatherback sea turtle, Dermochelys olivacea, the only dermochelyid. Molecular phylogenies find chelonioids within Cryptodira, as the sister group to Chelydroidea (Kinosternoidea + Chelydridae; e.g. Crawford et al. 2015; Perreira et al. 2017) in a clade called Americhelydia (Joyce et al. 2013). The number of independent origins of marine adaptation among eucryptodiran lineages depends on the relationships of fossil marine taxa with respect to chelonioids. A summary of phylogenetic hypotheses recovered in previous studies is presented in Figure 1.

Protostegids have frequently been placed on the stem of Dermochelyidae (Hirayama 1994, Kear \& Lee 2006; Tong \& Meylan 2013; Bardet et al. 2013; Cadena \& Parham 2015; Gentry et al. 2018; see Fig. 1E, H). However, Joyce (2007) and some subsequent analyses (Danilov \& Parham 2006, 2008; Sterli \& de la Fuente 2011, 2013; Anquetin 2012) have found protostegids as basal eucryptodires on the cryptodiran stem (Fig. 1A-B, F-G), or on the turtle stem (Sterli 2010; Sterli \& de la Fuente 2011; Fig. 1C). Either position would imply that protostegids evolved marine habits independently of chelonioids, and have typically been found by analysis of the Early Cretaceous Santanachelys as the sole representative of protostegids in a global matrix. When recovered outside of Chelonioidea, Santanachelys has been found in a clade with Solnhofia (Danilov \& Parham 2006), or Solnhofia and Jurassichelon to the exclusion of plesiochelyids (Joyce 2007; Pérez-García et al. 2012; Sterli \& de la Fuente 2013; Sterli et 
al. 2013), or a clade including Solnhofia, Jurassichelon, and plesiochelyids (Anquetin 2012).

Many previous studies have found the taxa included in Thalassochelydia (sensu Anquetin et al. 2017) as polyphyletic or paraphyletic (Danilov \& Parham 2006, 2008; Joyce 2007; Mateus et al. 2009; Anquetin 2012; Pérez-García et al. 2012; Sterli \& de la Fuente 2013; Sterli et al. 2013; Cadena 2015; Cadena \& Parham 2015; see Fig. 1A-F, I, H). This is in part because of the uncertainty that surrounds the positions of Jurassichelon ('Thalssemys' moseri in studies previous to the revision provided by PérezGarcía 2015) and Solnhofia, which have been variously grouped with nonthalassochelydian taxa such as the early protostegid Santanachelys (Danilov \& Parham 2006; Joyce 2007; Pérez-García et al. 2012; Sterli \& de la Fuente 2013; Sterli et al. 2013), but also sandownids (e.g. Mateus et al. 2009). Nevertheless, some concept of either one or more clades of Late Jurassic marine turtles has been present in many phylogenetic studies. Three major hypotheses have been presented concerning the positions of these turtles (regardless of their monophyly), as either: (1) stem-group chelonioids, implying an inclusive clade of marine cryptodires that originated in the Late Jurassic; (2) stemgroup cryptodires, and therefore representing a distinct, independent origin of marine life from that in chelonioids; (3) stem-group turtles, also representing a distinct origin of marine life. It is clear therefore that thalassochelydians share some traits with chelonioids, and others with stem-group turtles or stem-group cryptodires. Indeed, when constituents of Thalassochelydia have been found as stem-group chelonioids, groups that are otherwise widely regarded as stem-group cryptodires or stem-group turtles (xinjiangchelyids, sinemydids; Zhou \& Rabi 2015), have sometimes also been found on the stem-group of chelonioids (Cadena \& Parham 2015). However, a sinemydid-chelonioid relationship has also been found in some studies irrespective of 
the position of thalassochelydians (Brinkman \& Wu 1999; Danilov \& Parham 2008; Sterli 2010; Pérez-García 2012). Clearly, resolving the phylogenetic affinities of Thalassochelydia is of great importance for our knowledge of turtle evolution.

Little consensus exists about the relative placement of sandownids (Fig. 1A, E, GH). Specifically the relationships of sandownids to 'eurysternids', plesiochelyids and chelonioids are unclear. The first reported sandownid, Sandownia harrisi, was originally interpreted as a basal member of Trionychia (softshell turtles; Meylan et al. 2000). However, later studies found little support for this placement (e.g. Joyce 2007), and the patterning of the carapace of Levyachelys is also inconsistent with this hypothesis (Cadena 2015). Sandownia (commonly the only sandownid taxon included in global phylogenetic studies) was tentatively placed on the stem of Cryptodira as a basal eucryptodire by Joyce (2007). Mateus et al. (2009) found sandownids as sister to Solnhofia in a group called Angolachelonia, which formed part of a marine grade including Jurassichelon, Portlandemys and Plesiochelys on the stem of Cryptodira. Tong \& Meylan (2013) and Anquetin et al. (2015) found sandownids as the sister-taxon of chelonioids, and Solnhofia and Jurassichelon as eucryptodires. Finally, Cadena (2015) recovered sandownids as the sister to xinjianchelyids+sinemydids as stem-group chelonioids, forming a large panchelonioid clade including Jurassichelon and Solnhofia, but excluding plesiochelyids, which were found as stem-group turtles (Cadena 2015).

\section{MATERIAL AND METHODS}

Character dataset 
For our character matrix, we used information from three primary sources: Cadena (2015), Zhou and Rabi (2015), and Anquetin et al. (2015). All these matrices are modified versions of previous studies, and can all be traced back to Joyce (2007), which represents the first global phylogenetic analysis of Mesozoic turtles. All three source matrices are global in scope, but have different foci. Cadena's (2015) matrix is a modified version of the work of Cadena and Parham (2015) and includes character information specific to sandownids. The matrix of Cadena and Parham (2015) is a combination of global matrices (Joyce 2007; Anquetin 2012; Sterli 2008; Sterli \& de la Fuente 2013) but importantly includes characters from matrices that were designed to specifically test chelonioid relationships (Hirayama 1994; Hirayama 1998; Kear \& Lee 2006; Parham \& Pyenson 2010). The Zhou and Rabi (2015) matrix is similarly based on several previous studies, which were focussed on the relationships of stem-group turtles and stem-group cryptodires (Joyce 2007; Sterli 2008; Sterli \& de la Fuente 2013; Rabi et al. 2013, 2014; Zhou et al. 2014). Finally, the analysis of Anquetin et al. (2015) was specifically focussed on thalassochelydian relationships. By combining the character lists of these studies, we attempt to capture all morphological variation documented so far among non-pleurodiran turtles. The 257 characters of Cadena (2015) were reconciled with the slightly different character definitions given in the other two studies, and were further modified by our own observations. This resulted in a phylogenetic data matrix of 345 characters and 80 taxa. In total, 70 characters of Cadena \& Parham (2015) were modified (see Coding strategy) and modified versions of 13 characters used by Anquetin (2012), Anquetin et al. (2015), Cadena (2015), Havlik et al. (2014), and Zhou \& Rabi (2015) were added. We also added 58 new cranial and mandibular characters. We re-scored all cranial and mandibular characters from both Cadena \& Parham (2015) and other sources, for all taxa in our matrix. Our scorings are based on first hand 
examination of specimens (44 taxa), examination of CT scans for 59 taxa, photographs of specimens not seen first hand by the authors (shared with SWE by Dr. Walter Joyce), and published descriptions (data sources in Table 1). An illustrated character list with discussions of character modifications and additions, and justifications for modified scorings is available in Appendix S1.

\section{Coding strategy}

Phylogenetic analyses of morphology are used to infer relationships from a set of comparative anatomical observations. The concept of homology is central to the delimitation of these observations as characters and character states. Homology is the hypothesis that similar attributes shared by different species are equivalent to one another due to common ancestry, and therefore reflect their phylogenetic relationships (Platnick 1979; Eldregde \& Cracraft 1980; de Pinna 1991; see Patterson 1982 for a disambiguation and extensive discussion of homology). Hypotheses of homology are established based on topographic and ontogenetic correspondence and on compositional similarity of traits (Patterson 1982; Rieppel 1988; de Pinna 1991; Hawkins et al. 1997). These initial ('primary'; de Pinna 1991) hypotheses of homology are embodied by the characters and character states, and are tested against one another by means of congruence in parsimony analysis, which maximizes the number of initial homology propositions that are upheld as true homology rather than the result of convergent evolution (homoplasy; Patterson 1982; de Pinna 1991).

Character construction therefore represents the proposition of initial hypotheses of homology based on observations of similarity. Character states are different forms that a homologous trait (i.e. the character) can take among organisms, and are 
equivalent transformations of one another on a single hierarchical level (the level of the character) (Platnick 1979; de Pinna 1991; Hawkins 1997). Characters and character states therefore form a hierarchical framework of homology propositions. For example, a specific site in the aligned nucleotide sequences of several organisms is hypothesized to be comparable on the character level, and the (four or five) nucleobases represent possible variation of this character on the character state level (and could therefore not represent separate characters themselves) (Pleijel 1995). Construction of morphological characters is potentially more subjective. Nevertheless, we have taken various steps to ensure that our cladistics characters for turtles, both new, and modified from previous analyses, reflect homology (described below).

Character states should also be independent of each other (e.g. Pimental \& Riggins, 1987; Strong \& Lipscomb 1999). Non-independence of character states is problematic because it results in a single observation of similarity being coded twice, and therefore the character state is arbitrarily given a greater weight than others (Wilkinson 1995; Strong \& Lipscomb 1999). Logical dependence between characters exists when the score of a taxon for one character directly affects the scoring of the same taxon in another character (e.g. coding the absence and zero size of a feature; Wilkinson 1995), and this can be readily avoided. Biological dependence is a hypothesis that character states of different characters are non-independent due to functional or developmental linkage (Wilkinson 1995). Information on the underlying biological cause for such a linkage if often not available, which makes is hard to fully avoid biological independence in character construction.

Many morphological characters used in previous studies of turtle phylogeny combine complex observations across multiple hierarchical levels of similarity, or lump together independently varying character states. We re-coded characters so that 
independently varying aspects of morphological variation are coded in separate characters. For example, character 10 of Cadena \& Parham (2015) was defined as:

'Jugals, jugal-squamosal contact: $0=$ present; 1 = absent, contact between postorbital and quadratojugal present.'

In this character definition, the absence of a jugal-squamosal character is assumed to be linked to the presence of a postorbital-quadratojugal contact. The character includes the assumption that a postorbital-quadratojugal character must be present when a jugalsquamosal contact is absent. However, these contacts vary independently from one another, as taxa exist (trionychids) in which a postorbital-quadratojugal contact is absent, but a jugal-squamosal contact is also absent. The approach taken here is to break up this character into two separate characters, which each code for one of the contacts (our characters 25 and 42).

We also re-coded characters so that observations across multiple hierarchical levels of similarity are coded in separate characters. For example, we modified character 60 of Cadena \& Parham (2015), which was phrased as:

'Epipterygoid: 0 = present, rod like; 1 = present, laminar; 2 = absent.'

The comparative anatomical observations underlying this and similar characters include both the absence of a certain feature, and variation in the shape of that feature when present (the 'no tail; red tail; blue tail' problem; Maddison 1993; Smith 1994; Hawkins et al. 1997; Brazeau 2011). Coding these observations into a single character, as done in most turtles studies (e.g. Joyce 2007; Cadena \& Parham 2015; but see 
Anquetin 2012) assumes that the condition of having no epipterygoid is on the same hierarchical level as the observed shape conditions of taxa with epipterygoids. This disregards the homology implied by the presence of an epipterygoid in various taxa, irrespective of its of shape (Hawkins et al.1997), resulting in loss of information.

To reflect the hierarchical levels of similarity of these observations of the epipterygoid, and other characters in our analysis, we used a hierarchical coding strategy. For the above example, this reformulation results in two separate characters. One character codes for the presence vs. absence of the feature (e.g. epipterygoid; our character 87), and the second codes for the various shapes that the feature can take (e.g. epipterygoid shape; our character 88) (Hawkins et al. 1997; Brazeau 2011; see Anquetin 2012 for a turtle study using the same approach). Logical dependence of the character states of the second character on the first is avoided by scoring the second character as inapplicable ('-') when the first character is scored as 'absent'. Inapplicability does not introduce logical dependency (contra Strong \& Limpscomb 1999), because it does not represent a separate character state, and transitions to 'inapplicable' do not count towards the length of a cladogram. However, inapplicable scores can be problematic because inapplicability is treated the same as missing data in software implementations of parsimony analysis (e.g. Platnick et al. 1991; Strong \& Lipscomb 1999; Brazeau et al. 2017). This can introduce illogical character state reconstructions during the optimization process (e.g. Platnick et al. 1991; Maddison 1993). This problem relates to computational issues that may be solved in future generations of software (e.g. Brazeau et al. 2017), and problems with inapplicable character states are herein taken to be less problematic than the homology issues of compound characters discussed above (Strong \& Lipscomb 1999; Hawkins et al. 1997). 
Some of our characters appear superficially to be hierarchical compound characters (as in Cadena \& Parham 2015, character 60; above), because they include an absence state as well as several other non-absence states. However, these characters are measurements such as the size of a structure, for which absence equates to zero. It is therefore appropriate to treat their character states as homologous with each other at the same hierarchical level. For example, our character 7 (character 7 of Cadena \& Parham (2015)):

'Prefrontal, dorsal prefrontal exposure: 0 = present, large; 1 = present, reduced; 2 $=$ absent or near absent.'

Our approach also differs from some recent analyses of turtles (e.g. Anquetin 2012) that exclusively used binary characters. Instead, we coded instances for which multiple conditions are observed for a character as multistate characters, reflecting the hypothesis that these alternative conditions represent transformations of a single underlying feature. For example, our character 297 (identical to character 210 of Cadena \& Parham (2015)):

‘Caudals, anterior caudal centra: 0 = amphicoelous; 1 = procoelous or platycoelous; 2 = opisthocoelous.'

The alternative approach of only using binary characters (e.g. Anquetin 2012 for turtles) requires the construction of a series of characters, or ignoring observations to artificially create binary characters, or lumping a set of distinct character states into a single character state (as done for the above example by Anquetin (2012): ch 160, in which the 
conditions of procoely and opisthocoely are lumped into a single character state). Anquetin (2012) justified the usage of binary characters by stating that this approach minimizes the amount of 'a priori assumptions about homology' (Anquetin 2012: p. 5). However, this avoidance of homology proposition misapplies the similarity criterion used to establish primary hypotheses of homology, which are always a priori hypotheses (de Pinna 1991; Hawkins et al. 1997). Instead of avoiding assumptions of homology, the approach of Anquetin (2012) generates unexpected hypotheses of homology (e.g. that procoely and opisthocoely are interchangeable, and homologous with each other on a low hierarchical level).

\section{Taxon sampling}

Our operational taxonomic units (OTUs) were chosen specifically to test the phylogenetic relationships of non-pleurodiran marine turtles, and we preferentially used taxa for which we had CT data. Our matrix includes many chelonioids, thalassochelydians, protostegids, and sandownids (Table 1). To test the placement of these groups in a global framework, we also included a thorough sample of stem-group turtles, including Triassic and Early Jurassic species, as well as paracryptodires and meiolaniforms. We further included a range of xinjiangchelyids, sinemydids, and macrobaenids, which have been hypothesized to be stem-group cryptodires (e.g. Zhou \& Rabi 2015). We sampled extant representatives of modern clades including pleurodires, and all families of turtles. We included early fossil representatives of extant families when CT data was available to us or when sufficiently detailed anatomical descriptions were available in the literature. Of particular importance, two fossil chelydroids, Emarginachelys cretacea and Baptemys wyomingensis, were included because 
chelydroids (kinosternoids+chelydrids) are the extant sister-group to chelonioids (Crawford et al. 2015), and fossil representatives of this group can thus influence character optimizations for the total group of Americhelydia (chelydroids+chelonioids). Most of our OTUs represent modern or fossil taxa on the species level, but some OTUs are supraspecific: the extant taxa Chelodina, Chelonoidis, Kinosternon, Podocnemis, Staurotypus, Sternotherus, and Testudo. This was done because our CT scans, which were used to re-score the cranial and mandibular characters, belonged to different species from those used by Cadena \& Parham (2015) (Table 1), and we retained their postcranial characters. We chose to score a supraspecific OTU for Toxochelys because this allowed inclusion of data from specimens that have been assigned to different species, and thus score a more complete OTU. Species assignments regarding specimens of Toxochelys are currently uncertain (Zangerl 1953; Nicholls 1988; Brinkman et al. 2006), particularly because the holotype specimens of valid species are relatively incomplete and lack cranial material. Pending a taxonomic revision of Toxochelys material, we consider it best to refer most Toxochelys material to Toxochelys sp., as done by some other authors (e.g. Brinkman et al. 2006).

The protostegid Rhinochelys pulchriceps was scored primarily from CT scans of the holotype specimen CAMSM B55775. However, we also used data from CT scans of other specimens, which have been referred to different species of Rhinochelys (Collins 1970; see Table 1 for specimens used). These added information on the mandible $(R$. cantabrigiensis: CAMSM B55783; R. elegans: CAMSM B55776). It is likely that all British specimens of Rhinochelys represent a single species (SWE, unpublished data), and we therefore consider all material in Collins (1970) to be Rhinochelys pulchriceps. 
We used high-resolution X-ray computed-tomography (CT) data for as many taxa as possible (summarized in Table 1). To support our anatomical observations and opinions stated throughout this work, we deposited several CT datasets and 3D models generated through manual segmentation in the software Mimics (versions 16.0-19.0) (http://biomedical.materialise.com/mimics) at MorphoSource (http://www.MorphoSource.org; see data archiving statement below). The data provided represent a sample of fossil and extant turtle specimens that have been extensively used in character construction and illustration of characters (see Appendix 1). These are: Apalone spinifera emroyi (FMNH 222178), Dermochelys coriacea (UMZC R3031), Elseya dentata (NHMUK 76.5.19.77), Gopherus polyphemus (FMNH 211815), Lepidochelys olivacea (SMNS 11070), Phrynops geoffranus (SMF 45470), Plesiochelys planiceps (OUMNH J1582), Argillochelys cuneiceps (NHMUK R38955), Sandownia harrisi (MIWG 3480), Solnhofia parsoni (TM 4023), Sternotherus minor (FMNH 211696), and Rhinochelys pulchriceps (CAMSM B55783; referred to Rhinochelys cantabrigiensis by Collins (1970), but see section on taxon sampling). Because scanning parameters varied between all scans, details are given in the online repository with the data (Evers \& Benson 2018a), and are not summarized here.

\section{Similarity matrix}

To illustrate the structure of our dataset, we produced heatmaps of similarity matrices calculated from our character taxon matrix in R (R Core Team 2016). Polymorphisms and missing data ('?') were treated as inapplicable data. Similarity between two taxa was calculated as the number of identical scoring matches between 
these taxa divided by the number of comparable scores between them (e.g. Sneath \& Sokal 1973; Foote 1994; Wagner 1997; see Benson \& Druckenmiller 2014 for a similar code). The resulting values are represented in a symmetric similarity matrix. Similarity matrices were calculated for the total dataset, and partitions of that dataset representing cranial and mandibular characters, shell characters, limb characters, and axial+girdle characters. For the anatomical partitions of the total dataset, taxa with no anatomical information for the respective partition, as well as taxa with $90 \%$ or more missing data were excluded. Each similarity matrix was coloured by assigning a spectrum of colours to the similarity values of each matrix using the package gclus (Hurley 2012). The R code for calculating similarity and producing the heatmaps is available in Evers \& Benson $(2018 b)$.

Parsimony Analysis

Tree searches were performed in TNT 1.5 for Windows (Goloboff et al. 2008; Goloboff \& Catalano 2016). For all analyses, we used a molecular backbone constraint following the topology of Pereira et al. (2017) for extant taxa. All fossil taxa were left unconstrained and were thus allowed to fall anywhere within the constrained topology of extant taxa. Proganochelys quenstedti was set as the outgroup. In TNT, new technology algorithms were used with default settings, and tree drifting (Goloboff 1999) and parsimony rachet (Nixon 1999) enabled. The initial level of the driven search was set to 30 , and the number of times the minimum tree length should be obtained was set to 30 . This procedure does not require specifying a number of replicates to be performed (Goloboff 1999; Giribet 2007). The most parsimonious trees (MPTs) of this analysis 
were then subjected to a final round of tree bisection and reconnection (TBR). The resulting MPTs were used to construct a strict consensus tree.

Characters were treated as unordered and equally weighted in our initial analysis. We also executed a second run in which several characters were ordered, for comparison (characters 7, 14, 18, 34, 44, 67, 76, 79, 90, 93, 94, 103, 107, 123, 130, 131, $138,142,147,205,210,217,248,253,292,305,325,339,340,344)$. Ordering character states represent a priori hypotheses that transitions between character states only occur in a specific sequence (e.g. Wilkinson 1992, 1995). However, prior knowledge about the evolutionary sequence of character state transitions is often missing or otherwise not substantiated by evidence. Therefore, we only ordered multistate characters in which one character state was directly intermediate in form, size, or number of two other states (for instance character 340: Size of ulnare vs. intermedium: $0=$ ulnare smaller than intermedium; 1 = ulnare nearly as large as intermedium; $2=$ ulnare much larger than intermedium). If clear intermediates are not evident, the states were left unordered (for instance character 260: Medial contact of extragulars: $0=$ absent; $1=$ contacting each other anterior to gulars; 2 = contacting each other posterior to gulars).

Bremer support was calculated in TNT, using the absolute Bremer support setting and TBR branch swapping on existing trees to generate suboptimal trees. Character optimization was performed in PAUP* for Macintosh (Swofford 2002) because TNT only returns unambiguous synapomorphies (i.e. those in which ACCTRAN and DELTRAN agree in determining a character state change), whereas the optimization criterion can be specified in PAUP*. The optimization was computed on a fully resolved tree. This tree was chosen from the MPTs on the basis of high congruence with a $50 \%$ majority rule consensus tree. The most important differences of the tree selected for optimization and our consensus topology are that paracryptodires are monophyletic 
and that the species of Sinemys form a clade that is sister group to all remaining sinemydids (see Fig. S2.1). The tree topology chosen for the optimization, as well as unambiguous, ACCTRAN, and DELTRAN optimizations for all characters as well as all nodes are given as Supporting Information (Appendix S1-2).

To illustrate implications of our results for the age of crown-group chelonioids (see Discussion), we produced a time-scaled tree using age-ranges of taxa derived from the literature and the PalaeoDB (https://paleobiodb.org), summarized in Table 2. Commands from the strap (Bell \& Lloyd 2014) and paleotree (Bapst 2012) packages in R were used for time-scaling and visualisation. We arbitrarily used a minimum branch length argument of 1 myr for zero-branch lengths in the 'timePaleoPhy' command of the paleotree package (Bapst 2012). Because some lineages of turtles have older fossil representatives than the oldest fossils for those groups included in our study, we included minimum constraints for three nodes of our time scaled tree. First, we used the top of the Oxfordian (157.3 Ma) as a minimum constraint for Pleurodira based on Caribemys oxfordiensis (De la Fuente \& Iturralde-Vinent 2001; Joyce et al. 2013). Secondly, we used the base of the Cretaceous (145.0 Ma) as a minimum constraint for Cryptodira based on the total-group trionychian Sinaspideretes wimani. Although the type locality of Sinaspideretes is not exactly known (Tong et al. 2014), it is likely that the material as well as referred material is from the Shangshaximiao Formation (Danilov \& Parham 2006; Tong et al. 2014), which is probably of Late Jurassic but possibly even of Middle Jurassic age (Xing et al. 2013). Using the base of the Cretaceous as a minimum age is thus a conservative constraint, following Joyce et al. (2013). Lastly, again following Joyce et al. (2013), we use the top of the Campanian (72.1 Ma) as a minimum constraint for Chelydroidea based on a peripheral fragment that can be unambiguously 
identified as belonging to the total-group of Chelydridae, which was described by Brinkman \& Rodriguez de la Rosa (2006).

Testing the effect of 'marine' characters and advanced protostegids

To test if our phylogenetic results were influenced by the inclusion of characters that might be functionally linked to a marine lifestyle, we performed an additional analysis in which characters that were identified to be indicative of a marine lifestyle were deleted. Furthermore, to test of our phylogenetic results (specifically, the recovery of protostegids being crown-group chelonioids, see results) were driven by the inclusion of advanced taxa with a highly specialised body plan with clear adaptations to pelagic life, as suggested by some authors (e.g. Cadena \& Parham 2015), we performed a series of analyses in which only certain protostegids with the most plesiomorphic characters were included in the analyses. In the first of these 'least specialised taxa analyses', we only kept Santanachelys gaffneyi as the only representative of protostegids, as done in all studies that previously found protostegids outside of Chelonioidea (e.g. Joyce 2007; Danilov \& Parham 2008; Anquetin 2012; Sterli \& de la Fuente 2013). In our second analysis ('least specialised taxa analysis 2'), we additionally kept Rhinochelys pulchriceps, for which we had the most detailed cranial information. In a third analysis ('least specialised taxa analysis 3'), we kept all protostegids but Archelon ischyros and Protostega gigas, which are commonly described as 'advanced protostegids' (e.g. Kear \& Lee 2006).

Testing alternative hypotheses 
To test if our topology was significantly different in tree length compared to alternative hypotheses regarding the placement of key taxa, we used Templeton's nonparametric test (Templeton 1983) in PAUP* for Macintosh (Swofford 2002). Templeton's test uses the differences in counts of character state transitions for each character implied by a pair of trees. Resulting differences are sorted in ascending order and fractional rank scores are assigned to them. Rank scores for characters that have fewer transitions in the suboptimal tree are summed to produce a test statistic, which is subjected to a Wilcoxon's signed rank test. The default for PAUP* is a two-tailed test (Goldman et al. 2000). However, because we use Templeton's test with one tree being known to be optimal (the null hypothesis is that constrained topologies fit the data as well as the optimal, i.e. shortest, tree) a one-tailed test is appropriate (Templeton 1983; Goldman et al. 2000; Hipp et al. 2004). Although p-values of one-tailed tests are less conservative, their use has been advocated because they are generally close to the exact probability values for this test (Felsenstein 1985; Lee 2000), and p-values reported herein were corrected accordingly (see Goldman et al. 2000). Alternative hypotheses were chosen based on phylogenetic results presented in previous studies. Our alternative hypotheses test the position of plesiochelyids, thalassochelydians, sandownids, xinjiangchelyids, sinemydids, protostegids as stem-group cryptodires and stem-group chelonioids, respectively, and the position of protostegids as stem-group turtles. The alternative topologies were recovered by running parsimony analyses including one OTU relevant to each hypothesis into the molecular backbone constraint, while all other fossil OTUs were kept as floaters. For hypotheses relating to species-rich groups or groups that have not consistently been found to be monophyletic among previous studies, such as sinemydids or thalassochelydians, several constraints using different OTUs were used. Because Templeton's test uses character changes across a 
tree in a pairwise comparison, individual trees had to be selected from the available MPTs of the original and constraint analyses. To do this, we computed symmetric differences (Robinson \& Foulds 1981) between all MPTs from each constraint analysis and all MPTs of our original analysis using the command 'treedist' in PAUP*, which returns a pairwise symmetric differences matrix. The least and most symmetric tree pairs between original and constraint analyses were selected from the matrix for comparison. If several tree pairs matched the least or most symmetry criterion, we randomly chose a tree pair from the symmetric difference matrix for the Templeton's tests (the procedure, including PAUP* and R code, are provided in Evers \& Benson (2018b), along with all MPTs and consensus trees generated for alternative hypotheses ).

\section{RESULTS}

\section{Similarity matrix}

Similarity heatmaps show high or low similarity of character states. Most clades show relatively low between-group similarity, and relatively high within-group similarity (Fig. 2), congruent with our phylogenetic topology. Relatively high betweengroup similarity of some clades that are not close relatives to one another (according to our phylogenetic results) provide evidence of homoplasy, and possibly indicate convergent evolution.

Some of the highest between-group similarity is seen between protostegids on one hand, and sinemydids, xinjiangchelyids, and angolachelonians (i.e. thalassochelydians+sandownids; details are given below) on the other hand (Fig. 2). 
This pattern has been noted based on qualitative comparisons before (Cadena \& Parham 2015), and is according to our matrix driven predominantly by cranial, and, to a lesser extent, axial+girdle characters (Fig. 3A, C). Our phylogenetic results strongly support the hypothesis that protostegids are crown-group chelonioids, deeply nested within Cryptodira. This pattern of similarity therefore indicates a relatively high amount of convergence of the protostegid skull morphology with that of angolachelonians, sinemydids, and xinjiangchelyids. In accordance with our topology, protostegid skull morphology is most similar to the skull morphology of cheloniids. However, unlike in the axial+girdle or shell partitions, cranial similarity between protostegids and cheloniids never exceeds moderate values. Paired with the moderate similarity of cranial morphology of protostegids with non-chelonioid groups, the relatively strong differences of protostegid skulls to cheloniid skulls reveal a high amount of potential character conflict. This might explain the finding of protostegids outside of Chelonioidea in some previous studies (e.g. Joyce 2007; Anquetin 2012). Furthermore, the character similarity between sinemydids, xinjiangchelyids, and angolachelonians can be used as an explanation for the unstable positions of these groups among previous phylogenetic analyses (e.g. Rabi et al. 2013; Cadena \& Parham 2015; Zhou \& Rabi 2015, see discussion).

Although angolachelonians are particularly similar to protostegids, the similarity of angolachelonians to chelonioids in general is high. This pattern is seen across all data partitions, and is most evident in the cranial data. However, our data partitions also show that whereas angolachelonian skulls share more identical scorings with protostegids than with cheloniids, the shells of angolachelonians are more similar to cheloniids than to those of protostegids. High overall similarity between chelonioids and angolachelonians can possibly be explained by their marine lifestyle. Relatively high 
cranial similarity between Angolachelonia and Chelonioidea indicates that character convergence is more dominant in the cranium of these marine groups, than in other parts of the body.

Chelonioids (including protostegids) show high within-group similarity for all anatomical partitions, and relatively low similarity to other groups (Fig. 3). This is particularly evident for limb morphology (Fig. 3D). The same pattern, albeit weaker, is also seen in shell, and axial+girdle morphology. This indicates that chelonioids have a specific set of shell, postcranial, and especially limb characters that differs relatively strongly to the characters of other groups, but that these characters are consistently present among members of Chelonioidea. For skull characters, low similarity values to non-chelonioid groups are only observed in cheloniids (see discussion of protostegids above). This indicates that within Chelonioidea, the cheloniid skull has a high number of derived character states. Dermochelyoids show a strong dissimilarity to all other groups (but moderate to high similarity to cheloniids) in the shell partition, indicating a strongly derived shell morphology. Although within-group similarity in chelonioids is generally high, cheloniids and dermochelyoids can be distinguished in the cranial and limb partitions, indicating that these parts of the body are less similar than the shell or axial+girdle skeleton.

Relatively high between-group similarity is present among xinjiangchelyids, sinemydids and paracryptodires, which is particularly clear in the cranial and shell data, but also seen in the unpartitioned dataset. This is in accordance with our phylogenetic results, which find these groups relatively closely related to one another on the stemlineage of turtles. Moderate similarity is seen between testudinoids, sinemydids, and xinjiangchelyids, possibly explaining why the latter groups are sometimes found as 
stem-group cryptodires (e.g. Péréz-García et al. 2012; Sterli et al. 2013; Zhou \& Rabi 2015).

The similarity of pleurodires to other turtles is lower in the cranial and shell partitions than in the axial+girdle or limb partitions. Therefore, the limbs, girdles and axial elements of pleurodires are similar to those of cryptodires, whereas their skulls and shells are highly different. This might be explained by constraints imposed onto the limbs and postcranium by the presence of the shell in all turtle groups, and apparent absence of these constraints on the shell itself and the cranium.

Indeed, the limbs and axial+girdle partition shows relatively high similarity between almost all groups (Fig. 3C). Exceptions to the general pattern include chelonioid limbs, which are modified to flippers and thus dissimilar to those of all other turtles (Fig. 3D), and stem-group turtles including meiolaniforms and paracryptodires. These show relatively low similarity (i.e. are dissimilar) to all other groups, especially among early stem-group turtles. This indicates that the axial, girdle and limb morphology underwent substantial transformations on the turtle stem-lineage, but then was relatively conserved within the turtle crown-group. Finally, angolachelonians and sinemydids show higher axial+girdle and cranial similarity to cryptodires than to pleurodires, which could possibly explain their inferred positions as stem-group cryptodires in some studies (e.g. Zhou \& Rabi 2015).

\section{Phylogenetic Analysis using unordered characters}

Parsimony analysis of the unordered dataset in TNT resulted in 12 most parsimonious trees (MPTs) 1532 steps long. Subsequent TBR branch swapping resulted in recovery of 12 MPTs in total. Zero-branch lengths are collapsed during the construction of a strict 
consensus tree in TNT. In several cases (Trionychidae, Chelinae), resulting polytomies in our strict consensus tree can actually be resolved on the basis of the molecular backbone constraint, and nodes representing these clades have been added back in to the respective figures (Fig. 4).

In the following, results from our unordered analysis are presented. Differences in topology found in the ordered analysis are described in the section below, and shown in Figure 4. Key results from our unordered phylogenetic analysis are: (1) the recovery of a previously unknown clade comprised of sandownids + thalassochelydians, Angolachelonia, which is placed as the immediate sister group to crown-group turtles; (2) the recovery of a monophyletic Protostegidae as the sister to Dermochelyidae; (3) the recovery of all sinemydids, macrobaenids, and xinjiangchelyids as stem-group turtles. Our results imply two independent and monophyletic groups of marine turtles outside of Pleurodira, Angolachelonia and Chelonioidea. This shows that marine ecologies have evolved three times within non-pleurodiran turtles, including Odontochelys.

Angolachelonia. Angolachelonia includes two monophyletic groups that have been previously recognized, Sandownidae and Thalassochelydia. The branch support for Angolachelonia is moderate (Bremer support $=3$ ). Angolachelonia is supported by eight unambiguous synapomorphies (all cranial and mandibular; see Figs 5-6; Table 3), of which none are unique. Within Angolachelonia, sandownids and plesiochelyids have high branch support values (Bremer support $=4$ ), whereas Thalassochelydia (i.e. Plesiochelyidae + Solnhofia in the context of our taxon sampling) has moderate support (Bremer support $=2$ ). Thalassochelydians share eight unambiguous synapomorphies (four cranial and mandibular, see Fig. 7; four postcranial, one of which is unique (ch 278.0); Table 3), and sandownids are united by four unambiguous cranial 
synapomorphies (Fig. 8; Table 3), one of which is unique (ch 108.1). The sister-group relationship of Angolachelonia and crown-group turtles is well supported (Bremer support $=4)$.

Chelonioidea. Chelonioidea is a monophyletic group comprised of two major subgroups, Dermochelyoidea and Cheloniidae. Toxochelys is found as the only member of the chelonioid stem-group. Within the total-group of Cheloniidae, all extant cheloniids form a clade, and all fossil taxa are found as stem-group cheloniids and form a paraphyletic grade as successive sister-taxa to the crown. Eochelone is found as the earliest-diverging cheloniid in our taxon sample across all trees. The total-group of Cheloniidae has a Bremer support of 2 , and is supported by five unambiguous synapomorphies (Table 3), all of which are cranial, and none of which are unique. Dermochelyoidea includes the extant leatherback turtle Dermochelys coriacea, and its stem-group, including Eosphargis breineri and protostegids. Among the stem-group of Dermochelys, Eosphargis is found as the closest relative of Dermochelys. Different authors have used different taxonomic terminology to refer to Dermochelys and closely related taxa. The name Dermochelyidae has most frequently been used to describe Dermochelys and taxa on its stem-lineage to the exclusion of protostegids (e.g. Hirayama 1994, 1998; Kear \& Lee 2006). This has been formalized in a phylogenetic definition by Joyce et al. (2004). We use Dermochelyidae in that sense. Dermochelyidae is herein supported by a Bremer support of 4, and by six unambiguous cranial synapomorphies (Table 3), none of which are unique. The total-group of Dermochelys (i.e. dermochelyids + protostegids) has also received various names (Hirayama 1998; Joyce et al. 2004). Here, we use the name Dermochelyoidea for this group (as in Hirayama 1998; Lehman \& Tomlinson 2004). Dermochelyoidea has a low branch support (Bremer support = 2), and has four unambiguous synapomorphies (two cranial; two postcranial, one of which is 
unique (ch. 237.1); Table 3). Cranial synapomorphies of dermochelyoids are shown in Figure 9. However, the less inclusive crown-group Chelonioidea (i.e. Dermochelyoidea + Cheloniidae) and total-group Chelonioidea (i.e. Toxochelys + Chelonioidea) have a high branch support of a Bremer value of 4 and 5, respectively. This indicates that there is overall strong support for the placement of protostegids within Chelonioidea. The total group of Chelonioidea shares 21 unambiguous synapomorphies (Table 3; eleven cranial; ten postcranial, seven of which are unique (ch 255.2; ch 291.1; ch 295.0; ch 333.1; ch 334.1; ch 338.1; ch 342.1)). Crown-group chelonioids (i.e. excluding Toxochelys), are united by seven unambiguous synapomorphies (three cranial, one of which is unique (ch. 93.2); four postcranial, two of which are unique (ch. 306.1; ch. 344.1)).

Protostegidae, including Archelon ischyros, Bouliachelys suteri, Desmatochelys lowii, Desmatochelys padillai, Notochelone, Ocepechelon bouyai, Protostega gigas, Santanachelys gaffneyi, and Rhinochelys pulchriceps, is relatively well supported with a Bremer support of 3. Protostegids share eighth unambiguous synapomorphies (Table 3; three cranial; five postcranial, four of which are unique (ch 291.0; ch 328.1; ch 329.1; ch 335.1)). Cranial synapomorphies for protostegids are shown in Figure 10. The ingroup relationships of Protostegidae differ in our analysis to those of most previous analysis. Commonly, Early Cretaceous protostegids such as Santanachelys, Bouliachelys, Notochelone and Rhinochelys are found as a paraphyletic grade leading to a clade of Late Cretaceous taxa, which includes Desmatochelys lowii, Archelon, and Protostega (e.g. Hirayama 1998; Kear \& Lee 2006; Bardet et al. 2013). Bardet et al. (2013) found Ocepechelon in a polytomy with Bouliachelys, Santanachelys, other protostegids and dermochelyids. In our analysis, the gigantic Archelon and Protostega form a wellsupported clade (Bremer support $=7$ ) that is sister group to all other protostegids. Within those, the Early Cretaceous taxa Santanachelys, Bouliachelys, Notochelone, 
Desmatochelys padillai and Rhinochelys, and the Late Cretaceous Desmatochely lowii form a well-supported clade (Bremer support $=3$ ) to the exclusion of the Late Cretaceous Ocepechelon. The clade including Ocepechelon has relatively strong support with a Bremer value of 3. Desmatochelys lowii and Desmatochelys padillai are sister taxa, as also found in Cadena \& Parham (2015). The remaining protostegids from the Early Cretaceous (Bouliachelys, Rhinochelys, Notochelone, Santanachelys) are united in a clade that is well nested within the Protostegidae, despite their early branching positions in most other studies.

Sinemydidae, Macrobaenidae, and Xinjiangchelyidae. Various Asian and North American Mesozoic turtles that have classically been recovered on the stem of Cryptodira (Zhou \& Rabi 2015) have been classified as sinemydids, macrobaenids, or xinjiangchelyids (Brinkman \& Wu 1999; Sukhanov 2000; Brinkman 2001; Parham \& Hutchinson 2003; Danilov et al. 2006; Rabi et al. 2010, 2014). These groups have been formalized by Rabi et al. (2014), who established phylogenetic definitions for the groups. One challenge to the application of these definitions is that they technically cannot be applied, if the 'essential' taxon of such a definition (i.e. the taxon used to defined the clade) is not included in an analysis. In fact, the taxon used to define Macrobaenidae, Macrobaena mongolica, has, to our knowledge, never been included in a phylogenetic analysis, so that the taxonomic content of Macrobaenidae is entirely unclear.

We find taxa that have classically been assigned to the three groups defined by Rabi et al. (2014) in two monophyletic groups among the stem-group of turtles as successive sister-groups to Angolachelonia + crown-group turtles. The group placed more crownwardly is comprised largely by Cretaceous species, and includes Sinemys lens (Late Jurassic, all other species in this list are Cretaceous), Sinemys gamera, 
Dracochelys biscuspis, Ordosemys sp., Judithemys sukhanovi, Kirgizemys dmitrievi, and Kirgizemys hoburensis. Applying the phylogenetic definitions of Rabi et al. (2014), this entire group could be referred to as Sinemydidae. However, within our 'Sinemydidae', Sinemys lens and Sinemys gamera form a clade that is found in a polytomy with Dracochelys, Ordosemys, and a clade that includes Kirgizemys spp. and Judithemys, i.e. species that are commonly referred to as macrobaenids (e.g. Gaffney \& Ye 1992; Parham \& Hutchinson 2003). Depending on the (unresolved) phylogenetic position of Macrobaena mongolica, it is likely that our 'Sinemydidae' in fact comprises both sinemydids and macrobaenids. Therefore, we refer to the clade including Sinemys and Judithemys as Sinemydidae/Macrobaenidae throughout this work. Our Sinemydidae/Macrobaenidae is moderately supported by a Bremer support of 2 , and the placement of sinemydids as the sister to Angolachelonia + crown-group turtles also has a Bremer support of 2. Sinemydids/Macrobaenids share two cranial and two postcranial synapomorphies, none of which are unique (Table 3).

The more stemwardly positioned group is comprised of Jurassic Asian turtles, and includes species of Xinjiangchelys and Annemys. Technically, the phylogenetic definition of Xinjiangchelyidae of Rabi et al. (2014) cannot be applied to this group, as we did not include the species of Xinjiangchelys used to define the group. However, for ease of communication, we refer to the group as Xinjiangchelyidae within this paper. Xinjiangchelyidae is moderately supported with a Bremer support of 2 , although the ingroup relationships remain unclear in our analysis. Xinjiangchelyids share six unambiguous synapomorphies (three cranial; three postcranial, of which is unique (ch 257.1); Table 3). The node support for xinjiangchelyids plus all more crownwardly positioned turtles is high (Bremer support $=4$ ). 
Parsimony Analysis using ordered characters

Ordering characters resulted in 116 MPTs initially, and 195 MPTs 1566 steps long after additional TBR branch swapping. The results from the ordered analysis resulted in a large polytomy including all extant clades of turtles, xinjiangchelyids, angolachelonians, and the individual species of sinemydids/macrobaenids (Fig. 4B). This is caused by unstable positions of Angolachelonia, 'macrobaenids' Uudithemys + the species of Kirgizemys), and Ordosemys sp. and Dracochelys biscuspis. By inspecting the Adams consensus tree, we identified Ordosemys sp. as a 'wildcard' taxon that is alternatively found in clades with sinemydids/macrobaenids, only sinemydids, or xinjiangchelyids. When Ordosemys is discarded from the set of MPTs, three main topologies are evident, which are summarized in Figure 11. The MPT topologies include either (1) Angolachelonians and 'macrobaenids' as successive sister groups to Toxochelys + chelonioids, making them stem-group chelonioids; (2) only Angolachelonians as sister to Toxochelys + chelonioids, and sinemydids/macrobaenids forming a clade in the position in which they were also recovered in the unordered analysis; (3) an identical topology to that of the unordered analysis. The topologies in which Angolachelonia is found on the stem-group of chelonioids imply only one origin of marine lifestyles in non-pleurodiran turtles besides Odontochelys. However, the ordered analysis agrees with the unordered one in always finding a monophyletic Angolachelonia, and always recovers protostegids as dermochelyoids. 
Excluding 'marine' characters resulted in 86 MPTs 1480 steps long initially, and 104 MPTs were recovered in total after a second round of TBR branch swapping. This analysis resulted in a large polytomy that included pleurodires, trionychians, testudinoids, chelydroids, thalassochelydians, sandownids, Toxochelys, and chelonioids (Fig. S3.1). This polytomy resulted from the variable position of sandownids, which in some MPTs were found with thalassochelydians on the stem-group of turtles, and in some MPTs forming a clade with Toxochelys on the stem-group of chelonioids. Ingroup relationships of Chelonioidea were poorly resolved, resulting a polytomy of protostegids, crown-group cheloniids, dermochelyids, Eochelone, Allopleuron, Argillochelys, and Puppigerus. However, protostegids were found to be chelonioids in all MPTs.

The 'least specialised taxa analysis 1' (only using Santanachelys) resulted initially in 91 MPTs 1443 steps long, and 120 MPTs were recovered after a second round of TBR branch swapping. The 'least specialised taxa analysis 2' (Santanachelys and Rhinochelys included) resulted in 39 MPTs 1453 steps long, and an additional three MPTs recovered during a second round of TBR branch swapping. The 'least specialised taxon analysis 3' (only Archelon and Protostega excluded) resulted in 12 MPTs 1510 steps long, and a second round of TBR branch swapping did not recover any further MPTs. In the first analysis, Eochelone was found in a polytomy with dermochelyids and cheloniids, and Toxochelys and Santanachelys were found in a polytomy with crown-group chelonioids (Fig. S3.2). In the second analysis, Sanatanchelys and Rhinochelys formed a monophyletic Protostegidae as the earliest branching stem-group chelonioids (Fig. S3.3). Toxochelys was also recovered as a stem-group chelonioid, and as the immediate sister-taxon to crown-group Chelonioidea. Eochelone was found as the earliest branching stem-group cheloniid. When only Archelon and Protostega were excluded, the relationships of all 
taxa were as in our unordered analysis with the complete taxon sampling, i.e. protostegids were found as dermochelyoids (Fig. S3.4).

\section{Templeton's tests}

Of the alternative hypotheses of turtle interrelationships (see Table 4) that we tested, only one could be rejected based on significant or near-significant p-values: the hypothesis that protostegids fall outside of Chelonioidea (discussed below). Alternative hypotheses for xinjiangchelyids, sinemydids, and angolachelonians could not be rejected. A possible reason for this is illustrated in our similarity results, which show that these groups have relatively high similarity to various cryptodiran groups. Although these similarities in character scores are optimized to be homoplastic in our analysis, alternative interpretations require only few more steps (see Table 4 for differences in step-length) in parsimony analysis and are thus not significantly different to our preferred tree topology.

Our procedure of using only one OTU to set up the constraints allowed us to additionally explore the topological effects of these hypotheses. In many cases, alternative placements of individual OTUs resulted in strong topological deviations from our original analysis and affected positions of taxa not relevant to the constraint. Some groups recovered in our analysis are also relatively unstable; for instance, our monophyletic Sinemydidae/Macrobaenidae is broken into paraphyletic or even polyphyletic assemblages in many of the constrained analyses. On the other hand, some groups, such as Angolachelonia or Xinjiangchelyidae, are relatively robustly recovered as monophyletic groups among the constrained analyses, even if their position within the tree structure varied. Consensus trees and MPTs for all constraint analyses in 
Newick tree format are provided in Evers \& Benson (2018b), and consensus trees are figured in Appendix 3 (Figs S3.5-24).

Constraining members of Angolachelonia into alternative positions. Angolachelonia was recovered as a monophyletic group regardless of constraints on the positions of individual thalassochelydians (Plesiochelys, Jurassichelon, or Solnhofia; Figs S3.5-9), and when Sandownia is constrained to be a stem-group cryptodire (Fig. S3.10). In other words, specifying an alternative position for one of its members generally resulted in all members of Angolachelonia being found in that position. The one exception to this occurs when Sandownia was constrained to be a stem-group chelonioid, in which case only sandownids followed Sandownia into this position, and Thalassochelyida was recovered on the stem-group of turtles (Fig. S3.11). None of the constrained analyses in which any member of Angolachelonia was included could be rejected ( $p>0.05$; constraint analyses required between two and four additional steps; see Table 4).

Constraining xinjiangchelyids or sinemydids/macrobaenids to be stem-group cryptodires. We could not reject the hypothesis that xinjiangchelyids (i.e. Xinjianchelys wusu) or sinemydids/macrobaenids (Sinemys lens or Judithemys sukhanovi) are stem-group cryptodires ( $p>0.05$; four or six additional steps required; see Table 4). Constraining xinjiangchelyids to be stem-group cryptodires resulted in a large polytomy that includes a clade comprising pleurodires and paracryptodires, a monophyletic Xinjiangchelyidae, sinemydids/macrobaenids (not forming a single clade), all cryptodiran clades revovered in our original analyis, and a monophyletic Angolachelonia (Fig. S3.14). Constraining any member of our Sinemydidae/Macrobaenidae to be stem-group cryptodires did not change the position of xinjiangchelyids as stem-group turtles, but resulted in the 
recovery of Angolachelonia as part of the total-group of Chelonioidea, and the recovery of sinemydids/macrobaenids as a clade of stem-group cryptodires (Fig. S3.15-17).

Constraining xinjiangchelyids or sinemydids/macrobaenids to be stem-group chelonioids. Alternative hypotheses in which xinjiangchelyids or sinemydids/macrobaenids were stem-chelonioids could not be rejected (sinemydids/macrobaenids: $\mathrm{p}>0.05$; five additional steps required; see Table 4), although p-values for the constraint including Xinjiangchelys wusu were relatively low and tree length was relatively high (tree length $=1542$ steps, i.e. 10 additional steps; maximum distance tree: $\mathrm{p}=0.12$; minimum distance tree: $\mathrm{p}=0.11$ ). When xinjiangchelydis were constrained to be stem-group chelonioids, xinjiangchelyids and sinemydids formed a monophyletic group, and Angolachelonia was found on the stem-group of turtles (Fig. S3.19). When sinemydids were constrained to be stem-group chelonioids, Angolachelonia was found as the immediate sister to Chelonioidea and Toxochelys, and therefore more crownward on the cheloinioid stem than the sinemydids constrained to be stem-group chelonioids, which formed a clade (Fig. S3.20-21). In these analyses, xinjiangchelyids were found to be stem-group turtles.

Constraining members of Protostegidae to be stem-group chelonioids. We conducted an analysis in which Santanachelys gaffneyi was constrained to be a stem-group chelonioid. This was done because this topology was found in our 'least specialised taxa analysis 1'. This phylogenetic hypothesis could not be rejected statistically (tree length $=1534$, i.e. two additional steps; maximum and minimum distance trees $\mathrm{p}>0.5$ ). This constraint resulted in a large polytomy among chelonioids (Fig. S3.24). We additionally explored the Adams consensus tree, in which all fossil cheloniids were found members of the 
chelonioid stem-group: Dermochelyidae (including Eosphagis) was sister to a clade comprising extant cheloniids, and taxa recovered as stem-cheloniids in our original analysis formed a paraphyletic grade leading to crown-group chelonioids. A monophyletic Protostegidae formed the next successive sister taxon, and Toxochelys was found as the earliest branching stem-group chelonioid. Angolachelonia, Sinemydidae/Macrobaenidae and Xinjiangchelyidae were recovered in positions identical to those in the original analysis.

Constraining members of Protostegidae to be stem-group cryptodires or stem-group turtles. Constraining protostegids into alternative positions onto the stem-group of cryptodires or turtles resulted in the statistically significant or near significant p-values, suggesting that alternative hypotheses are unlikely, although not always decisively rejected (see Table 4). The topological effects of these constraints resulted in major differences to our trees. When Rhinochelys or Santanachelys were constrained to be stem-group cryptodires (tree length $=1548$, i.e. 16 additional steps for either constraint; Rhinochelys: maximum distance tree $\mathrm{p}=0.054 ;$ minimum distance tree $\mathrm{p}=0.033$; Santanachelys: maximum distance tree $\mathrm{p}=0.0495$; minimum distance tree $\mathrm{p}=0.033$ ) or stem-group turtles, protostegids were found to be polyphyletic. The topological effects of these constraints were identical when Rhinochelys or Santanachelys were constrained to be stem-group cryptodires (Fig. S3.12, 22): Archelon and Protostega formed a clade on the stem of Dermochelys as crown-group chelonioids, and the remaining protostegids were found as a monophyletic group that was sister to Thalassochelydia. Sandownids formed a clade one node more stemwardly positioned than the clade that includes Santanachelys or Rhinochelys and thalassochelydians. When Santanachelys was constrained to be a stem-group turtle (tree length $=1547$, i.e. 15 additional steps; 
maximum distance tree $\mathrm{p}=0.031$; minimum distance tree $=0.004)$, it was recovered as a plesiochelyid but all remaining protostegids were found as dermochelyoids (Fig. S3.23). Constraining Rhinochelys to be a stem-group turtle (tree length $=1548$, i.e. 16 additional steps; maximum distance tree $p=0.07$; minimum distance tree $=0.02$ ) resulted in the formation of a clade that included all protostegids except Archelon and Protostega (which remained dermochelyoids), plesiochelyids, and a clade including Solnhofia and sandownids (to which the phylogenetic definition of Angolachelonia sensu Mateus et al. (2009) can be applied, but which differs in taxonomic content of the Angolachelonia in our original analysis) (Fig. S3.13).

When Protostega was constrained to be a stem-group cryptodire (tree length = 1553, i.e. 21 additional steps; maximum distance tree $p=0.015$; minimum distance tree $p=0.002$ ), a monophyletic Protostegidae was recovered as the sister group to Angolachelonia (Fig. S3.17). This clade was the immediate sister group to cryptodires. Sinemydids/Macrobaenids were found to be paraphyletic, and on the stem-group turtles. Xinjiangchelyids were also found as stem-group turtles. When Protostega was constrained to be a stem-group turtle (tree length = 1553, i.e. 21 additional steps; maximum distance tree $\mathrm{p}=0.032$; minimum distance tree $\mathrm{p}=0.005$ ), a monophyletic Protostegidae was recovered as the sister-taxon of plesiochelyids. This clade was the sister clade to sandownids and Solnhofia, which formed a monphyletic group (Fig. S3.18). Sinemydids/macrobaenids and xinjiangchelyids were again recovered as clades on the stem-group turtles. In all constraints including protostegids, sinemydids/macrobaenids and xinjiangchelyids were always found to be stem-group turtles. 
Institutional abbreviations. BP, Bernhard Price Institute, Johannesburg, South Africa; BSPG, Bayerische Staatsammlung für Paläontologies und Geologie, Munich, Germany; CAMSM, Sedgwick Museum of Earth Sciences, Cambridge, UK; CMNH, Cleveland Museum of Natural History, Cleveland, OH, USA; DMNH, Denver Museum of Nature and Science, Denver, CO, USA; FCG-CBP, Fundación Colombiana de Geobiología, Dentro de Investigaciones Paleontológicas, Villa de Leyva, Colombia; FMNH, Field Museum of Natural History, Chicago, IL, USA; FUM, Fur Museum (Museum Salling), Fur, Denmark; FWMSH, Fort Worth Museum of Science and History, Forth Worth, TX, USA; IVPP, Institute of Vertebrate Paleontology and Paleoanthropology, Beijing, China; IW, Ingmar Werneburg private collection; KUVP, University of Kansas, Lawrence, KS, USA; MCZ, Museum of Comparative Zoology, Harvard University, Cambridge, MA, USA; MIWG, Museum of Isle of Wight Geology, Sandown, Isle of Wight; MNA, Museum of Northern Arizona, Flagstaff, AZ, USA; MNB, Naturhistorisches Museum Basel, Basel, Switzerland; MPEF, Museo Paleontológico Egidio Feruglio, Trelew, Argentina; NHMM, Natuurhistorisch Museum Maastricht, Maastricht, Netherlands; NHMUK, Natural History Museum, London, UK; NMS, National Museum of Scotland, Edinburgh, UK; OCPDEK, Office Chérifien des Phosphates, Khouribga, Morocco; OUMNH, Oxford University Museum of Natural History, Oxford, UK; PIMUZ, Paläontologisches Institut und Museum der Universität Zürich, Zurich, Switzerland; PIN, Paleontological Insitute, Russian Academy of Sciences, Moscow, Russia; PMOL, Paleontological Museum of Liaoning, Shenyang Normal University, China; QM, Queensland Museum, Brisbane, Australia; SMF, Senckenberg Museum Frankfurt, Frankfurt, Germany; SMNS, Staatliches Museum für Naturkunde, Stuttgart, Germany; SMU, Shuler Museum of Paleontology, Southern Methodist University, Dallas, TX, USA; TM, Teylers Museum, Haarlem, Netherlands; TMM, Texas Memorial Museum, Austin, TX, USA; TMP, Royal Tyrell Museum, 
Drumheller, AB, Canada; UCMP, University of California Museum of Paleontology, Berkeley, CA, USA; UMZC, University Museum of Zoology, Cambridge, UK; USNM, United States National Museum, Washington, DC, USA; WGJ, Waler Joyce private collection; YPM, Yale Peabody Museum, New Haven, CT, USA; ZIN PH, Zoological Insitute of Russian Academy of Sciences palaeoherpotological collection, St. Petersburg, Russia.

\section{SYSTEMATIC PALAEONTOLOGY}

THALASSOCHELYDIA Anquetin et al., 2017

Modified definition. The clade that includes all turtles more closely related to Eurysternum wagleri Meyer, 1839, Plesiochelys etalloni (Pictet and Humbert, 1857), and Thalassemys hugii Rütimeyer, 1873, than to Pelomedusa subrufa (Bonnaterre, 1789), Testudo graeca Linnaeus, 1758, Protostega gigas (Cope, 1871b), or Sandownia harrisi Meylan et al, 2000.

Diagnosis. Thalassochelydia can be diagnosed on the basis of the following unambiguous synapomorphies: processus trochlearis oticum is limited to the medial part of the otic chamber, and a deep recess is present on the anterior surface of the quadrate medially to the processus trochlearis oticum (ch 81.1); presence of a fossa on the posterodorsal surface of the floor or the supratemporal fossa (ch 113.1); splenial present (ch 185.0); costals lack lateral ossification, allowing the dorsal exposure of the distal end of ribs and the development of fontanelles only at the most anterior and posterior costals (ch 210.2); rib free peripherals are present (ch 211.1); vertebrals 2 to 4 are signicantly broader than pleurals (ch 224.0); central articulations of cervical vertebrae are not 
formed, cervical vertebrae are amphicoelous or platycoelous (ch 278.0).

Remarks. Thalassochelydia was defined by Anquetin et al. (2017) to provide a name for the group that includes Eurysternidae, Plesiochelyidae, and Thalassemydidae. To retain the association of the clade name with this taxonomic content, we chose to modify the original definition of Thalassochelydia to exclude Sandownia harrisi (the type species of Sandowniidae).

Phylogenetic definitions have been recently proposed for several commonly recovered clades of Mesozoic turtles (Joyce et al. 2004; Mateus et al. 2009; Rabi et al. 2014; Cadena \& Parham 2015; Anquetin et al. 2017). These definitions usually include one or several statements of taxa excluded from the definition, and therefore associate a name very specifically to a set of fossil species or higher taxa to the exclusion of others. For example, Anquetin et al. (2017: p. 329) provide a phylogenetic definition for their newly coined clade Thalassochelydia, which includes 'all turtles more closely related to Eurysternon wagleri Meyer, 1839, Plesiochelys etalloni (Pictet and Humbert, 1857), and Thalassemys hugii Rütimeyer, 1873, than to Pelomedusa subrufa (Bonnaterre, 1789), Testudo graeca Linnaeus, 1758, or Protostega gigas (Cope, 1871b)'. Implicit in the definition of Thalassochelydia is that Anquetin et al. (2017) had a specific idea about the content of Thalassochelydia, i.e. the group that only includes plesiochelyids, eurysternids, and thalassemydids.

However, there are difficulties with applying definitions like the one above, because some of the specifiers have not been included in any phylogenetic analysis (see also definitions of Rabi et al. 2014). For example, no probable thalassemydid has ever been included in a phylogenetic analysis, and the species suitable to define Eurysternidae (i.e Eurysternon wagleri) has also not been included in comprehensive 
analyses (Anquetin et al. 2017). Therefore, the application of the name rests on various untested assumptions (such as that Thalassemys hugii is more closely related to Plesiochelys etalloni than to Protostega gigas).

Despite the lack of evidence of the phylogenetic positions of the exact taxa included in the phylogenetic definition of Thalassochelyida as proposed by Anquetin et al. (2017), the definition of this taxon seems justifiable on the basis of (i) cladistic evidence that species within the hypodigm of the three traditional families have recently been found to form a clade (plesiochelyids and the putative eurysternid Solnhofia; Anquetin et al. 2015); and (ii) informal comparative anatomical evidence suggesting the existence of the group (Anquetin et al. 2017).

If the definition for Thalassochelyida is applied to our phylogenetic results, in which we find a clade comprised of Solnhofia parsoni (a putative eurysternid), Plesiochelys etalloni (a plesiochelyid), and Sandownia harrisi (a sandownid) to the exclusion of protostegids, pleurodires, and cryptodires, then sandownids are also included in Thalassochelydia. However, this extended Thalassochelydia would then become an objective junior synonym of Angolachelonia, which is a clade named by Mateus et al. (2009) that is phylogenetically defined as the clade containing Solnhofia and sandownids. 'Thalassochelydia' as intended by Anquetin et al. (2017; i.e. not including sandownids) still exists in our topology, but as a less inclusive clade within the extended Thalassochelydia. We consider it useful to have clade names available for sandownids, thalassochelydians (sensu Anquetin et al. (2017)) and the clade that includes both of the former. Therefore, it is either necessary to accept the synonymy of Thalassochelydia with Angolachelonia and erect a new name for what Anquetin et al. (2017) intended to be Thalassochelydia, or to change the definition of either Angolachelonia or Thalassochelydia. Because Angolachelonia has priority over 
Thalassochelydia, we modify the definition of Thalassochelyida to specifically exclude sandownids.

ANGOLACHELONIA Mateus et al., 2009

Definition. The clade originating from the most recent common ancestor of Angolachelys mbaxi Mateus et al., 2009 and Solnhofia parsoni Gaffney, $1975 b$.

Diagnosis. Angolachelonia can be diagnosed on the basis of the following unambiguous synapomorphies: the foramen stapedio-temporale is concealed in dorsal view by the temporal skull roof (ch 18.0); the posterior surface of the quadrate bears an infolding ridge ventral to the incisura columella auris (ch 83.1); the articular process of the cranium is strongly posteriorly directed (ch 84.1); the pterygoids are in a very long medial contact with one another, longer than the basisphenoid total length in midline (ch 94.0); the pterygoid contacts the medial edge of the mandibular condyle when is seem in ventral view (ch 103.1); the posterior margin of the coronoid has a deep notch (ch 181.1); the coronoid bears a foramen at the anterior end, which leads from the fossa meckelii into the space between the mandibular rami (ch 182.1); the coronoid process is relatively high and dorsally or posterodorsally pointed (ch 184.1).

Remarks. Mateus et al. (2009) recovered sandownids as more closely related to crowngroup cryptodires than to plesiochelyids, and erected the clade Angolachelonia for a group uniting Solnhofia parsoni with Angolachelys mbaxi, a sandownid not included in our analysis. Angolachelys was not included in our analysis, because limited anatomical information is available while new material is in preparation (pers. comm. Octavio 
Mateus to SWE in 2015). However, if Angolachelys is in fact a sandownid, as found by previous analyses (Mateus et al. 2009; Tong \& Meylan 2013; Cadena 2015), then this name is applicable to the clade that includes thalassochelydians (which include Solnhofia) and sandownids (which include Angolachelys). Unlike in the analysis of Mateus et al. (2009), Angolachelonia includes plesiochelyids as well as Solnhofia and sandownids according to our results. Although we find Solnhofia as sister to plesiochelyids, branch support for this is only moderate (Bremer support $=2$ ). If future analyses show that Solnhofia is indeed more closely related to sandownids than to plesiochelyids or other thalassemydids, Solnhofia would be removed from Thalassochelydia, and Angolachelonia would become applicable to the less inclusive clade of sandownids + Solnhofia .

SANDOWNIDAE Tong \& Meylan, 2013

New definition. The clade that includes Sandownia harrisi Meylan et al., 2000, but not Pelomedusa subrufa (Bonnaterre, 1789), Testudo graeca Linnaeus, 1758, Solnhofia parsoni Gaffney, 1975b, Eurysternum wagleri Meyer, 1839, Plesiochelys etalloni (Pictet and Humbert, 1857), Thalassemys hugii Rütimeyer, 1873, or Protostega gigas (Cope, $1871 b)$.

Diagnosis. Sandownidae can be diagnosed on the basis of the following unambiguous synapomorphies: weak to no lower temporal emargination, the margin of the lower temporal emargination is formed by the quadratojugal or quadratojugal and jugal (ch 34.0); a vomer-palatine contact anterior to the internal naris is present (ch 57.1); the vomer contributes to the upper triturating surface (ch 68.1); the pterygoid forms a 
posteromedial wing that partially or completely covers the parabasisphenoid, and sometimes the basioccipital in ventral view (ch 108.1); the dorsum sellae is deep, i.e. the dorsal surface of parabasisphenoid between the clinoid processes is a transversely concave floor forming a trough between the posterior part of the dorsal surface of the parabasisphenoid, which is usually cup-like, and the anterior portion of the parabasisphenoid forming the rostrum basisphenoidale and sella turcica (ch 139.0).

Remarks. A monphyletic group including Sandownia harrisi, Brachyopsemys tingitana, Angolachelys mbaxi, and Leyvachelys cipadi has been recognized in several studies (Mateus et al. 2009; Tong \& Meylan 2013; Cadena 2015), and the group has been named as a family following a rank-based definition by Tong \& Meylan (2013). Here, we provide a phylogenetic definition of the group that is in accordance with the associated taxoncontent of the group implied by previous studies, and phrased coherently in comparison with other phylogenetic definitions for Mesozoic turtles.

\section{DISCUSSION}

Independent origins of marine ecologies

Our phylogenetic results using unordered character states support the hypothesis of two independent origins of marine ecologies among non-pleurodiran turtle from the Jurassic onwards: Angolachelonia (thalassochelydians + sandownids) and Chelonioidea (including protostegids). In addition to the Triassic stem-group turtle Odontochelys, and 2-3 origins among pleurodires (depending on the phylogenetic relationships of Bothremydidae; Gaffney et al. 2006; Rabi et al. 2012), this demonstrates 
a total of 5-6 origins of marine habits through the evolutionary history of turtles. Our study represents the first analysis with a large sample of thalassochelydians and sandownids, in which these groups are found to form a clade. The only previous study with a similar sample size for these groups (Cadena 2015), recovered a polyphyletic Thalassochelydia (Plesiochelys was recovered as a stem-group turtle, and Solnhofia and Jurassichelon were found as stem-group chelonioids), and sandownids as stem chelonioids. Compared to previous analyses, we included more observations regarding the cranial anatomy of turtle groups. This was possible thanks to 3D models derived from CT data for species of all major subgroups of turtles included in our taxon sampling, including several sandownids, thalassochelydians, protostegids, and nonprotostegid chelonioids. However, alternative hypotheses in which angolachelonians are found to be stem-group chelonioids cannot be rejected at present. Indeed, a parsimony analysis using ordered character states of our data supports this hypothesis in a subset of the resulting MPTs. If anglolachelonians are indeed in the stem-group of Chelonioidea, this would imply only a single origin of marine ecology outside of pleurodires and Odontochelys. Angolachelonians are known from Jurassic, Cretaceous and Palaeogene deposits (e.g. Tong \& Meylan 2013; Cadena 2015). Furthermore, marine bothremydids and chelonioids are also known both before and after the Cretaceous-Palaeogene boundary. Our results therefore indicate that all three major clades of Cretaceous marine turtles survived the $\mathrm{K} / \mathrm{Pg}$ mass extinction. This contrasts with other marine reptiles, such as mosasaurs and plesiosaurs (Bardet 1994; Motani 2009; Benson 2013), and explanations of marine turtle survival warrant further investigation.

Differences in the nature of marine adaptation are evident among clades. Members of Angolachelonia are generally interpreted to live in shallow, nearshore marine habitats, because these turtles lack osteological evidence for a pelagic lifestyle, 
and are found in relatively nearshore deposits (Anquetin et al. 2017). Marine pleurodires such as bothremydids also lack evidence for a pelagic ecology, and are usually interpreted to have lived in near-shore marine environments (e.g. Gaffney et al. 2006; Ferreira et al. 2018). Features interpreted to indicate a pelagic lifestyle, such as rigid inter-phalangeal articulations in the manus, are only present in chelonioids, including protostegids. Because protostegids are found as chelonioids within our analysis, a pelagic lifestyle can be inferred to have evolved only once within turtles. Evolutionary refinement of key adaptations such as flippers cannot be resolved until a better understanding of the ingroup relationships of protostegids is obtained.

The Early Cretaceous protostegid Santanachelys gaffneyi has flippers in which some moveable articulations are still retained, a condition that is also present in Toxochelys (Hirayama 1998). This observation caused Hirayama $(1994,1998)$ to infer that derived flippers, with rigid manual articulations, evolved independently in dermochelyids, cheloniids, and advanced protostegids. However, S. gaffneyi is nested deeply within Protostegidae in our analysis, and Toxochelys is found as a stem-group chelonioid rather than a stem-group cheloniid as in Hirayama (1998). Therefore, the presence of less specialized flippers in Santanachelys is optimized as a reversal, and the derived condition of flippers in which all manual articulations are rigid is optimized as a synapomorphy for crown-group chelonioids (this was also implied by the matrix of Kear \& Lee (2006), although not specifically stated). Unfortunately, the flipper morphology of most Early Cretaceous protostegids (e.g. Notochelone costata, Rhinochelys pulchriceps) is not known. However, Desmatochelys padillai from the Early Cretaceous of Colombia has been scored to have the advanced flipper condition (Cadena \& Parham 2015), and Late Cretaceous protostegids also lack movable articulations (Hirayama 1994). In-group relationships of Protostegidae require further investigation, because our phylogenetic 
results differ from those of previous analyses. If protostegids with derived flippers are found to be nested within protostegids showing the primitive condition (as in most previous studies), the flippers of protostegids and other chelonioids could have evolved convergently.

The phylogenetic position of protostegids

Protostegids have been hypothesized to be either (1) on the stem-group of the leatherback turtle Dermochelys coriacea within Chelonioidea (i.e. as dermocheyloids; Hirayama 1994, 1998; Brinkman et al. 2006; Kear \& Lee 2006; Bardet et al. 2013; Cadena \& Parham 2015; Cadena 2015), (2) to be an independent lineage of pelagic turtles on the stem-group of cryptodires (Danilov \& Parham 2006, 2008; Joyce 2007; Sterli \& de la Fuente 2011, 2013; Anquetin 2012;), or (3) on the turtle stem (Sterli 2010; Sterli \& de la Fuente 2011). The finding of protostegids as stem-group cryptodires, and therefore outside of Chelonioidea by previous analyses, has always been based on the inclusion of the early protostegid Santanachelys as the sole representative of that group (Danilov \& Parham 2006, 2008; Joyce 2007; Sterli \& de la Fuente 2011, 2013; Anquetin 2012). Dermochelyoid affinities for protostegids are usually based on studies focussed on the relationships of marine turtles (e.g. Hirayama 1994; Kear \& Lee 2006; Bardet et al. 2013; Gentry et al. 2018), although some global studies have found protostegids in the same position (e.g. Cadena \& Parham 2015; Cadena 2015).

Our matrix includes nine protostegids covering their temporal and geographic spread, body size range, and ecological adaptations. Skulls of three Early Cretaceous protostegids, Rhinochelys pulchriceps, Bouliachelys suteri, and Notochelone costata, were CT-scanned and complete skull models have been produced to facilitate character 
scoring. Our 3D models provide the most detailed account of the cranial osteology of protostegids. This allowed us to score numerous characters, which previously could not be scored, as well as formulate new characters, describing variation in the skull, and particularly the braincase. We find protostegids as dermochelyoids, and the total-group and crown-group of Chelonioidea, as well as Dermochelyoidea (i.e. Dermochelyidae + Protostegidae) are supported by a long list of unambiguous synapomorphies.

Furthermore, Bremer support for these groups is robust (see results).

It has been suggested that the finding of protostegids as chelonioids results from the convergent acquisition of a high number of phylogenetically-misleading anatomical character states related to a pelagic lifestyle in both groups (Cadena \& Parham 2015). To investigate this, we identified synapomorphies that support the chelonioid relationships of protostegids and could plausibly result from functional constraints on marine adaptation (Table 5). These include characters related to the reduction of shell ossification, the modification of limbs to flippers, formation of a secondary palate, and modifications of the triturating surface more generally that could be related to feeding. Several of these characters are also optimized as independently-obtained synapomorphies of angolachelonians or angolachelonian subgroups (Table 5). Although we do not support the practice of deleting characters due to assumed ecological function, protostegids are still recovered as chelonioids by analysis excluding the characters listed in Table 5 (see Fig. S3.1). This suggests that protostegids can be found as chelonioids independently of functionally convergent features related to marine or pelagic life. Our 'least specialised taxa analyses' provide further support for the hypothesis that protostegids are chelonioids, although they are found as stem-group chelonioids rather than dermochelyoids when only the taxa from the Early Cretaceous (Santanachelys, Rhinochelys) are included. Nevertheless, our analysis is the first study in 
which protostegids are still allied with chelonioids when 'advanced' protostegids are excluded from the analysis.

Our heatmaps of similarity indicate that protostegids do show relatively high similarity with various non-chelonioids among stem-group turtles, particularly to sinemydids, xinjiangchelyids, and angolachelonians. Similarities between protostegids and stem-group turtles were also noted by Cadena \& Parham (2015). While the high similarity of protostegids to sinemydids and xinjiangchelyids cannot be explained by ecological convergence, it is possible that at least some of the similarity between protostegids (and also chelonioids more generally) and angolachelonians can be explained by their marine lifestyle.

Our Templeton's tests provide explicit tests of hypotheses that protostegids are stem-group turtles, or stem-group cryptodires. These hypotheses, although not being strictly rejected in all cases $(10$ tests result in $\mathrm{p}<0.05$, and two tests result in $0.054<\mathrm{p}<$ 0.073; Table 4), have poor support, despite the high amount of similarity of protostegid character scorings to those of the non-chelonioid groups. Interestingly, when the Early Cretaceous protostegids Rhinochelys or Santanachelys are used to constrain protostegids into alternative positions, protostegids are found to be polyphyletic, with Late Cretaceous protostegids still being recovered as the sister to Dermochelyidae. In contrast, when Protostega was constrained to alternative positions, protostegids were found to be monophyletic. This provides an explanation for the frequent recovery of protostegids as non-chelonioids, when the early protostegid Santanchelys was used as the only protostegid representative in phylogenetic analyses (Danilov \& Parham 2006, 2008; Joyce 2007; Sterli \& de la Fuente 2011, 2013; Anquetin 2012). Therefore, our matrix provides strong support for the position of protostegids within Chelonioidea. However, the hypothesis that protostegids are stem-group chelonioids, rather than 
dermochelyoids, cannot be statistically rejected ( $p>0.05$; Table 4$)$, and was also found in our 'least specialised taxa analyses' when only Early Cretaceous protostegids were included in the phylogenetic analysis.

Implication on the timing of the origin and biogeographic evolution of Chelonioidea

Molecular phylogenies strongly support a sister-group relationship between Chelydroidea (chelydrids + kinosternids) and Chelonioidea (e.g. Parham et al. 2006; Crawford et al. 2015; Pereira et al. 2017) as a clade called Americhelydia (Joyce et al. 2013). Estimates of divergence times place the chelonioid/chelydroid split in the late Early Cretaceous (113 Ma; Joyce et al. 2013), and the origin of crown-group chelonioids in the latest Cretaceous (66 Ma; Joyce et al. 2013). The fossil calibrations used in these analyses represent the oldest specimens that can be assigned to the respective crowngroups with high certainty (Joyce et al. 2013), and these specimens are generally younger than more ambiguous representatives such as protostegids. For example, protostegids, which are recovered confidently as crown-group chelonioids in our analysis, are substantially older (Barremian-Aptian, $120 \mathrm{Ma}$ ) than the fossil calibration specimens used by Joyce et al. (2013) as the oldest crown-group chelonioids (Eosphargis breineri from the Eocene, $55 \mathrm{Ma}$ ). Because the oldest protostegids are older than the molecular clock divergence time estimated for Americhelydia, our phylogenetic results have implications for the timings of deep divergences of the turtle crown-group. Furthermore, the inclusion of protostegids into Chelonioidea has implications for the biogeographic evolution of Americhelydia.

The oldest unambiguous (although fragmentary) chelydrid and kinosternoid remains are from the Campanian of Mexico (Brinkman \& Rodriguez de la Rosa 2006; 
Joyce et al. 2013; Joyce 2016; Joyce \& Bourque 2016) and the United States (Lyson et al. 2017), and relatively complete specimens are known from the Maastrichtian of North America (Emarginachelys cretacea; Whetstone 1978; Hoplochelys clark; Knauss et al. 2011; Joyce \& Bourque 2016). Furthermore, the oldest commonly accepted stem-group chelonioid is Toxochelys from the Upper Santonian or Lower Campanian Niobrara Formation of North America (Nicholls 1988; Weems \& Brown 2017; Gentry et al. 2018). Therefore, the earliest undisputed americhelydians suggest a North American origin of the clade (e.g. Crawford et al. 2015; Parham et al. 2014; Cadena \& Parham 2015; Pereira et al. 2017), and their ages are consistent with molecular clock estimates dating the origin of Americhelydia into the late Early Cretaceous. A North American origin for Chelonioidea is also supported by a number of pre-Maastrichtian fossils for which phylogenetic positions are currently uncertain, but which have been hypothesized to either be stem-group chelonioids, stem-group cheloniids, or stem-group dermochelyids, such as Ctenochelys (e.g. Matzke 2007; Gentry 2016) or Corsochelys (Zangerl 1960). Nevertheless, some poorly known fossils of Chelonioidea incertae sedis are also found in pre-Maastrichtian deposits outside of North America, such as the putative dermochelyid Mesodermochelys undulatus from the Santonian-Maastrichtian of Japan (Sato et al. 2012).

The oldest uncontentious crown-group chelonioids are generally much younger than crown-group chelydroid material, and are not from North America. Although putative dermochelyid specimens are known from the Cretaceous, this mostly fragmentary material has not been included in a phylogenetic analysis (Joyce et al. 2013). Therefore, the oldest widely-accepted dermochelyid is the Eocene Eosphargis breineri from Denmark (Wood et al. 1996; Joyce et al. 2013). Similarly, several Eocene taxa from Europe, including Argillochelys cuneiceps, Eochelone brabantica, and 
Puppigerus camperi, have been consistently found as stem-group cheloniids (e.g. Weems \& Brown 2017), and this is supported by our analysis. Putative stem-group cheloniids are also known from the Cretaceous (e.g. Brinkman et al. 2006, 2009; Parham et al. 2014; Gentry et al. 2018), but phylogenetic uncertainty surrounding these taxa has been used as an argument against their use as calibration points (Joyce et al. 2013). However, there is a growing body of evidence to suggest that some Cretaceous taxa which have been previously found in alternating phylogenetic positions (like Ctenochelys from the Coniacian-Campanian of the United States, and Peritresius from the Campanian of the United States) can be firmly assigned to the stem-group of cheloniids based on newly discovered or re-analysed material (e.g. Gentry 2016; Gentry et al. 2018).

Minimum age constraints for fossil calibrations should be based on strong phylogenetic support indicating the taxon in question is actually a member of the crowngroup (Parham et al. 2012). Although we reject the possibility that protostegid fall outside of the crown-group of Cryptodira, we cannot reject the possibility that protostegids are stem-group chelonioids. Therefore, protostegids might not be ideal candidates for constraining the crown-group age of Chelonioidea, although they could be used as a calibration for the crown-group of Americhelydia. Nevertheless, we find strong support for the presence of crown-group members of Chelonioidea in the Cretaceous, even ignoring protostegids. For example, Allopleuron hofmanni from the Maastrichtian of central Europe is found as a stem-group cheloniid. Irrespective of the affinities of protostegids (i.e. even if protostegids are not crown-group chelonioids), use of Allopleuron or even older taxa such as Ctenochelys or Peritresius (Gentry et al. 2018) as a calibration point for the crown-group of Chelonioidea is likely to affect molecular clock estimates for the crown-group age of chelonioids, and should be investigated. Although we do not provide a formal molecular clock analysis, we produced a time-calibrated 
version of our tree using a posteriori calibration methods in R (see Methods), which illustrates the extensions of chelonioid ranges implied by our phylogenetic results (see Fig. 12).

The hypothesis of protostegids being crown-group chelonioids complicates biogeographic scenarios for the evolution of Americhelydia (e.g. Joyce et al. 2013; Parham et al. 2014; Cadena \& Parham 2015). This is because the cosmopolitan distribution of the earliest protostegids, lacking any records from the Early Cretaceous of North America, is hard to reconcile with the occurrence of earliest chelydroid and stem-group chelonioid material exclusively in North America. Given the predominantly North American records of all their close relatives, our phylogenetic results nevertheless imply a North American origin of protostegids, and therefore suggest an early, and rapid global dispersal for the group. The inferred marine ecology for all protostegids, including earliest members of the group (Cadena \& Parham 2015) makes this hypothesis plausible. Furthermore, our hypothesised Late Cretaceous age for the chelonioid crown-group also invokes rapid, early dispersal to explain the distribution of stem-cheloniids in the Late Cretaceous: Maastrichtian, stem-group cheloniids have a near-global distribution, indicated by the presence of Allopleuron in Europe, and the widespread distribution of Euclastes spp. (Parham et al. 2014). In context of our phylogenetic hypothesis, it is also noteworthy that the 'advanced' protostegids Archelon and Protostega, which are known from the Santonian-Campanian of North America, are, contrary to earlier phylogenetic studies (e.g. Kear \& Lee 2006), not deeply nested within the Protostegidae according to our analysis. This topology implies that the last common ancestor of protostegids originated in North America, but so far remains unsampled. If protostegids indeed are crown-group chelonioids, as proposed here, both chelydroids and cheloniids have relatively long ghost lineages of minimally $40 \mathrm{Ma}$, 
ranging from the Campanian (the oldest occurrence of chelydroids) or the Maastrichtian (the oldest occurrence of cheloniids) back to the top of the Barremian (the oldest occurrence of protostegids; Cadena \& Parham 2015). The cheloniid ghost lineage is significantly shortened, if Ctenochelys is accepted as a stem-group cheloniid (Gentry 2016; Gentry et al. 2018). The alternative hypothesis, in which protostegids are not chelonioids (e.g. Joyce 2007; Danilov \& Parham 2008; Sterli 2010; Anquetin 2012) reduces the ghost-lineages for americhelydian crown-groups, but in doing so implies a long ghost-lineage for the americhelydian stem-group that spans through the entire Early Cretaceous and into the early Late Cretaceous. Ghost-lineages for various phylogenetic hypotheses are compared in Figure 12, and the biogeographic distributions of the earliest members of the different turtle clades considered in this study are indicated to compare biogeographic implications of these hypotheses. The (thus far unsampled) existence of Early Cretaceous americhelydians is not implausible because the sedimentary and fossil record of post-Tithonian to pre-Campanian tetrapods in North America is relatively poor, with only few tetrapod-bearing formations known, and few turtle species of any groups (Ronov et al. 1980; Benson et al. 2013; Joyce et al. 2013; Nicholson 2015). Therefore, the absence of chelydroid, non-protostegid chelonioid, and protostegid fossils in the late Early and early Late Cretaceous of North America could be a taphonomic or discovery artefact.

Finally, an Early Cretaceous age for crown-chelonioids, as implied by our phylogenetic hypothesis of protostegids, is not inconsistent with divergence time estimates for other groups of turtles, or with the oldest crown-group turtle occurrences. The oldest unambiguous total-group pleurodire is Caribemys oxfordiensis from the Oxfordian of Cuba (de la Fuente \& Iturralde-Vinent 2001; Joyce et al. 2013), and stemgroup pleurodires are also known from the Late Jurassic of North America, South 
America, and Europe (Platychelyidae; Lapparent de Broin et al. 2007; López-Conde \& Alvarado-Ortega 2017; Sullivan \& Joyce 2017), indicating that the cryptodire-pleurodire split occurred by the Late Jurassic. The origin of crown-group Cryptodira has been dated by using representatives of the oldest documented cryptodiran clade, Trionychia (e.g. Joyce et al. 2013). The stem-group trionychian Sinaspideretes wimani represents the oldest currently known material of Cryptodira, but the ambiguous locality information for specimens of this taxon make it difficult to use Sinaspideretes as a calibration point, as the possible age of the fossils range from the Middle Jurassic to the Early Cretaceous (Joyce et al. 2013; Tong et al. 2014). Therefore, Joyce et al. (2013) used stem-trionychid remains from the Barremian (e.g. Hirayama et al. 2013; Joyce et al. 2013) as a minimum age constraint for Cryptodira, and dated the origin of Cryptodira to the Early Jurassic, a result that was partially driven by their soft maximum constraint at the base of the Jurassic. The oldest crown-group trionychians are known from the Aptian and Albian (Tong et al. 2009; Joyce 2014; Li et al. 2015; Brinkman et al. 2017; Vitek et al. 2017). Within Trionychia, trionychids have a well-studied fossil record that indicates the group was widely distributed and diverse in the Early Cretaceous (e.g. Hirayama et al. 2013; Danilov et al. 2014; Vitek \& Joyce 2015; Joyce et al. 2016; Georgalis \& Joyce 2017). Similar patterns of diversification have been observed for Pleurodira: the oldest crowngroup pleurodire is Atolchelys lepida from the Barremian of Brazil (Romano et al. 2014). The pleurodire-cryptodire split and the origin of Trionychia represent early crowngroup turtle divergences. In contrast, chelonioids are deeply nested within Cryptodira. Therefore, although not inconsistent with the ages of major groups of crown-group turtles in general, our results imply longer ghost lineages for at least some of the more deeply-nested groups of Cryptodira than have previously been recognised. 
The Early Cretaceous diversification of at least some higher clades of the turtle crown-group (pleurodires, trionychids, and chelonioids, as suggested here) is consistent with large increases in subsampled richness estimates for regional turtles assemblages during the Early Cretaceous (Nicholson 2015). Our phylogenetic results suggest rapid diversification of crown-groups of turtle subclades during this interval. This hypothesis will continue to be tested by new fossil discoveries, and re-interpretation of existing specimens using methods like CT scanning.

\section{CONCLUSIONS}

Our new phylogenetic matrix represents an effort to combine previously observed variation across non-pleurodiran turtles with new observations informed by the study of high-resolution CT scans. The character data has been vetted to directly reflect primary hypotheses of homology. The new phylogenetic hypothesis presented here supports two origins of marine ecology in non-pleurodiran turtles outside of Odontochelys. One of these is a newly recognized group, Angolachelonia, which includes thalassochelydians from the Late Jurassic, and sandownids from the Cretaceous and Palaeogene. Angolachelonians lack features indicative of a pelagic lifestyle, which are only present in chelonioids, supporting a single origin of pelagic ecology in turtles. Our results indicate extensive survivorship of marine turtles during the CretaceousPalaeogene mass extinction in comparison to other marine tetrapods, because members of all marine clades that were present at the end of the Cretaceous (i.e. bothremydid pleurodires, angolachelonians, and chelonioids) survived into the Cenozoic. Furthermore, our analysis provides strong evidence for the position of protostegids within the crown-group of chelonioids. Alternative positions for protostegids cannot be 
robustly statistically rejected in all cases, but these alternative hypotheses lack any substantial support from our data, and even the exclusion of 'marine' characters or a reduced taxon sampling only including early and less specialised taxa support our proposed relationships for protostegids. Previously proposed alternative positions for protostegids can be explained by high levels of similarity (i.e. homoplasy) to several turtle clades that are positioned more stemwardly, and have been derived by using only a single early representative of the group, Santanachelys. The inclusion of protostegids, as well as some other taxa such as Allopleuron from the Maastrichtian, in the crowngroup of chelonioids implies an earlier diversification of the group than previously thought, and implies an Early Cretaceous age for the origin of the crown-group of Chelonioidea. Although this needs further exploration, these findings are consistent with the hypothesis of rapid evolution and diversification of subclades of the turtle crown in the Early Cretaceous.

Acknowledgements. This research was supported by a NERC studentship to SWE on the DTP Environmental Research (NE/L0021612/1) and further received support from the SYNTHESYS Project (http://www.synthesys.info/), which is financed by European Community Research Infrastructure Action under the FP7 "Capacities" Program (grant awarded to SWE). We are thankful to all the curators that granted access to specimens under their care, namely Carl Mehling and Mark Norell (AMNH); Oliver Rauhut (BSPG); Matt Riley (CAMSM); Jason Head (Cambridge University); William Simpson and Alan Resatar (FMNH); René Lyng Sylvestersen (FUR); Jérémy Anquetin (Jurassica); Alex Peaker (MIWG); Loïc Costeur (MNB); Sandra Chapman, Patrick Campbell and Paul Barrett (NHMUK); Hilary Ketchum (OUMNH); Alexander Kupfer and Rainer Schoch (SMNS); Jonah Choiniere and Bruce Rubridge (ESI at WITS), Anne Schulp (TM and 
Naturalis); Jessica Maisano, Matt Colbert and Chris Rowe (TMM). We further thank research and technical staff and PIs at the CT scanning facilities we used for this research, namely Yi Hongyu (AMNH, IVPP); Tom Davies and Ben Moon (University of Bristol), Farah Ahmed (NHMUK), Zhe-Xi Luo and April Isch Neander (University of Chicago). We thank Stephanie Wright for help with segmenting our specimen of Dermochelys. We are also grateful to colleagues who shared CT data and/or pictures of turtle material, specifically but in no particular order Paul Barrett, Marc Jones, Don Brinkman, Thorsten Scheyer, Ingmar Werneburg, Walter Joyce, Gabriel Ferreira, Stephan Lautenschlager, and Jérémy Anquetin. David Ford, Hermione Beckett, James Neenan, Erin Saupe, Gabriel Ferreira, Márton Rabi, James Parham, Donald Davesne, and Gemma Benevento are thanked for discussions. We are thankful for the constructive and helpful reviews of Juliana Sterli and James Parham, which improved a previous version of this work. TNT is made freely available through the Willi Henning Society.

\section{DATA ARCHIVING STATEMENT}

Data for this study (including CT volume files and mesh files for segmented models) are available in the MorphoSource Repositiory (Evers \& Benson 2018a): http://www.morphosource.org/Detail/ProjectDetail/Show/project_id/462. Additional data (files and instructions for Templeton's tests; files and R code for similarity analysis; appendices including the character-taxon matrix, the character list, and the character optimisation) are available in the Dryad Digital Repository (Evers \& Benson 2018b): http://datadryad.org/review?doi=doi:10.5061/dryad.2pb356h [please note that the data for this paper are not yet published and this temporary link should not be shared without the express permission of the author]. 


\section{SUPPORTING INFORMATION}

Additional Supporting Information can be found in the online version of this article:

Appendix S1. Character list, including discussion and figures of modified characters, extended discussion on carotid circulation characters, and deleted characters. Appendix S2. Character optimization for all nodes. Appendix S3. Figures of additional trees produced in the study (constraint analyses for Templeton's test, reduced dataset with marine characters deleted, and 'least specialised taxa analyses').

Appendix S4. Character-taxon matrix in TNT-readable text format.

\section{REFERENCES}

AHLBERG, P. E. and MILNER, A. R. 1994. The origin and early diversification of tetrapods. Nature, $\mathbf{3 6 8}, 507-514$.

- — - and JOHANSON, Z. 1998. Osteolepiforms and the ancestry of tetrapods. Nature, 395, 792-794.

———, CLACK, J. A. and LUKŠEVIČS, E. 1996. Rapid braincase evolution between Panderichthys and the earliest tetrapods. Nature, 381, 61-64.

ANQUETIN, J. 2010. The anatomy of the basal turtle Eileanchelys waldmani from the Middle Jurassic of the Isle of Skye, Scotland. Earth and Environmental Science Transactions of the Royal Society of Edinburgh, 101, 67-96.

_-_ 2012. Reassessment of the phylogenetic interrelationships of basal turtles 
(Testudinata). Journal of Systematic Palaeontology, 10, 3-45.

_- - and CHAPMAN, S. D. 2016. First report of Plesiochelys etalloni and Tropidemys

langii from the Late Jurassic of the UK and the palaeobiogeography of plesiochelyid turtles. Royal Society Open Science, 3, 150470.

_- - and JOYCE, W. G. 2014. A reassessment of the Late Jurassic turtle Eurysternum wagleri (Eucryptodira, Eurysternidae). Journal of Vertebrate Paleontology, 34, 1317-1328.

-—-, DESCHAMPS, S. and CLAUDE, J. 2014a. The rediscovery and redescription of the holotype of the Late Jurassic turtle Plesiochelys etalloni. PeerJ, 2, e258.

- - - PÜNTENER, C. and BILLON-BRUYAT, J.-P. 2014b. A taxonomic review of the Late Jurassic eucryptodiran turtles from the Jura Mountains (Switzerland and France). PeerJ, 2, e369.

——, PÜNTENER, C. and BILLON-BRUYAT, J.-P. 2015. Portlandemys gracilis n. sp., a New Coastal Marine Turtle from the Late Jurassic of Porrentruy (Switzerland) and a Reconsideration of Plesiochelyid Cranial Anatomy. PLOS ONE, 10, e0129193.

——, PÜNTENER, C. and JOYCE, W. G. 2017. A Review of the Fossil Record of Turtles of the Clade Thalassochelydia. Bulletin of the Peabody Museum of Natural History, 58, 317-369.

BAPST, D. W. 2012. paleotree: an R package for paleontological and phylogenetic analyses of evolution. Methods in Ecology and Evolution, 3 (5), 803-807.

BARDET, N. 1994. Extinction events among Mesozoic marine reptiles. Historical Biology, 7 (4), 313-324.

———, JALIL, N. E., DE LAPPARENT DE BROIN, F., GERMAIN, D., LAMBERT, O. and AMAGHZAZ, M. 2013. A giant chelonioid turtle from the Late Cretaceous of Morocco with a suction feeding apparatus unique among tetrapods. PLOS ONE, 8, 1-10. 
——, FALCONNET, J., FISCHER, V., HOUSSAYE, A., JOUVE, S., PEREDA SUBERBIOLA, X., PÉREZ-GARCÍA, A., RAGE, J.-C. and VINCENT, P. 2014. Mesozoic marine reptile palaeobiogeography in response to drifting plates. Gondwana Research, 26, 869887.

BELL, M. a. and LLOYD, G. T. 2014. strap: an R package for plotting phylogenies against stratigraphy and assessing their stratigraphic congruence. Palaeontology, 58 (2), 379-389.

BENSON, R. B. J. 2013. Marine Reptiles. In MACLEOD, N., ARCHIBALD, J. D. and LEVIN, P. S. (eds.) Grzimek's Animal Life Encyclopedia, Extinction, Gale Cengage Learning, Farminton Hills, Michigan, 267-279 pp.

- - - and DRUCKENMILLER, P. S. 2014. Faunal turnover of marine tetrapods during the Jurassic-Cretaceous transition. Biological Reviews, 89, 1-23.

———, MANNION, P. D., BUTLER, R. J., UPCHURCH, P., GOSWAMI, A. and EVANS, S. E. 2013. Cretaceous tetrapod fossil record sampling and faunal turnover: Implications for biogeography and the rise of modern clades. Palaeogeography, Palaeoclimatology, Palaeoecology, 372, 88-107.

BEVER, G. S. 2009. Postnatal ontogeny of the skull in the extant North American turtle Sternotherus odoratus (Cryptodira, Kinosternidae). Bulletin of the American Museum of Natural History, 330, 1-97.

BILLON-BRUYAT, J.-P., LÉCUYER, C., MARTINEAU, F. and MAZIN, J.-M. 2005. Oxygen isotope compositions of Late Jurassic vertebrate remains from lithographic limestones of western Europe: implications for the ecology of fish, turtles, and crocodilians. Palaeogeography, Palaeoclimatology, Palaeoecology, 216, 359-375. BONNATERRE, P.-J. 1789. Tableau Encyclopédique et Méthodique Des Trois Règnes De La Nature. Erpétologie. Paris. 
BRAZEAU, M. D. 2011. Problematic character coding methods in morphology and their effects. Biological Journal of the Linnean Society, 104, 489-498.

———, GUILLERME, T. and SMITH, M. R. 2017. Morphological phylogenetic analysis with inapplicable data. BioRxiv, published online 26 October, 2017. doi: https://doi.org/10.1101/209775

BRINKMAN, D. B. 2001. New material of Dracochelys (Eucryptodira: Sinemydidae) from the Junggar Basin, Xinjiang, People's Republic of China. Canadian Journal of Earth Sciences, 38, 1645-1651.

——— and PENG, J.-H. 1993. New material of Sinemys (Testudines, Sinemydidae) from the Early Cretaceous of China. Canadian Journal of Earth Sciences, 30, 2139-2152.

- - - and RODRIGUEZ-DE LA ROSA, R. 2006. Nonmarine turtles from the Cerro Delpueblo Formation (Campanian), Coahuila State, Mexico. Late Cretaceous Vertebrates from the Western Interior: Bulletin, 35, 229.

- - - and WU, X.-C. 1999. The skull of Ordosemys, an early Cretaceous turtle from Inner Mongolia, People’s Republic of China, and the interrelationships of Eucryptodira (Chelonia, Cryptodira). Paludicola, 2, 134-147.

——- HART, M., JAMNICZKY, H. and COLBERT, M. 2006. Nichollsemys baieri gen. et sp. nov., a primitive chelonioid turtle from the Late Campanian of North America. Paludicola, 5, 111-124.

———, AQUILLON-MARTINEZ, M. C., DE LEON DÁVILA, C. A., JAMNICZKY, H., EBERTH, D. A. and COLBERT, M. 2009. Euclastes coahuilaensis sp. nov., a basal cheloniid turtle from the late Campanian Cerro del Pueblo Formation of Coahuila State, Mexico. PaleoBios, 28, 76-88.

———, EBERTH, D. A., XU, X., CLARK, J. M. and WU, X.-C. 2013. Turtles from the Jurassic Shishugou Formation of the Junggar Basin, People’s Republic of China, with 
comments on the basicranial region of basal eucryptodires. In BRINKMAN, D. B., HOLROYD, P. A. and GARDNER, J. D. (eds.) Morphology and Evolution of Turtles, Springer, Dordrecht, 147-172 pp.

———, RABI, M. and ZHAO, L. 2017. Lower Cretaceous fossils from China shed light on the ancestral body plan of crown softshell turtles (Trionychidae, Cryptodira). Scientific Reports, 7, 6719.

CADENA, E. 2015. The first South American sandownid turtle from the Lower Cretaceous of Colombia. PeerJ, 3, e1431.

——— and PARHAM, J. F. 2015. Oldest known marine turtle? A new protostegid from the Lower Cretaceous of Colombia. PaleoBios, 32, 1-421.

CARROLL, R. L. 1996. Revealing the patterns of macroevolution. Nature, 381, 19-20.

CASE, E. C. 1897. On the osteology and relationships of protostega. Journal of Morphology, 14, 21-60.

CASIER, E. 1968. Le squelette cephalique de Eochelone brabantica L. Dollo, du Bruxellien (Lutetien inférieour) de Belgique, et sa comparaison avec celui Chelone mydas Linné. Bulletin de l'Institut Royal des Sciences Naturelles de Belgique, Sciences de la Terre, 44, 1-22.

CERDA, I. A., STERLI, J. and SCHEYER, T. M. 2016. Bone shell microstructure of Condorchelys antiqua Sterli, 2008, a stem turtle from the Jurassic of Patagonia. Comptes Rendus Palevol, 15, 128-141.

CLACK, J. A. 2009. The Fish-Tetrapod Transition: New Fossils and Interpretations. Evolution: Education and Outreach, 2, 213-223.

COLLINS, J. I. 1970. The chelonian Rhinochelys Seeley from the Upper Cretaceous of England and France. Palaeontology, 13, 355-378.

COPE, E. D. 1871a. A description of the genus Protostega, a Form of Extinct Testudinata. 
Proceedings of the American Philosophical Society, 12, 422-433.

- _ - 1871b. Letter to Professor Lesley giving an account of a journey in the valley of the Smoky Hill River in Kansas. Proceedings of the American Philosophical Society, $12,174-176$.

CRAWFORD, N. G., PARHAM, J. F., SELLAS, A. B., FAIRCLOTH, B. C., GLENN, T. C., PAPENFUSS, T. J., HENDERSON, J. B., HANSEN, M. H. and SIMISON, W. B. 2015. A phylogenomic analysis of turtles. Molecular Phylogenetics and Evolution, 83, 250257.

DANILOV, I. G. and PARHAM, J. F. 2006. A redescription of 'Plesiochelys' tatsuensis from the Late Jurassic of China, with comments on the antiquity of the crown clade Cryptodira. Journal of Vertebrate Paleontology, 26, 573-580.

- - - and PARHAM, J. F. 2008. A reassessment of some poorly known turtles from the Middle Jurassic of China, with comments on the antiquity of extant turtles. Journal of Vertebrate Paleontology, 28, 306-318.

——, AVERIANOV, A. O., SKUTCHAS, P. P. and REZVYI, A. S. 2006. Kirgizemys (Testudines, 'Macrobaenidae'): New material from the Lower Cretaceous of Buryatia (Russia) and taxonomic revision. In DANILOV, I. G. and PARHAM, J. F. (eds.) Fossil Turtle Research. Proceedings of the Symposium on Turtle Origins, Evolution and Systematics, St. Petersburg.

———, HIRAYAMA, R., SUKHANOV, V. B., SUZUKI, S., WATABE, M. and VITEK, N. S. 2014. Cretaceous soft-shelled turtles (Trionychidae) of Mongolia: new diversity, records and a revision. Journal of Systematic Palaeontology, 37-41.

ELDREDGE, N. and CRACRAFT, J. 1980. Phylogenetic patterns and the evolutionary process. Method and theory in comparative biology. Columbia University Press, New York, $329 \mathrm{pp}$. 
EVANS, J. and KEMP, T. S. 1975. The cranial morphology of a new Lower Cretaceous turtle from southern England. Palaeontology, 18, 25.

EVERS, S. W. and BENSON, R. B. J. 2018a. Project: Evers \& Benson 2018, Turtle CT data and 3D models. MorphoSource.

http://www.morphosource.org/Detail/ProjectDetail/Show/project_id/462 - and BENSON, R. B. J. 2018b. Data from: A new phylogenetic hypothesis of turtles with implications for the number of evolutionary transitions to marine lifestyles supports an Early Cretaceous origin and rapid diversification of Chelonioidea. Dryad Digital Repository. http://datadryad.org/review?doi=doi:10.5061/dryad.2pb356h

FELSENSTEIN, J. 1985. Confidence limits on phylogenies with a molecular clock. Systematic Biology, 34, 152-161.

FERNÁNDEZ, M. S. and DE LA FUENTE, M. S. 1988. Nueva tortuga (Cryptodira: Thalassemydidae) de la Formación Vaca Muerta (Jurásico, Tithoniano) de la provincia de Neuquén, Argentina. Ameghiniana, 25 (2), 129-138.

FERREIRA, G. S., RINCÓN, A. D., SOLÓRZANO, A. and LANGER, M. C. 2015. The last marine pelomedusoids (Testudines: Pleurodira): a new species of Bairdemys and the paleoecology of Stereogenyina. PeerJ, 3, e1063.

——, BRONZATI, M., LANGER, M. C., and STERLI, J. 2018. Phylogeny, biogeography and diversification patterns of side-necked turtles (Testudines: Pleurodira). Royal Society Open Science, 5, 171773, 1-17.

F00TE, M. 1994. Morphological disparity in Ordovician-Devonian crinoids and the early saturation of morphological space. Paleobiology, 20, 320-344.

GAFFNEY, E. S. 1972. The systematics of the North American family Baenidae (Reptilia, Cryptodira). Bulletin of the American Museum of Natural History, 147, 243-319 . 
- - 1975a. A taxonomic revision of the Jurassic turtles Portlandemys and

Plesiochelys. American Museum Novitates, 2574, 1-19.

1975b. Solnhofia parsonsi, a new cryptodiran turtle from the late Jurassic of

Europe. American Museum Novitates, 2576, 1-25.

—_- 1976. Cranial morphology of the European Jurassic turtles Portlandemys and

Plesiochelys. Bulletin of the American Museum of Natural History, 157, 487-544.

- - 1979. Comparative cranial morphology of recent and fossil turtles. Bulletin of the

American Museum of Natural History, 164, 65-376.

_-_ 1982a. Cranial morphology of the baenid turtles. American Museum Novitates,

2737, 1-22.

- - 1982b. The lower jaws of baenid turtles. American Museum Novitates, 2749, 1-

10.

- - 1983. The cranial morphology of the extinct horned turtle, Meiolania platyceps,

from the Pleistocene of Lord Howe Island, Australia. Bulletin of the American

Museum of Natural History, 175, 361-480.

_- - 1990. The comparative osteology of the Triassic turtle Proganochelys. Bulletin of the American Museum of Natural History, 194, 1-176.

——— and JENKINS JR, F. A. 2010. The cranial morphology of Kayentachelys , an Early

Jurassic cryptodire, and the early history of turtles. Acta Zoologica, 91, 335-368.

——— and KITCHING, J. W. 1995. The morphology and relationships of Australochelys,

an early Jurassic turtle from South Africa. American Museum Novitates, 3130, 1-29.

——— and MEYLAN, P. a. 1992. The Transylvanian turtle, Kallokibotion, a primitive

cryptodire of Cretaceous Age. American Museum Novitates, 3040, 1-37.

- - - and YE, X. 1992. Dracochelys: a new cryptodiran turtle from the early Cretaceous of China. American Museum Novitates, 3048, pages. 
———, TONG, H. and MEYLAN, P. a. 2006. Evolution of the side-necked turtles: the families Bothremydidae, Euraxemydidae, and Araripemydidae. Bulletin of the American Museum of Natural History, 300, 1-698.

——, RICH, T. H., VICKERS-RICH, P., CONSTANTINE, A., VACCA, R. and KOOL, L. 2007. Chubutemys, a new eucryptodiran turtle from the Early Cretaceous of Argentina, and the relationships of the Meiolaniidae. American Museum Novitates, 3599, 1-35.

——, MEYLAN, P. A., WOOD, R. C., SIMONS, E. and DE ALMEIDA CAMPOS, D. 2011. Evolution of the side-necked turtles: the family Podocnemididae. Bulletin of the American Museum of Natural History, 350, 1-237.

GAUTHIER, J. 1986. Saurischian monophyly and the origin of birds. Memoirs of the California Academy of Sciences, 8, 1-55.

GENTRY, A. D. 2016. New material of the Late Cretaceous marine turtle Ctenochelys acris Zangerl, 1953 and a phylogenetic reassessment of the 'toxochelyid'-grade taxa. Journal of Systematic Palaeontology, 15 (8), 675-696.

——, PARHAM, J. F., EHRET, D. J., and EVERSOLE J. A. 2018. A new species of Peritresius Leidy, 1856 (Testudines: Pan-Cheloniidae) from the Late Cretaceous (Campanian) of Alabama, USA, and the occurrence of the genus within the Mississippi Embayment of North America. PLoS ONE, 13 (4), e0195651.

GEORGALIS, G. L. and JOYCE, W. G. 2017. A review of the fossil record of old world turtles of the clade Pan-Trionychidae. Bulletin of the Peabody Museum of Natural History, 58, 115-208.

GIRIBET, G. 2007. Efficient tree searches with available algorithms. Evolutionary Bioinformatics, 3, 341-356.

GOLDMAN, N., ANDERSON, J. P., RODRIGO, A. G. and OLMSTEAD, R. 2000. Likelihoodbased tests of topologies in phylogenetics. Systematic Biology, 49, 652-670. 
GOLOBOFF, P. A. 1999. Analyzing large data sets in reasonable times: solutions for composite optima. Cladistics, 15, 415-428. - and CATALANO, S. A. 2016. TNT version 1.5, including a full implementation of phylogenetic morphometrics. Cladistics, 32, 221-238.

——, FARRIS, J. S. and NIXON, K. C. 2008. TNT, a free program for phylogenetic analysis. Cladistics, 24, 774-786.

GRAY, J. E. 1831. Synopsis reptilium: or short descriptions of the species of reptiles. PartI., Cataphracta. Tortoises, crocodiles, and enaliosaurians. G.B. Sowerby: London, 84 pp. HAVLIK, P. E., JOYCE, W. G. and BÖHME, M. 2014. Allaeochelys libyca , a new carettochelyine turtle from the Middle Miocene (Langhian) of Libya. Bulletin of the Peabody Museum of Natural History, 55, 201-214.

HAWKINS, J., HUGHES, C. and SCOTLAND, R. 1997. Primary homology assessment, characters and character states. Cladistics, 283, 275-283.

HAY, O. P. 1896. On the skeleton of Toxochelys latiremis. Field Columbian Museum Publications, Zoological Series, 1.

_-_. 1908. The fossil turtles of North America. Carnegie Institution of Washington. HIPP, A. L., HALL, J. C., SYTSMA, K. J. and LUTZONI, F. 2004. Congruence versus phylogenetic accuracy: revisiting the incongruence length difference test. Systematic Biology, 53, 81-89.

HIRAYAMA, R. 1994. Phylogenetic systematics of chelonioid sea turtles. Island Arc, 3, 270-284.

_- - 1997. Distribution and Diversity of Cretaceous Chelonioids. In Ancient Marine Reptiles, Elsevier, 225-241 pp.

—_- 1998. Oldest known sea turtle. Nature, 392, 705-708.

——-, ISAJI, S. and HIBINO, T. 2013. Kappachelys okurai gen. et sp. nov., a new stem 
soft-shelled turtle from the Early Cretaceous of Japan. 179-185. In BRINKMAN, D.

B., HOLROYD, P. A. and GARDNER, J. D. (eds.). Morphology and Evolution of Turtles. Springer, Dordrecht, 577 pp.

HOOKS, G. E. 1998. Systematic revision of the Protostegidae, with a redescription of Calcarichelys gemma Zangerl, 1953. Journal of Vertebrate Paleontology, 18, 85-98.

HURLEY, C. 2012. gclus: Clustering Graphics. R package version 1.3.1. https://cran.rproject.org/package=gclus

JANSSEN, R., VAN BAAL, R. R. and SCHULP, A. S. 2011. On the taphonomy of the late Maastrichtian (Late Cretaceous) marine turtle Allopleuron hofmanni. Geologie en Mijnbouw/Netherlands Journal of Geosciences, 90, 187-196.

JONES, M. E. H., WERNEBURG, I., CURTIS, N., PENROSE, R., O'HIGGINS, P., FAGAN, M. J. and EVANS, S. E. 2012. The head and neck anatomy of sea turtles (Cryptodira: Chelonioidea) and skull shape in testudines. PLOS ONE, 7, e47852.

JOYCE, W. G. 2000. The first complete skeleton of Solnhofia parsonsi (Cryptodira, Eurysternidae) from the Upper Jurassic of Germany and its taxonomic implications. Journal of Paleontology, 74, 684-700.

_- - 2007. Phylogenetic relationships of Mesozoic turtles. Bulletin of the Peabody Museum of Natural History, 48, 3-102.

- - 2014. A review of the fossil record of turtles of the clade Pan-Carettochelys. Bulletin of the Peabody Museum of Natural History, 55, 3-33.

—_ 2016. A review of the fossil record of turtles of the clade Pan-Chelydridae. Bulletin of the Peabody Museum of Natural History, 57, 21-56.

- - - 2017. A review of the fossil record of basal Mesozoic turtles. Bulletin of the Peabody Museum of Natural History, 58, 65-113.

- _- and BOURQUE, J. R. 2016. A review of the fossil record of turtles of the clade Pan- 
Kinosternoidea. Bulletin of the Peabody Museum of Natural History, 57, 57-95.

——— and GAUTHIER, J. A. 2004. Palaeoecology of Triassic stem turtles sheds new light on turtle origins. Proceedings of the Royal Society B, 271, 1-5.

——— PARHAM, J. F. and GAUTHIER, J. A. 2004. Developing a protocol for the conversion of rank-based taxon names to phylogenetically defined clade names, as exemplified by turtles. Journal of Paleontology, 78, 989-1013.

——, PARHAM, J. F., LYSON, T. R., WARNOCK, R. C. M. and DONOGHUE, P. C. J. 2013. A divergence dating analysis of turtles using fossil calibrations: an example of best practices. Journal of Paleontology, 87, 612-634.

——— LYSON, T. R. and WILLIAMS, S. 2016a. New cranial material of Gilmoremys lancensis (Testudines, Trionychidae) from the Hell Creek Formation of southeastern Montana, U.S.A. Journal of Vertebrate Paleontology, 36, e1225748.

——, RABI, M., CLARK, J. M. and XU, X. 2016b. A toothed turtle from the Late Jurassic of China and the global biogeographic history of turtles. BMC Evolutionary Biology, 16, 236.

KEAR, B. P. and LEE, M. S. Y. 2006. A primitive protostegid from Australia and early sea turtle evolution. Biology letters, 2, 116-119.

KNAUSS, G. E. 2014. A morphological description of Baptemys wyomingensis and an analysis of its phylogenetic relationship within Kinosternoidea. Unpublished M.Sc. thesis, University of Iowa, Iowa City, $181 \mathrm{pp}$.

———, JOYCE, W. G., LYSON, T. R. and PEARSON, D. 2011. A new kinosternoid from the Late Cretaceous Hell Creek Formation of North Dakota and Montana and the origin of the Dermatemys mawii lineage. Paläontologische Zeitschrift, 85, 125-142.

DE LA FUENTE, M. S. and FERNÁNDEZ, M. S. 2011. An unusual pattern of limb morphology in the Tithonian marine turtle Neusticemys neuquina from the Vaca 
Muerta Formation, Neuquén Basin, Argentina. Lethaia, 44, 15-25.

——— and ITURRALDE-VINENT, M. 2001. A new pleurodiran turtle from the Jagua Formation (Oxfordian) of western Cuba. Journal of Paleontology, 75, 860-869. DE LAPPARENT DE BROIN, F., DE LA FUENTE, M. S., and FERNANDEZ, M. S. 2007. Notoemys laticentralis (Chelonii, Pleurodira), Late Jurassic of Argentina: new examination of the anatomical structures and comparisons. Revue de Paléobiologie, 26 (1), 99-136.

LEE, M. S. Y. 2000. Tree robustness and clade significance. Systematic Biology, 49, 829836.

LEHMAN, T. M. and TOMLINSON, S. L. 2004. Terlinguachelys fischbecki, a new genus and species of sea turtle (Chelonioidea: Protostegidae) from the Upper Cretaceous of Texas. Journal of Paleontology, 78, 1163-1178.

LI, C., WU, X.-C., RIEPPEL, O., WANG, L.-T. and ZHAO, L.-J. 2008. An ancestral turtle from the Late Triassic of southwestern China. Nature, 456, 497-501.

LI, L., JOYCE, W. G. and LIU, J. 2015. The first soft-shelled turtle from the Jehol Biota of China. Journal of Vertebrate Paleontology, 35, e909450.

LINNAEUS, C. 1758. Systema Naturae. Stockholm: Laurentius Salvius.

LIPKA, T. R., THERRIEN, F., WEISHAMPEL, D. B., JAMNICZKY, H. a., JOYCE, W. G., COLBERT, M. W. and BRINKMAN, D. B. 2006. A new turtle from the Arundel Clay facies (Potomac Formation, Early Cretaceous) of Maryland, U.S.A. Journal of Vertebrate Paleontology, 26, 300-307.

LONG, J. A. and GORDON, M. S. 2004. The greatest step on vertebrate history: a paleobiological review of the fish-tetrapod transition. Physiological and Biochemical Zoology, 77, 700-719.

LÓPEZ-CONDE, O. A. and ALVARADO-ORTEGA, J. 2017. Revisión morfólogica de las 
trotugas del género Notoemys. Paleontología Mexicana, 6 (2), 79-89.

LYSON, T. R., BEVER, G. S., BHULLAR, B.-A. S., JOYCE, W. G. and GAUTHIER, J. A. 2010.

Transitional fossils and the origin of turtles. Biology letters, 6, 830-833.

——-, JOYCE, W. G. and SERTICH, J. J. W. 2017. A new chelydroid turtle, Lutemys warreni, gen. et sp. nov., from the Upper Cretaceous (Campanian) Kaiparowits Formation of southern Utah. Journal of Vertebrate Paleontology, 37 (6), e139067210.

MADDISON, W. P. 1993. Missing data versus missing characters in phylogenetic analysis. Systematic Biology, 42, 576-581.

MATEUS, O., JACOBS, L., POLCYN, M., SCHULP, A. S., VINEYARD, D., BUTA NETO, A. and TELLES ANTUNES, M. 2009. The oldest African eucryptodiran turtle from the Cretaceous of Angola. Acta Palaeontologica Polonica, 54, 581-588.

MULDER, E. W. A. 2003. Comparative osteology, palaeoecology and systematics of the Late Cretaceous turtle Allopleuron hofmanni (Gray 1831) from the Maastrichtian type area. Pubicaties van het Natuurhistorisch Genootschap in Limburg, 23-92.

VON MEYER, H. 1839. Eurysternum wagleri, Münster. Eine Schildkröte aus dem Kalkschiefer von Solnhofen. Beiträge zur Petrefacten-Kunde, 1, 75-82.

MATZKE, A. T. 2007. An almost complete juvenile specimen of the cheloniid turtle Ctenochelys stenoporus (Hay, 1905) from the Upper Cretaceous Niobrara Formation of Kansas, USA. Palaeontology, 50 (3), 669-691.

MEYLAN, P. A. 1996. Skeletal morphology and relationships of the early Cretaceous sidenecked turtle, Araripemys barretoi (Testudines: Pelomedusoides: Araripemydidae), from the Santana Formation of Brazil. Journal of Vertebrate Paleontology, 16, 20-33. - and GAFFNEY, E. S. 1989. The skeletal morphology of the Cretaceous cryptodiran turtle, Adocus, and the relationships of the Trionychoidea. American Museum 
Novitates, 2941, 1-60.

——, MOODY, R. T. J., WALKER, C. a and CHAPMAN, S. D. 2000. Sandownia harrisi, a highly derived trionychoid turtle (Testudines : Cryptodira) from the Early Cretaceous of the Isle of Wight, England. Journal of Vertebrate Paleontology, 20, $522-532$.

MLYNARSKI, M. 1976. Teil 6. Testudines. In KUHN, O (eds). Handbuch der Paläoherpetologie = Encyclopedia of paleoherpetology. Verlag Dr. Friedrich Pfeil, Stuttgart: 130pp.

MOODY, R. T. J. 1974. The taxonomy and morphology of Puppigerus camperi (Gray), an Eocene sea-turtle from Northern Europe. Bulletin of the British Museum (Natural History), Geology, 25, 153-186.

MOTANI, R. 2009. The evolution of marine reptiles. Evolution: Education and Outreach, 2, $224-235$.

NEAR, T. J., MEYLAN, P. A. and SHAFFER, H. B. 2005. Assessing concordance of fossil calibration points in molecular clock studies: an example using turtles. The American naturalist, 165, 137-46.

NICHOLLS, E. L. 1988. New material of Toxochelys latiremis Cope, and a revision of the genus Toxochelys (Testudines, Chelonioidea). Journal of Vertebrate Paleontology, 8, 181-187.

NICHOLSON, D. B., HOLROYD, P. A., BENSON, R. B. J. and BARRETT, P. M. 2015. Climatemediated diversification of turtles in the Cretaceous. Nature Communications, $\mathbf{6}$, 7848.

NIELSEN, E. 1959. Eocene turtles from Denmark. Dansk Geologisk Forening, 14, 96-114.

NIXON, K. C. 1999. The parsimony ratchet, a new method for rapid parsimony analysis. Cladistics, 15, 407-414. 
OSTROM, J. H. 1975. The origin of birds. Annual review of earth and Planetary Sciences, 3, $55-77$.

PARHAM, J. F. and HUTCHISON, J. H. 2003. A new eucryptodiran turtle from the Late Cretaceous of North America (Dinosaur Provincial Park, Alberta, Canada). Journal of Vertebrate Paleontology, 23, 783-798.

- - - and PYENSON, N. D. 2010. New sea turtle from the Miocene of Peru and the iterative evolution of feeding ecomorphologies since the Cretaceous. Journal of Paleontology, 84, 231-247.

-_- FELDMAN, C. and BOORE, J. 2006. The complete mitochondrial genome of the enigmatic bigheaded turtle (Platysternon): description of unusual genomic features and the reconciliation of phylogenetic hypotheses based on mitochondrial and nuclear DNA. BMC Evolutionary Biology, 6, 11.

——, DONOGHUE, P. C. J., BELL, C. J., CALWAY, T. D., HEAD, J. J., HOLROYD, P. A., INOUE, J. G., IRMIS, R. B., JOYCE, W. G., KSEPKA, D. T., PATANE, J. S. L., SMITH, N. D., TARVER, J. E., VAN TUINEN, M., YANG, Z., ANGIELCZYK, K. D., GREENWOOD, J. M., HIPSLEY, C. A., JACOBS, L., MAKOVICKY, P. J., MULLER, J., SMITH, K. T., THEODOR, J. M., WARNOCK, R. C. M. and BENTON, M. J. 2012. Best practices for justifying fossil calibrations. Systematic Biology, 61, 346-359.

———, OTERO, R. A. and SUÁREZ, M. E. 2014. A sea turtle skull from the Cretaceous of Chile with comments on the taxonomy and biogeography of Euclastes (formerly Osteopygis). Cretaceous Research, 49, 181-189.

PATTERSON, C. 1982. Morphological characters and homology. In JOYSEY, K. A. and FRIDAY, A. E. (eds.) Problems of Phylogenetic Reconstruction, Academic Press, London, 21-74 pp.

PEREIRA, A. G., STERLI, J., MOREIRA, F. R. R. and SCHRAGO, C. G. 2017. Multilocus 
phylogeny and statistical biogeography clarify the evolutionary history of major lineages of turtles. Molecular Phylogenetics and Evolution, 113, 59-66.

PÉREZ-GARCÍA, A. 2012. The European early Cretaceous cryptodiran turtle

Chitracephalus dumonii and the diversity of a poorly known lineage of turtles. Acta Palaeontologica Polonica, 57, 575-588.

_- - 2015. New data on the poorly-known Late Jurassic European turtles Thalassemys and Enaliochelys and description of a new basal eucryptodiran taxon. Journal of Iberian Geology, 41, 21-30.

———, FUENTE, M. S. de la and ORTEGA, F. 2012. A new freshwater basal eucryptodiran turtle from the Early Cretaceous of Spain. Acta Palaeontologica Polonica, 57, 285298.

PICTET, F.-J. and HUMBERT, A. 1857. Description d'une emyde nouvelle (Emys etalloni) du terrain jurassique supérieur des environs de Saint-Claude. Matériaux pour la Paléontologie Suisse, 1, 1-10.

PIMENTAL, R. A. and RIGGINS, R. 1987. The nature of cladistic data. Cladistics, 3, 201209.

PINNA DE, M. G. G. 1991. Concepts and tests of homology in the cladistic paradigm. Cladistics, 7, 367-394.

PLATNICK, N. I. 1979. Philosophy and the transformation of cladistics. Systematic Biology, 28, 537-546.

——, GRISWOLD, C. E. and CODDINGTON, J. A. 1991. On missing entries in cladistic analysis. Cladistics, 7, 337-343.

PLEIJEL, F. 1995. On character coding for phylogeny reconstruction. Cladistics, 11, 309315.

RABI, M., JOYCE, W. G. and WINGS, O. 2010. A review of the Mesozoic turtles of the 
Junggar Basin (Xinjiang, Northwest China) and the paleobiogeography of Jurassic to Early Cretaceous Asian testudinates. Palaeobiodiversity and Palaeoenvironments, 90, 259-273.

- - - TONG, H. and BOTFALVAI, G. 2012. A new species of the side-necked turtle Foxemys (Pelomedusoides: Bothremydidae) from the Late Cretaceous of Hungary and the historical biogeography of the Bothremydini. Geological Magazine, 149, 662-674.

——, ZHOU, C.-F., WINGS, O., GE, S. and JOYCE, W. G. 2013. A new xinjiangchelyid turtle from the Middle Jurassic of Xinjiang, China and the evolution of the basipterygoid process in Mesozoic turtles. BMC Evolutionary Biology, 13, 203. ———, SUKHANOV, V. B., EGOROVA, V. N., DANILOV, I. G. and JOYCE, W. G. 2014. Osteology, relationships, and ecology of Annemys (Testudines, Eucryptodira) from the Late Jurassic of Shar Teg, Mongolia, and phylogenetic definitions for Xinjiangchelyidae, Sinemydidae, and Macrobaenidae. Journal of Vertebrate Paleontology, 34, 327-352.

R CORE TEAM. 2016. R: A Language and Environment for Statistical Computing. REISZ, R. R. and HEAD, J. J. 2008. Palaeontology: Turtle origins out to sea. Nature, 456, $450-451$.

RIEPPEL, O. 1980. The skull of the Upper Jurassic cryptodire turtle Thalassemys, with a reconsideration of the chelonian braincase. Palaeontographica Abteilung A, 105140.

——— 1988. Fundamentals of comparative biology. Birkhauser Verlag.

ROBINSON, D. F. and FOULDS, L. R. 1981. Comparison of phylogenetic trees. Mathematical Biosciences, 53, 131-147.

ROMANO, P. S. R., GALLO, V., RAMOS, R. R. C. and ANTONIOLI, L. 2014. Atolchelys lepida, 
a new side-necked turtle from the Early Cretaceous of Brazil and the age of crown Pleurodira. Biology letters, 10, 20140290.

RONOV, A. B., KHAIN, V. E., BALUKHOVSKY, A. N. and SESLAVINSKY, K. B. 1980. Quantitative analysis of Phanerozoic sedimentation. Sedimentary Geology, 25, 311325.

RÜTIMEYER, L. 1973. Die fossilen Schildkröten von Solothurn und der übrigen Juraformation. Neue Denkschriften der allgemeinen Schweizerischen Gesellschaft für die gesamten Naturwissenschaften, 25, 1-185.

SÁNCHEZ-VILLAGRA, M. R., BURNHAM, R. J., CAMPBELL, D. C., FELDMANN, R. M., GAFFNEY, E. S., KAY, R. F., LOZSÁN, R., PURDY, R. and THEWISSEN, J. G. M. 2000. A new near-shore marine fauna and flora from the Early Neogene of northwestern Venezuela. Journal of Paleontology, 74, 957-968.

SATO, T., KONISHI, T., HIRAYAMA, R., and CALDWELL, M. W. 2012. A review of the Upper Cretaceous marine reptiles from Japan. Cretaceous Research, 37, 319-340.

SCHEYER, T. M. and SANDER, P. M. 2007. Shell bone histology indicates terrestrial palaeoecology of basal turtles. Proceedings. Biological sciences, 274, 1885-93.

——- DANILOV, I. G., SUKHANOV, V. B. and SYROMYATNIKOVA, E. V. 2014. The shell bone histology of fossil and extant marine turtles revisited. Biological Journal of the Linnean Society, 112, 701-718.

SHAFFER, H. B., MEYLAN, P., MCKNIGHT, M. L. and LARSON, A. 1997. Tests of turtle phylogeny: molecular, morphological, and paleontological approaches. Systematic Biology, 46, 235-268.

SMITH, A. B. 1994. Systematics and the fossil record: Documenting evolutionary patterns. Blackwell Scientific, Oxford, 223 pp.

SNEATH, P. H. A., SOKAL, R. R. and OTHERS. 1973. Numerical taxonomy. The principles 
and practice of numerical classification. W. H. Friedman and Company, San Francisco, 573 pp.

STERLI, J. 2008. A new, nearly complete stem turtle from the Jurassic of South America with implications for turtle evolution. Biology Letters, 4, 286-289.

- - 2010. Phylogenetic relationships among extinct and extant turtles: The position of pleurodira and the effects of the fossils on rooting crown-group turtles. Contributions to Zoology, 79, 93-106.

——— and DE LA FUENTE, M. S. 2011. A new turtle from the La Colonia Formation (Campanian-Maastrichtian), Patagonia, Argentina, with remarks on the evolution of the vertebral column in turtles. Palaeontology, 54, 63-78.

- — - and DE LA FUENTE, M. S. 2013. New evidence from the Palaeocene of Patagonia (Argentina) on the evolution and palaeo-biogeography of Meiolaniformes (Testudinata, new taxon name). Journal of Systematic Palaeontology, 11, 835-852. - — - and JOYCE, W. G. 2007. The cranial anatomy of the Early Jurassic turtle Kayentachelys aprix. Acta Palaeontologica Polonica, 52, 675-694.

———, POL, D. and LAURIN, M. 2013. Incorporating phylogenetic uncertainty on phylogeny-based palaeontological dating and the timing of turtle diversification. Cladistics, 29, 233-246.

——, DE LA FUENTE, M. S. and UMAZANO, A. M. 2015. New remains and new insights on the Gondwanan meiolaniform turtle Chubutemys copelloi from the Lower Cretaceous of Patagonia, Argentina. Gondwana Research, 27, 978-994.

STRONG, E. E. and LIPSCOMB, D. 1999. Character coding and inapplicable data. Cladistics, 15, 363-371.

SUKHANOV, V. B. 2000. Mesozoic turtles of middle and central Asia. The age of dinosaurs in Russia and Mongolia, 17, 309-367. 
SULLIVAN, P. M. and JOYCE W. G. 2017. The shell and pelvic anatomy of the Late Jurassic turtle Platychelys oberndorferi based on material from Solothurn, Switzerland. Swiss Journal of Palaeontology, 136 (2), 323-343.

SWOFFORD, D. L. 2002. PAUP*. Phylogenetic Analysis Using Parsimony (*and other methods). Version. 4.0. Sinauer Associates, Sunderland, MA.

TEMPLETON, A. R. 1983. Phylogenetic inference from restriction endonuclease cleavage site maps with particular reference to the evolution of humans and the apes. Evolution, 37 (2), 221-244.

TONG, H. and MEYLAN, P. 2013. Morphology and Relationships of Brachyopsemys tingitana gen. et sp. nov. from the Early Paleocene of Morocco and Recognition of the New Eucryptodiran Turtle Family: Sandownidae. 187-212. In BRINKMAN, D. B., HOLROYD, P. A. and GARDNER, J. D. (eds.). Morphology and Evolution of Turtles. Springer, Dordrecht, 577 pp.

——, CLAUDE, J., SUTEETHORN, V., NAKSRI, W. and BUFFETAUT, E. 2009. Turtle assemblages of the Khorat Group (Late Jurassic-Early Cretaceous) of NE Thailand and their palaeobiogeographical significance. Geological Society, London, Special Publications, 315, 141-152.

VINEYARD, D. 2009. A new eucryptodiran turtle from the Lower Cretaceous Glen Rose Formation of Texas. Unpublished M.Sc. thesis, Southern Methodist University, Dallas, 123pp.

VITEK, N. S. and JOYCE, W. G. 2015. A review of the fossil record of new world turtles of the clade Pan-Trionychidae. Bulletin of the Peabody Museum of Natural History, 56, $185-244$.

-, DANILOV, I. G., NAKAJIMA, Y. and HIRAYAMA, R. 2018. Redescription of the skull of 'Trionyx' kyrgyzensis and improved phylogenetic taxon sampling of Cretaceous 
and Palaeogene soft-shelled turtles (Trionychidae) of Asia, including the oldest crown trionychids. Journal of Systematic Palaeontology, 16, 199-211.

WAGNER, P. J. 1997. Patterns of morphologic diversification among the Rostroconchia. Paleobiology, 23, 115-150.

WEEMS, R. E. and BROWN, K. M. 2017. More-complete remains of Procolpochelys charlestonensis (Oligocene, South Carolina), an occurrence of Euclastes (upper Eocene, South Carolina), and their bearing on Cenozoic pancheloniid sea turtle distribution and phylogeny. Journal of Paleontology, 91, 1228-1243.

WHETSTONE, K. N. 1978. A new genus of cryptodiran turtles (Testudinoidea, Chelydridae) from the Upper Cretaceous Hell Creek Formation of Montana. The University of Kansas Sciene Bulletin, v. 51, 539-563.

WIELAND, G. R. 1896. Archelon ischyros: A new gigantic Cryptodire Testudinate from the Fort Pierre Cretaceous of South Dakota. American Journal of Science (1880-1910), 2, 399.

- 1900. The skull, pelvis, and probable relationships of the huge turtles of the genus Archelon. American Journal of Science, 9 (52), 1-237.

- _ - 1902. Notes on the Cretaceous turtles, Toxochelys and Archelon, with a classification of the marine Testudinata. The American Journal of Science, 14, 95108.

——_. 1906. The osteology of Protostega. Memoirs of the Carnegie Museum, II, 279-305. WILKINSON, M. 1992. Ordered versus unordered characters. Cladistics, 8, 375-385. - - 1995. A comparison of two methods of character construction. Cladistics, 11, 297-308.

WINKLER, J. D. and SANCHEZ-VILLAGRA, M. R. 2006. A nesting site and egg morphology of a Miocene turtle from Urumaco, Venezuela: evidence of marine adaptations in 
Pelomedusoides. Palaeontology, 49, 641-646.

WOOD, R. C., JOHNSON-GOVE, J., GAFFNEY, E. S. and MALEY, K. F. 1996. Evolution and phylogeny of the leatherback turtles (Dermochelyidae), with descriptions of new fossil taxa. Chelonian Conservation and Biology, 2, 266-286.

ZANGERL, R. 1953. The vertebrate fauna of the Selma Formation of Alabama. Part IV. The turtles of the family Toxochelyidae. Fieldiana. Geology Memoirs, 3, 1-176.

—_- 1960. The vertebrate fauna of the Selma Formation of Alabama. Part V. An advance cheloniid sea turtle. Fieldiana. Geology Memoirs, 3 (5), 281-312.

- - 1980. Patterns of phylogenetic differentiation in the toxochelyid and cheloniid sea turtles. Integrative and Comparative Biology, 20, 585-596.

ZHOU, C.-F. and RABI, M. 2015. A sinemydid turtle from the Jehol Biota provides insights into the basal divergence of crown turtles. Scientific Reports, 5, 16299.

_-_, and RABI, M.and JOYCE, W. G. 2014. A new specimen of Manchurochelys manchoukuoensis from the Early Cretaceous Jehol Biota of Chifeng, Inner Mongolia, China and the phylogeny of Cretaceous basal eucryptodiran turtles. $B M C$ Evolutionary Biology, 14, 77.

\section{FIGURE CAPTIONS}

FIG. 1. Simplified phylogenetic hypotheses of selected previous studies highlighting different phylogenetic positions that have been proposed for marine, non-pleurodiran turtles. A, Joyce (2007); B, Danilov \& Parham (2008); C, Sterli (2010); D, Anquetin (2012); E, Tong \& Meylan (2013); F, Sterli \& De la Fuente (2013); G, Anquetin et al. (2015); H, Cadena \& Parham (2015) and Cadena (2015); I, Zhou \& Rabi (2015). Note that the colours denote proposed clades, following Anquetin et al. (2017) for 
Thalassochelydia, Tong \& Meylan (2013) for Sandownidae; Cadena \& Parham (2015) for Protostegidae; Rabi et al. (2014) for Sinemydidae/Macrobaenidae. Note that 'Chelonioidea' is used to denote the crown-group herein.

FIG. 2. Heatmap of symmetric pairwise-taxon similarity matrix using our full character dataset $(n=345)$. The phylogenetic tree to the left is identical to our strict consensus tree using unordered character data. Dotted lines delimit turtle subclades for readability. Abbreviations: $\mathrm{AC}$, Angolachelonia; BS, basal stem-group turtles; $\mathrm{CH}$, Cheloniidae; CY, Chelydroidea; D, Dermochelyidae; M, Meiolaniformes; PC, Paracryptodira; PL, Pleurodira; PR, Protostegidae; SM; Sinemydidae/Macrobaenidae; T, Toxochelys sp.; TE, Testudinoidea; TR, Trionychia, XI, Xinjiangchelyidae.

FIG. 3. Heatmaps of symmetric pairwise-taxon similarity matrices of subsets of our characters data. A, Cranial character data $(n=185)$; B, Shell character data $(n=87) ; C$, Axial and girdle character data $(n=50)$; , Limb character data $(n=23)$. Note that NA values result from comparisons of taxa with non-overlapping character preservation. Abbreviations: AC, Angolachelonia; BS, basal stem-group turtles; $\mathrm{CH}$, Cheloniidae; CY, Chelydroidea; D, Dermochelyidae; M, Meiolaniformes; PC, Paracryptodira; PL, Pleurodira; PR, Protostegidae; SM; Sinemydidae/Macrobaenidae; T, Toxochelys sp.; TE, Testudinoidea; TR, Trionychia, XI, Xinjiangchelyidae.

FIG. 4. Strict consensus trees of our phylogenetic analysis. A, Strict consensus tree of 12 MPTs from analysing our data treating the characters as unordered. B, strict consensus tree of 195 MPTs treating characters as ordered. Numbers above nodes are Bremer values. 
FIG. 5. Cranial synapomorphies of Angolachelonia illustrated by renderings of 3D models generated using CT data. A, cranium of Solnhofia parsoni (TM 4023) in dorsal view showing the extend of the dermal skull roof in the temporal region, obliterating the foramen stapedio-temporale in dorsal view (ch. 18.0); B, cranium of Sandownia harrisi (MIWG 3480) in dorsal view, showing the same features as in A; C, cranium of Solnhofia parsoni (TM 4023) in ventral view, showing the posterior direction of the articular process (ch. 84.1), the long interpterygoid contact (ch. 94.0), and the contact of the pterygoid with the mandibular articular surface of the quadrate (ch 103.1); D, cranium of Plesiochelys planiceps (OUMNH J1582) in ventral view, showing the same features as in C; E cranium of Solnhofia parsoni (TM 4023) in posteroventral view, showing the infolding ridge of the quadrate (ch. 83.1); F, cranium of Brachyopsemys tingitana (AMNH FARB 30612) in posteroventral view, showing the same features as in E. Scale bars in A, B, C, E are $10 \mathrm{~mm}$; scale bars in D, F are $20 \mathrm{~mm}$. Abbreviations: apc, articular process of cranium; fst, foramen stapedio-temporale; iqr, infolding ridge of quadrate; pt, pterygoid; q, quadrate.

FIG. 6. Mandibular synapomorphies of Angolachelonia illustrated by renderings of 3D models generated using CT data. A, right mandibular ramus of Solnhofia parsoni (TM 4023) in lateral view, showing the coronoid notch (ch. 181.1), and the tall and pointed coronoid process (ch. 184.1); B, right mandibular ramus of Solnhofia parsoni (TM 4023) in medial view, showing the foramen in the coronoid (ch. 182.1); C, right mandibular ramus of Sandownia harrisi (MIWG 3480) in lateral view, showing the same features as in A; D, right mandibular ramus of Sandownia harrisi (MIWG 3480) in medial view, showing the same features as in B. Note that the coronoid has been shaded in all images. 
Scale bars are $10 \mathrm{~mm}$. Abbreviations: cor $\mathrm{f}$, foramen in coronoid; cor $\mathrm{n}$, coronoid notch; cor $\mathrm{p}$, coronoid process.

FIG. 7. Cranial and mandibular synapomorphies of Thalassochelydia illustrated by renderings of 3D models generated using CT data. A, posterior part of the cranium of Plesiochelys planicpes (OUMNH J1582) in anterior view, showing the recess on the anterior surface of the quadrate lateral to the processus trochlearis oticum (ch. 81.1); B, cranium of Plesiochelys planicpes (OUMNH J1582) in posterior view, showing the presence of a fossa on the supraoccipital-opisthotic-exoccipital contact area (ch 113.1); C, parabasisphenoid of Plesiochelys planicpes (OUMNH J1582) in anterior view, showing the closely-spaced foramina anterius canalis caroticus cerebralis (ch 142.1); D, right mandibular ramus of Solnhofia parsoni (TM 4023) in medial view, showing the presence of a splenial (ch 185.0). Note that dotted line in B surround fossa. Scale bars in A-B, D are $10 \mathrm{~mm}$, scale bar in B is $5 \mathrm{~mm}$. Abbreviations: aqr, anterior quadrate recess; ex, exoccipital; op, opisthotic; faccc, foramen anterius canalis caroticus internus; pto, processus trochlearis oticum; q, quadrate; soc, supraoccipital; sp, splenial.

FIG. 8. Cranial synapomorphies of Sandownidae illustrated by renderings of 3D models generated using CT data. A, cranium of Sandownia harrisi (MIWG 3480) in left lateral view, showing the extend of the lower temporal emargination which is exclusively formed by the jugal and quadratojugal (ch 34.0); B, cranium of Sandownia harrisi (MIWG 3480 ) in ventral view, showing the vomer-palatine contact anterior to the internal naris (ch. 57.1), the contribution of the vomer to the triturating surface (ch. 68.1), and the posterior process of the pterygoid covering parts of the parabasisphenoid and basioccipital (ch. 108.1). Dotted line in A denotes the ventral margin of the lower 
temporal emargination, and the dotted line in B denotes the position of the internal naris. Scale bars are $10 \mathrm{~mm}$. Abbreviations: boc, basioccipital; j, jugal; pal; palatine; pbsp, parabasisphenoid; pt, pterygoid; q, quadrate; qj, quadratojugal.

FIG. 9. Cranial synapomorphies of Dermochelyoidea illustrated by renderings of 3D models generated using CT data. A, cranium of Dermochelys coriacea (UMZC R3031) in ventral view, showing absence of medial process of jugal (ch. 27.0); B, cranium of Rhinochelys pulchriceps (CAMSM B55783) in ventral view, showing the same features as in A; C, cranium of Dermochelys coriacea (UMZC R3031) in dorsal view with the left postorbital removed, showing the opisthotic contribution to the foramen stepediotemporale (ch. 161.1); D, cranium of Bouliachelys suteri (QMF 31669) in dorsal view, showing the same features as in C. Scale bars in A, C, and D are $20 \mathrm{~mm}$; scale bar in B is 1 mm. Abbreviations: fst, foramen stepedio-temporale; j, jugal; op, opisthotic; pal, palatine.

FIG. 10. Cranial synapomorphies of Protostegidae illustrated by renderings of 3D models generated using CT data. A, cranium of Rhinochelys pulchriceps (CAMSM B55783) in ventral view, showing the interpalatine contact (ch. 62.1); B, cranium of Rhinochelys pulchriceps (CAMSM B55783) in anterodorsal view, showing the lack of a medial contact between the prefrontals (ch. 4.0); C, posterior part of cranium of Rhinochelys pulchriceps (CAMSM B55783) in ventral view, showing the contact of the pterygoid with the mandibular articular surface of the quadrate (ch 103.1). Scale bars are 1 mm. Abbreviations: pal, palatine; prf, prefrontal; pt, pterygoid; q, quadrate.

FIG. 11. Competing MPT topologies of our ordered analysis resulting in a large polytomy. A, topology supported by a subset of MPTs that is identical with results from 
the unordered analysis; B, topology supported by a subset of MPTs in which angolachelonians and macrobaenids are stem-group chelonioids; C, topology supported by a subset of MPTs in which angolachelonians, but not macrobaenids are stem-group chelonioids. Note that Ordosemys has been pruned from the MPTs, and that protostegids are included in Chelonioidea.

FIG. 12. Simplified phylogenetic tree scaled to geologic time using range data for turtles.

FIG. 13. Implications of alternative positions of Protostegidae for americhelydian ghostlineages and biogeography illustrated by simplified calibrated trees. A, preferred hypothesis of this study, supported by unordered phylogenetic analysis; B, hypothesis placing Angolachelonia on the stem-group of chelonioids, supported by a subset of MPTs in the ordered analysis; $\mathrm{C}$, hypothesis of protostegids being stem-group chelonioids, supported by a subset of our 'least specialised taxa analyses'; D, hypothesis following Joyce (2007) and other authors in placing protostegids in close relation to thalassochelydians and sandownids, and having an extended cryptodiran stem-lineage that further includes sinemydids/macrobaenids and xinjiangchelyids. Ghost lineages for americhelydian lineages are indicated by dashed arrows. Coloured squares indicate the distribution of earliest fossils according to continents.

\section{TABLES}

TABLE 1. Sources for scorings in our character-taxon matrix. Note that postcranial scorings were taken from Cadena \& Parham (2015). 
TABLE 2. Stratigraphic ranges for taxa used for our time-calibrated tree.

TABLE 3. Synapomorphies for taxa discussed in the main text. Numbers in 'unambiguous synapomorphies' are character numbers as given in Appendix S1.

TABLE 4. Constraints and hypotheses for Templeton's test and test results. P-values are resulting from a one-tailed test.

TABLE 5. 'Marine' synapomorphies. Synapomorphies listed represent character states that have been linked to a marine ecology. 
A

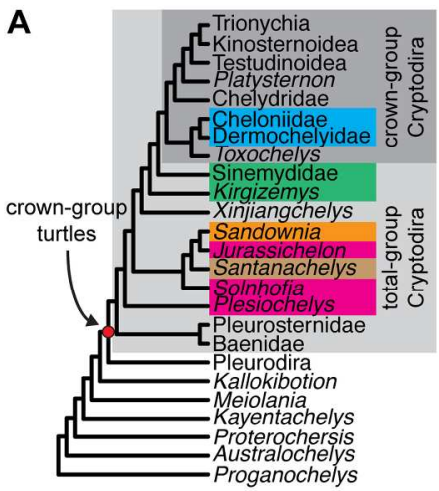

D

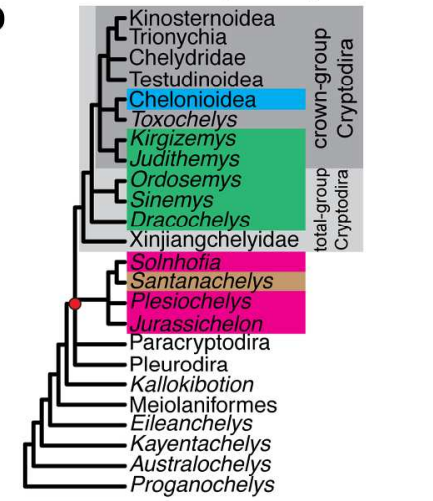

G

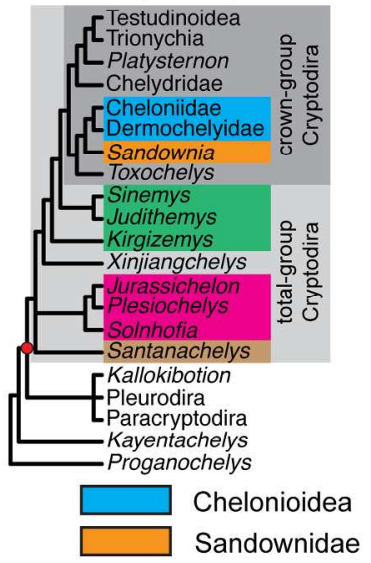

B

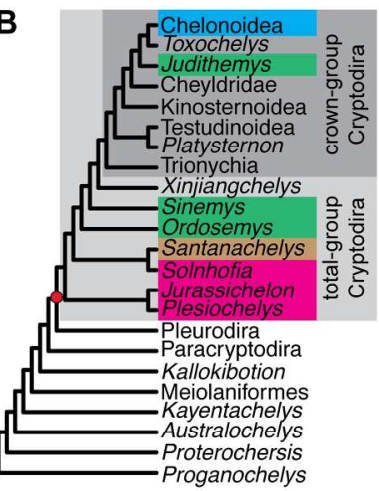

E

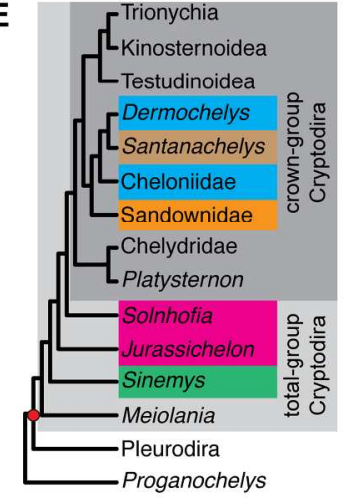

H

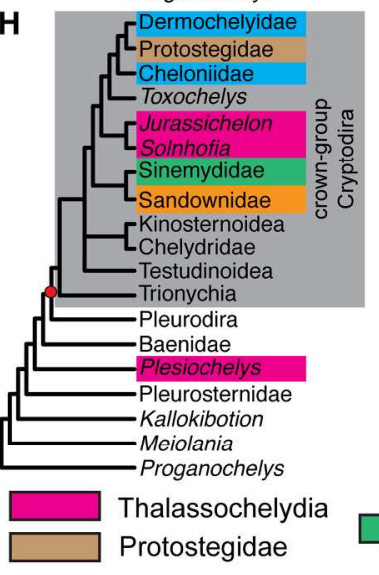

C

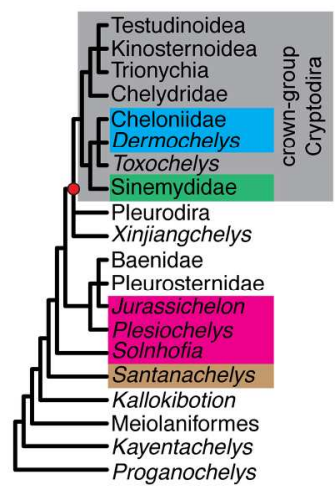

F

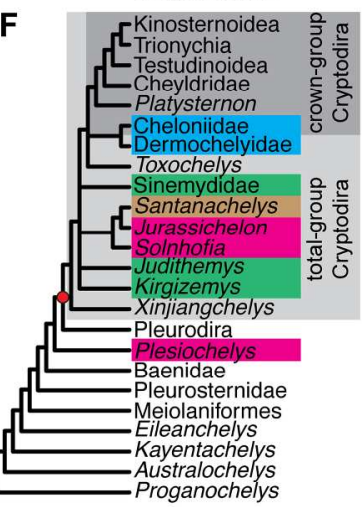

I

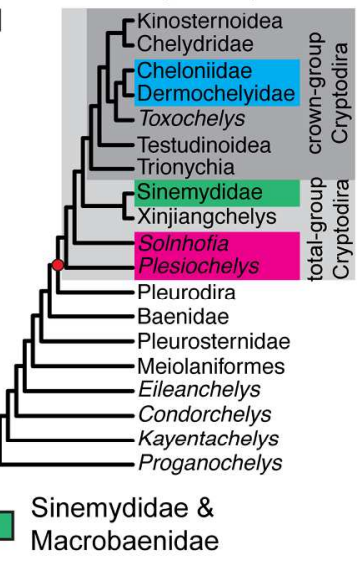

FIG. 1. Simplified phylogenetic hypotheses of selected previous studies highlighting different phylogenetic positions that have been proposed for marine, non-pleurodiran turtles. A, Joyce (2007); B, Danilov \& Parham (2008); C, Sterli (2010); D, Anquetin (2012); E, Tong \& Meylan (2013); F, Sterli \& De la Fuente (2013); G, Anquetin et al. (2015); H, Cadena \& Parham (2015) and Cadena (2015); I, Zhou \& Rabi (2015). Note that the colours denote proposed clades, following Anquetin et al. (2017) for Thalassochelydia, Tong \& Meylan (2013) for Sandownidae; Cadena \& Parham (2015) for Protostegidae; Rabi et al. (2014) for Sinemydidae/Macrobaenidae. Note that 'Chelonioidea' is used to denote the crown-group herein.

$201 \times 249 \mathrm{~mm}(300 \times 300 \mathrm{DPI})$ 
FIG. 2. Heatmap of symmetric pairwise-taxon similarity matrix using our full character dataset $(n=345)$. The phylogenetic tree to the left is identical to our strict consensus tree using unordered character data. Dotted lines delimit turtle subclades for readability. Abbreviations: AC, Angolachelonia; BS, basal stemgroup turtles; $\mathrm{CH}$, Cheloniidae; CY, Chelydroidea; D, Dermochelyidae; M, Meiolaniformes; PC,

Paracryptodira; PL, Pleurodira; PR, Protostegidae; SM; Sinemydidae/Macrobaenidae; T, Toxochelys sp.; TE, Testudinoidea; TR, Trionychia, XI, Xinjiangchelyidae.

$$
120 \times 83 \mathrm{~mm}(300 \times 300 \text { DPI })
$$


A

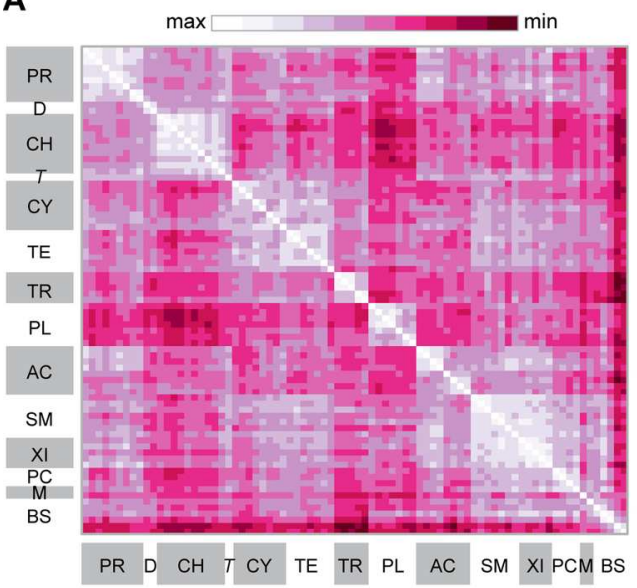

C

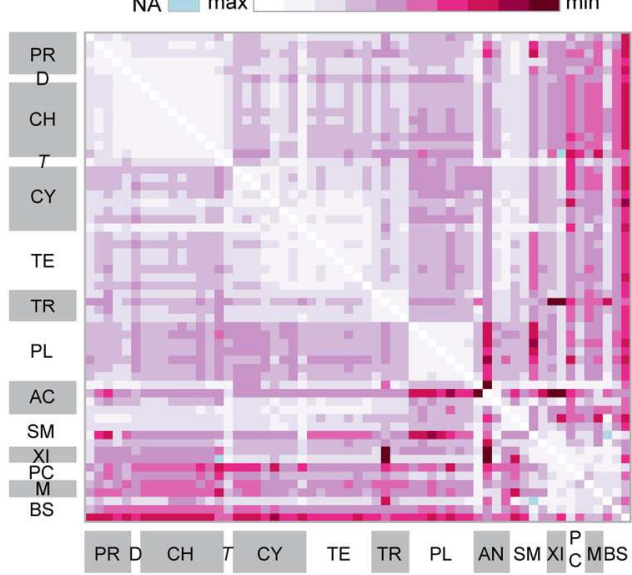

B

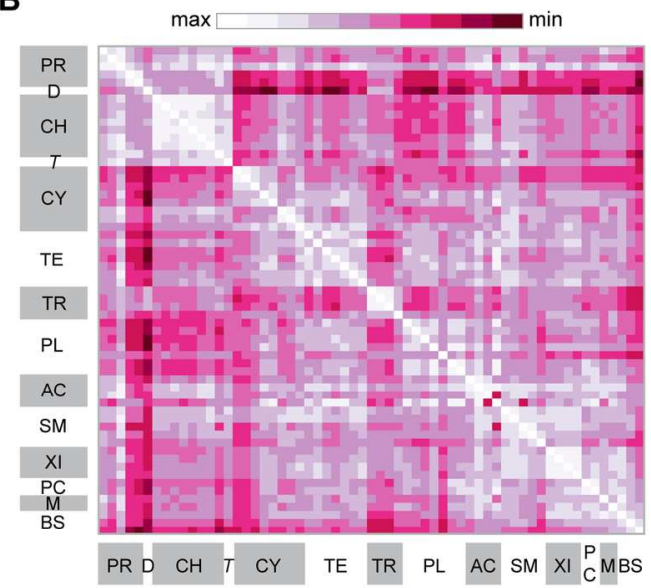

D

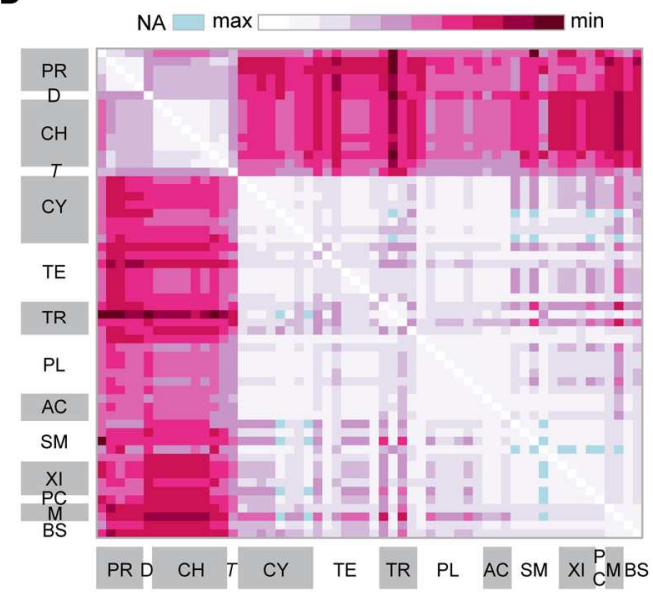

FIG. 3. Heatmaps of symmetric pairwise-taxon similarity matrices of subsets of our characters data. A, Cranial character data $(n=185)$; B, Shell character data $(n=87)$; C, Axial and girdle character data $(n=$ 50); $D$, Limb character data $(n=23)$. Note that NA values result from comparisons of taxa with nonoverlapping character preservation. Abbreviations: AC, Angolachelonia; BS, basal stem-group turtles; $\mathrm{CH}$, Cheloniidae; CY, Chelydroidea; D, Dermochelyidae; M, Meiolaniformes; PC, Paracryptodira; PL, Pleurodira; PR, Protostegidae; SM; Sinemydidae/Macrobaenidae; T, Toxochelys sp.; TE, Testudinoidea; TR, Trionychia, XI, Xinjiangchelyidae.

$162 \times 153 \mathrm{~mm}(300 \times 300 \mathrm{DPI})$ 
A

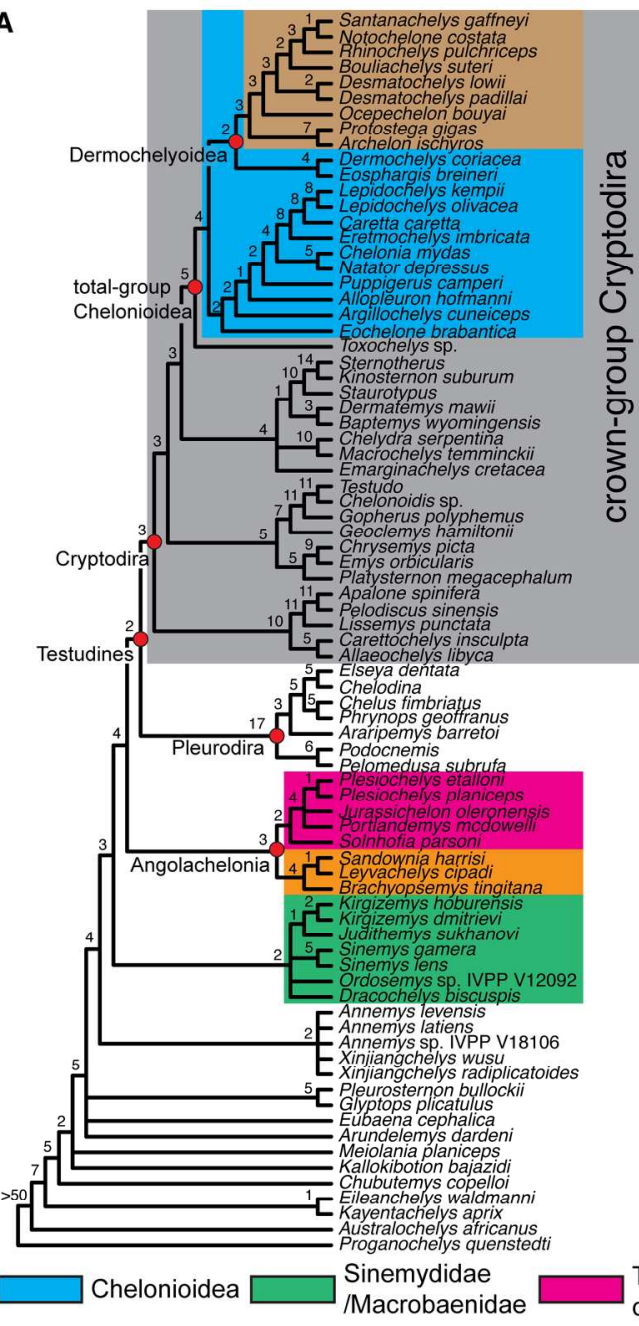

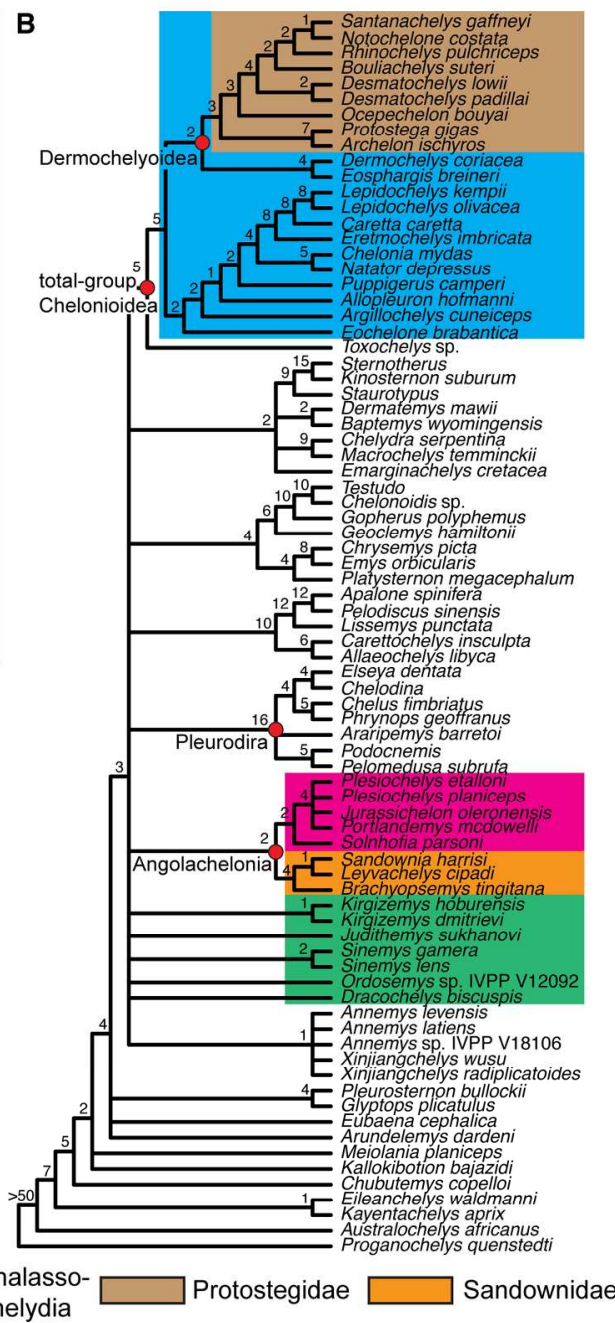

FIG. 4. Strict consensus trees of our phylogenetic analysis. A, Strict consensus tree of 12 MPTs from analysing our data treating the characters as unordered. B, strict consensus tree of 195 MPTs treating characters as ordered. Numbers above nodes are Bremer values.

$184 \times 188 \mathrm{~mm}(300 \times 300 \mathrm{DPI})$ 

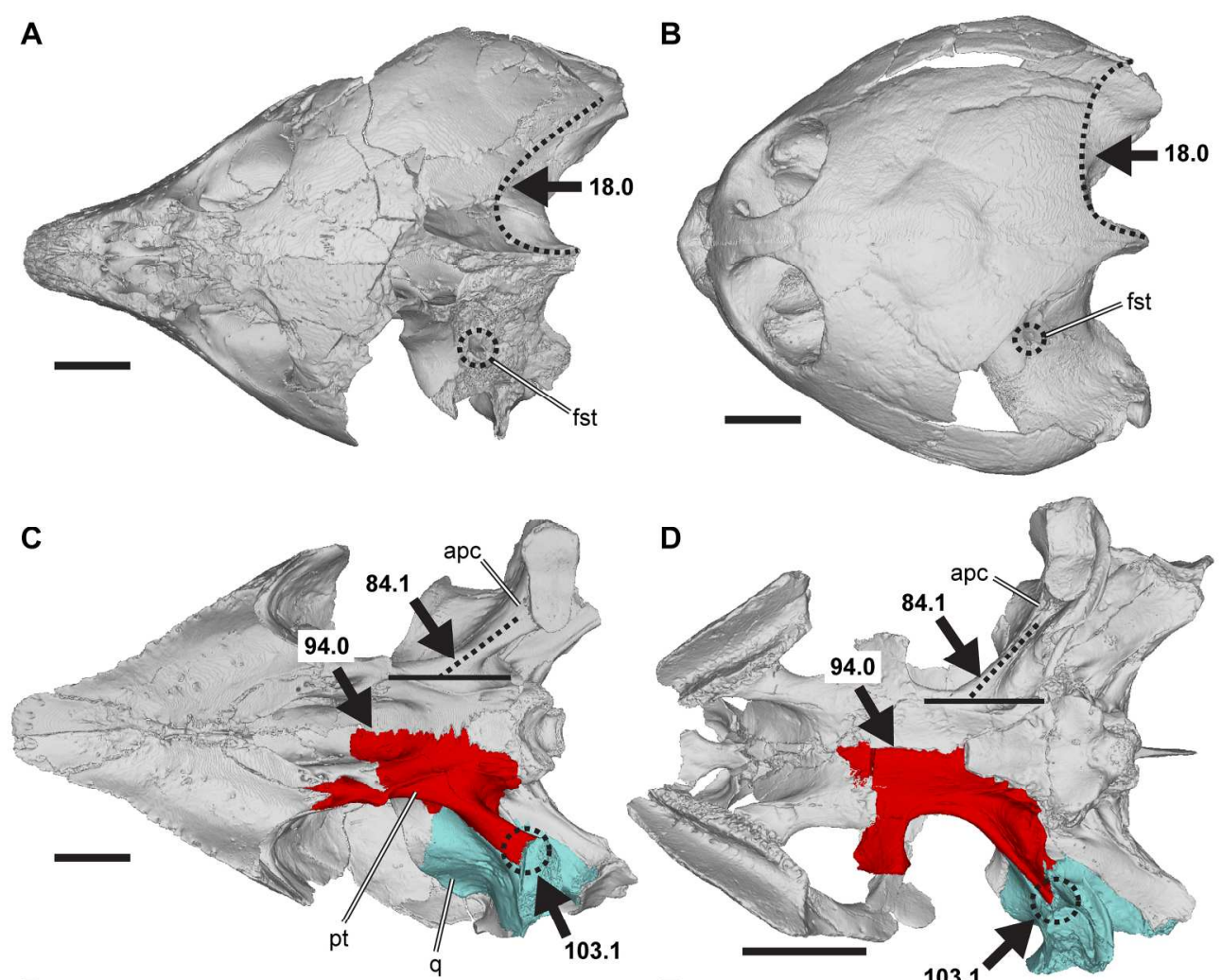

E
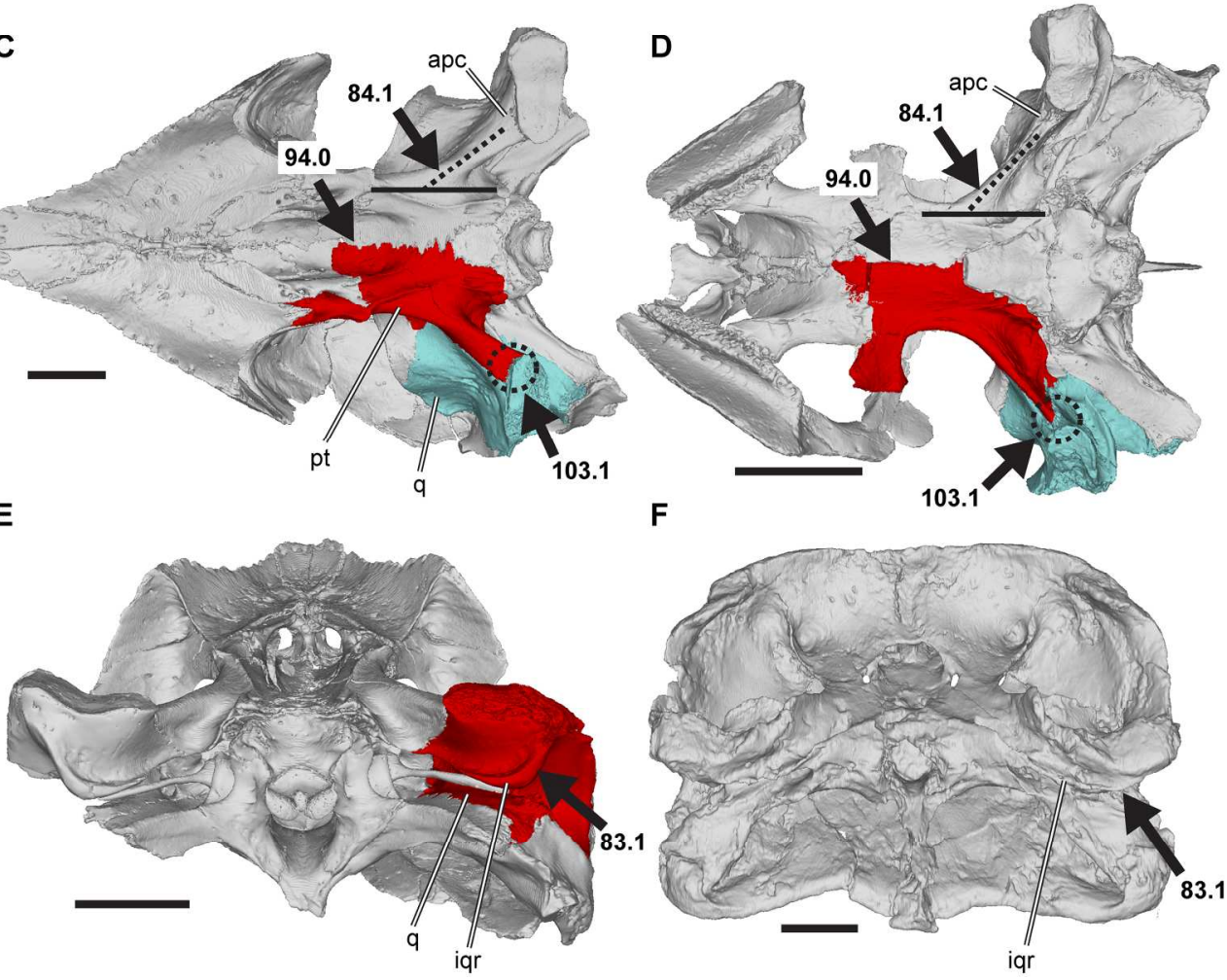

$F$

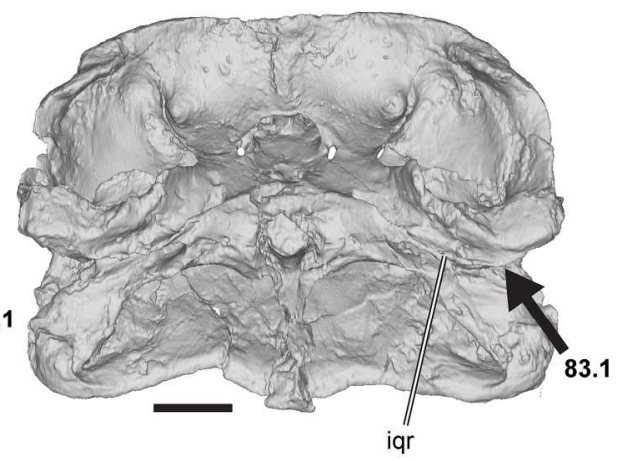

FIG. 5. Cranial synapomorphies of Angolachelonia illustrated by renderings of 3D models generated using CT data. A, cranium of Solnhofia parsoni (TM 4023) in dorsal view showing the extend of the dermal skull roof in the temporal region, obliterating the foramen stapedio-temporale in dorsal view (ch. 18.0); B, cranium of Sandownia harrisi (MIWG 3480) in dorsal view, showing the same features as in A; C, cranium of Solnhofia parsoni (TM 4023) in ventral view, showing the posterior direction of the articular process (ch. 84.1), the long interpterygoid contact (ch. 94.0), and the contact of the pterygoid with the mandibular articular surface of the quadrate (ch 103.1); D, cranium of Plesiochelys planiceps (OUMNH J1582) in ventral view, showing the same features as in C; E cranium of Solnhofia parsoni (TM 4023) in posteroventral view, showing the infolding ridge of the quadrate (ch. 83.1); F, cranium of Brachyopsemys tingitana (AMNH FARB 30612) in posteroventral view, showing the same features as in E. Scale bars in A, B, C, E are $10 \mathrm{~mm}$; scale bars in $\mathrm{D}, \mathrm{F}$ are $20 \mathrm{~mm}$. Abbreviations: apc, articular process of cranium; fst, foramen stapedio-temporale; iqr, infolding ridge of quadrate; pt, pterygoid; q, quadrate. 


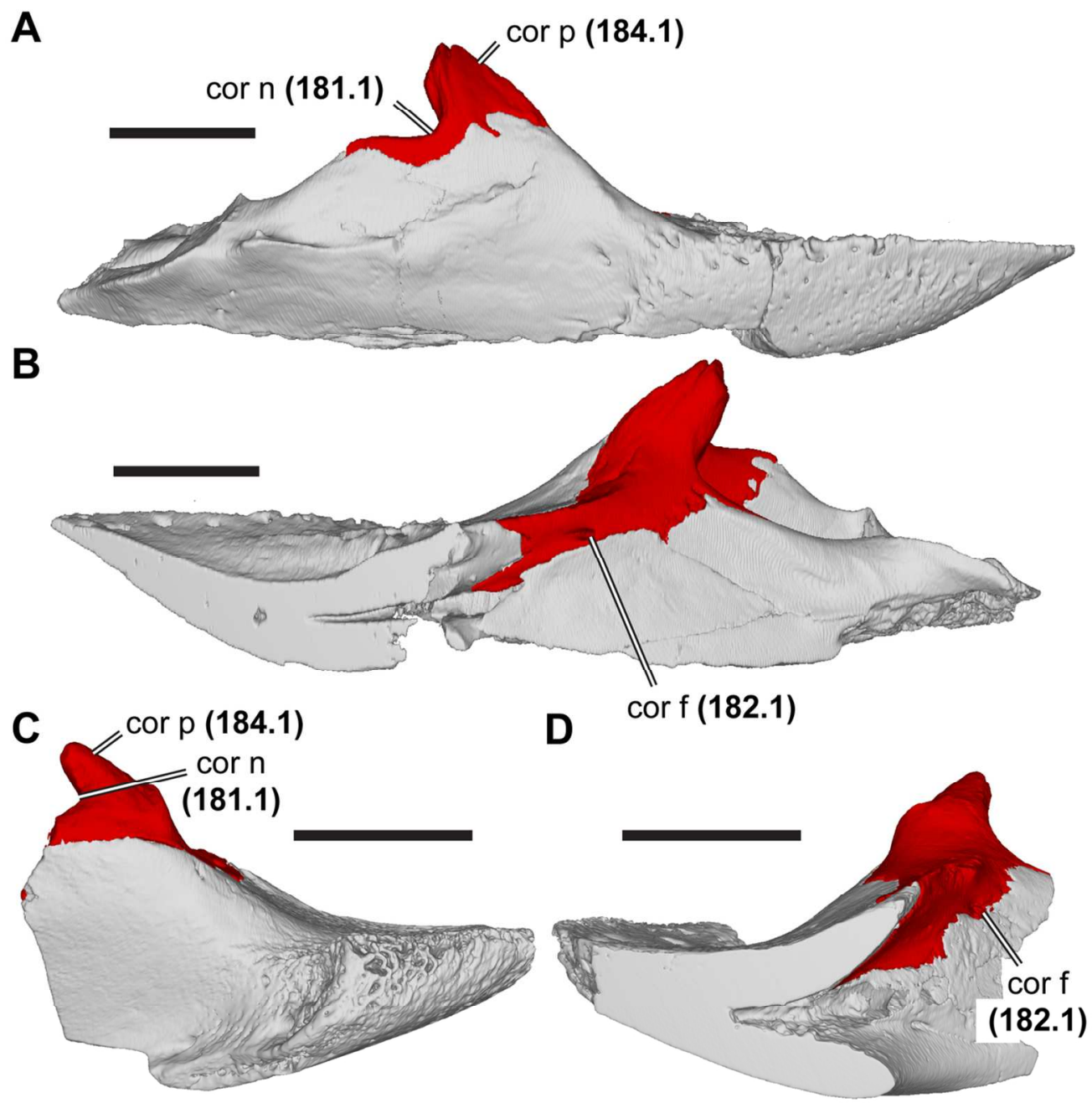

FIG. 6. Mandibular synapomorphies of Angolachelonia illustrated by renderings of 3D models generated using CT data. A, right mandibular ramus of Solnhofia parsoni (TM 4023) in lateral view, showing the coronoid notch (ch. 181.1), and the tall and pointed coronoid process (ch. 184.1); B, right mandibular ramus of Solnhofia parsoni (TM 4023) in medial view, showing the foramen in the coronoid (ch. 182.1); C, right mandibular ramus of Sandownia harrisi (MIWG 3480) in lateral view, showing the same features as in A; D, right mandibular ramus of Sandownia harrisi (MIWG 3480) in medial view, showing the same features as in $\mathrm{B}$. Note that the coronoid has been shaded in all images. Scale bars are $10 \mathrm{~mm}$. Abbreviations: cor $\mathrm{f}$, foramen in coronoid; cor $n$, coronoid notch; cor $p$, coronoid process.

$$
112 \times 115 \mathrm{~mm}(300 \times 300 \mathrm{DPI})
$$


A

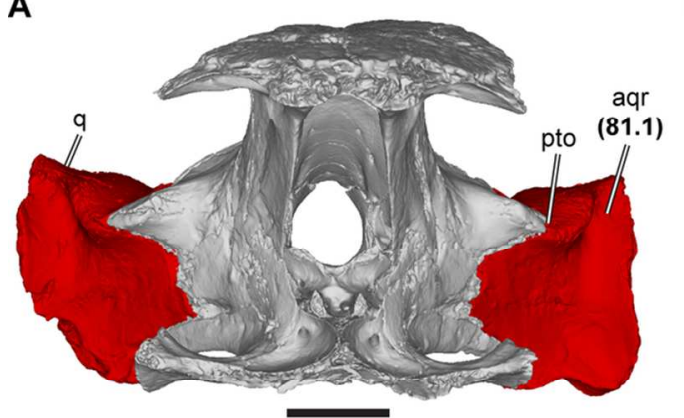

B

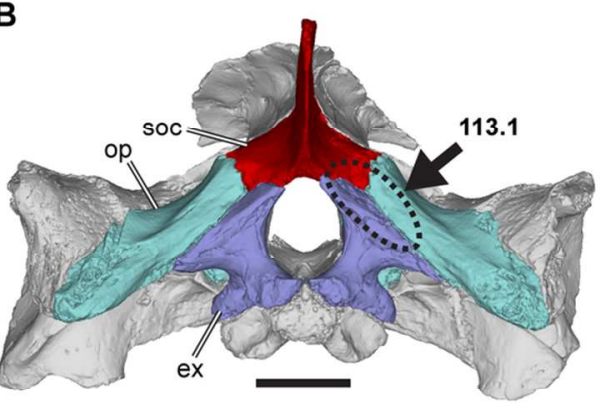

c

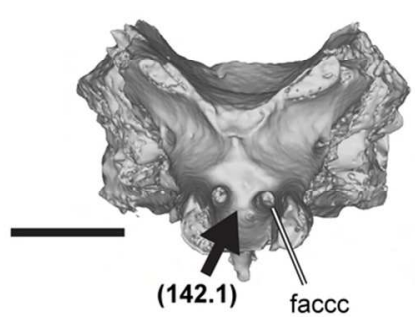

D

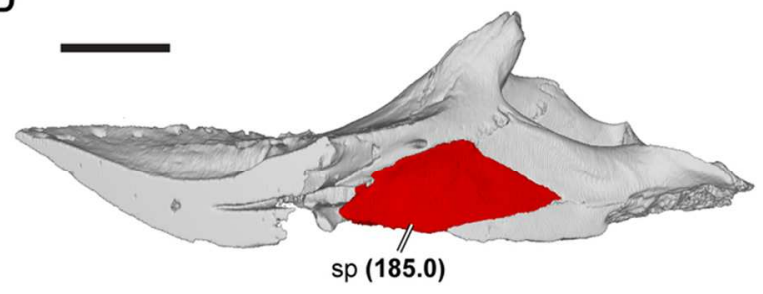

FIG. 7. Cranial and mandibular synapomorphies of Thalassochelydia illustrated by renderings of 3D models generated using CT data. A, posterior part of the cranium of Plesiochelys planicpes (OUMNH J1582) in anterior view, showing the recess on the anterior surface of the quadrate lateral to the processus trochlearis oticum (ch. 81.1); B, cranium of Plesiochelys planicpes (OUMNH J1582) in posterior view, showing the presence of a fossa on the supraoccipital-opisthotic-exoccipital contact area (ch 113.1); C, parabasisphenoid of Plesiochelys planicpes (OUMNH J1582) in anterior view, showing the closely-spaced foramina anterius canalis caroticus cerebralis (ch 142.1); D, right mandibular ramus of Solnhofia parsoni (TM 4023) in medial view, showing the presence of a splenial (ch 185.0). Note that dotted line in B surround fossa. Scale bars in $A-B, D$ are $10 \mathrm{~mm}$, scale bar in B is $5 \mathrm{~mm}$. Abbreviations: aqr, anterior quadrate recess; ex, exoccipital; op, opisthotic; faccc, foramen anterius canalis caroticus internus; pto, processus trochlearis oticum; q, quadrate; soc, supraoccipital; sp, splenial. 
A

FIG. 8. Cranial synapomorphies of Sandownidae illustrated by renderings of 3D models generated using CT data. A, cranium of Sandownia harrisi (MIWG 3480) in left lateral view, showing the extend of the lower temporal emargination which is exclusively formed by the jugal and quadratojugal (ch 34.0); B, cranium of Sandownia harrisi (MIWG 3480) in ventral view, showing the vomer-palatine contact anterior to the internal naris (ch. 57.1), the contribution of the vomer to the triturating surface (ch. 68.1), and the posterior process of the pterygoid covering parts of the parabasisphenoid and basioccipital (ch. 108.1). Dotted line in A denotes the ventral margin of the lower temporal emargination, and the dotted line in $\mathrm{B}$ denotes the position of the internal naris. Scale bars are $10 \mathrm{~mm}$. Abbreviations: boc, basioccipital; j, jugal; pal; palatine; pbsp, parabasisphenoid; pt, pterygoid; q, quadrate; qj, quadratojugal.

\section{$145 \times 192 \mathrm{~mm}(300 \times 300 \mathrm{DPI})$}



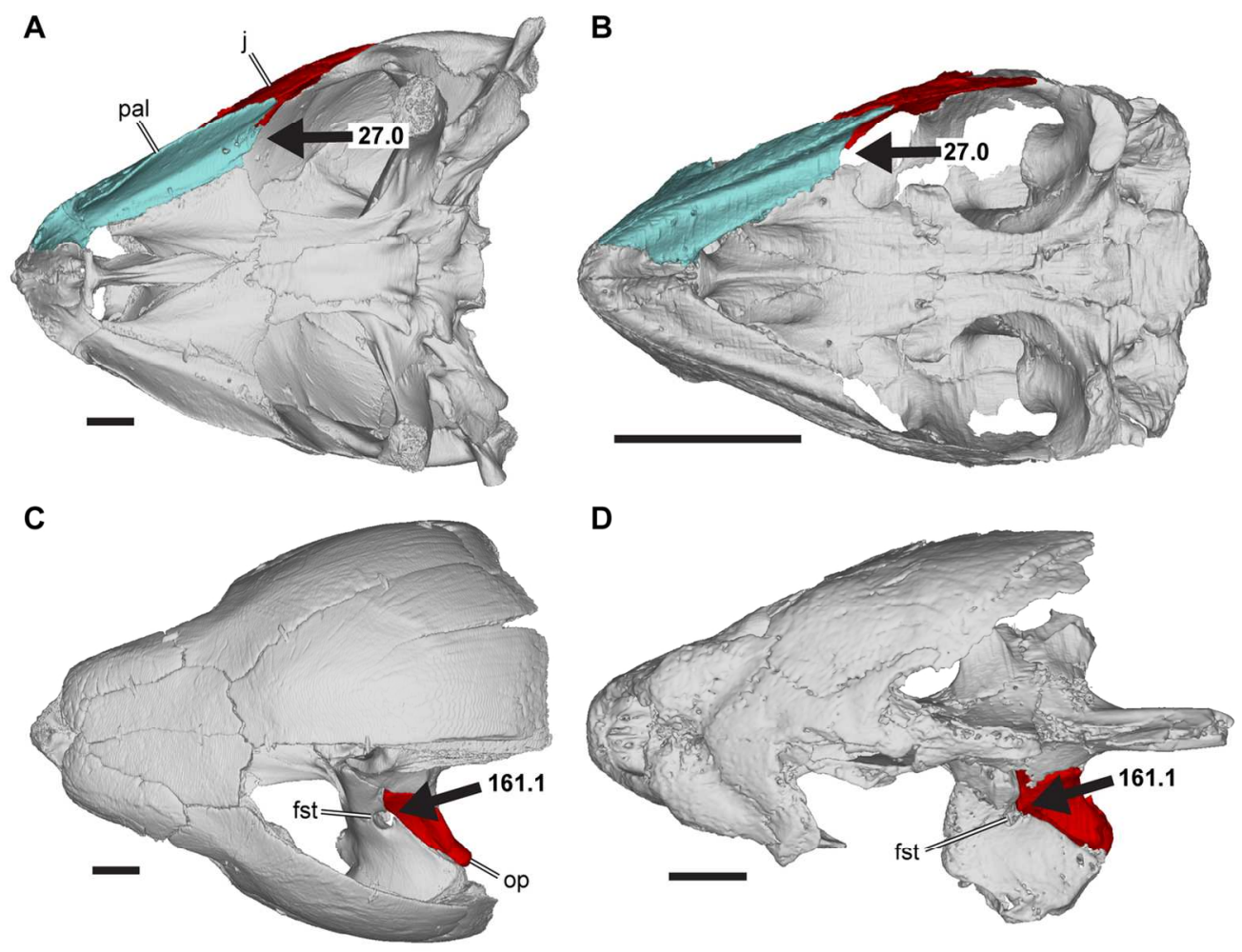

FIG. 9. Cranial synapomorphies of Dermochelyoidea illustrated by renderings of 3D models generated using CT data. A, cranium of Dermochelys coriacea (UMZC R3031) in ventral view, showing absence of medial process of jugal (ch. 27.0); B, cranium of Rhinochelys pulchriceps (CAMSM B55783) in ventral view, showing the same features as in A; C, cranium of Dermochelys coriacea (UMZC R3031) in dorsal view with the left postorbital removed, showing the opisthotic contribution to the foramen stepedio-temporale (ch. 161.1); D, cranium of Bouliachelys suteri (QMF 31669) in dorsal view, showing the same features as in C. Scale bars in A, C, and D are $20 \mathrm{~mm}$; scale bar in B is $1 \mathrm{~mm}$. Abbreviations: fst, foramen stepediotemporale; j, jugal; op, opisthotic; pal, palatine. 

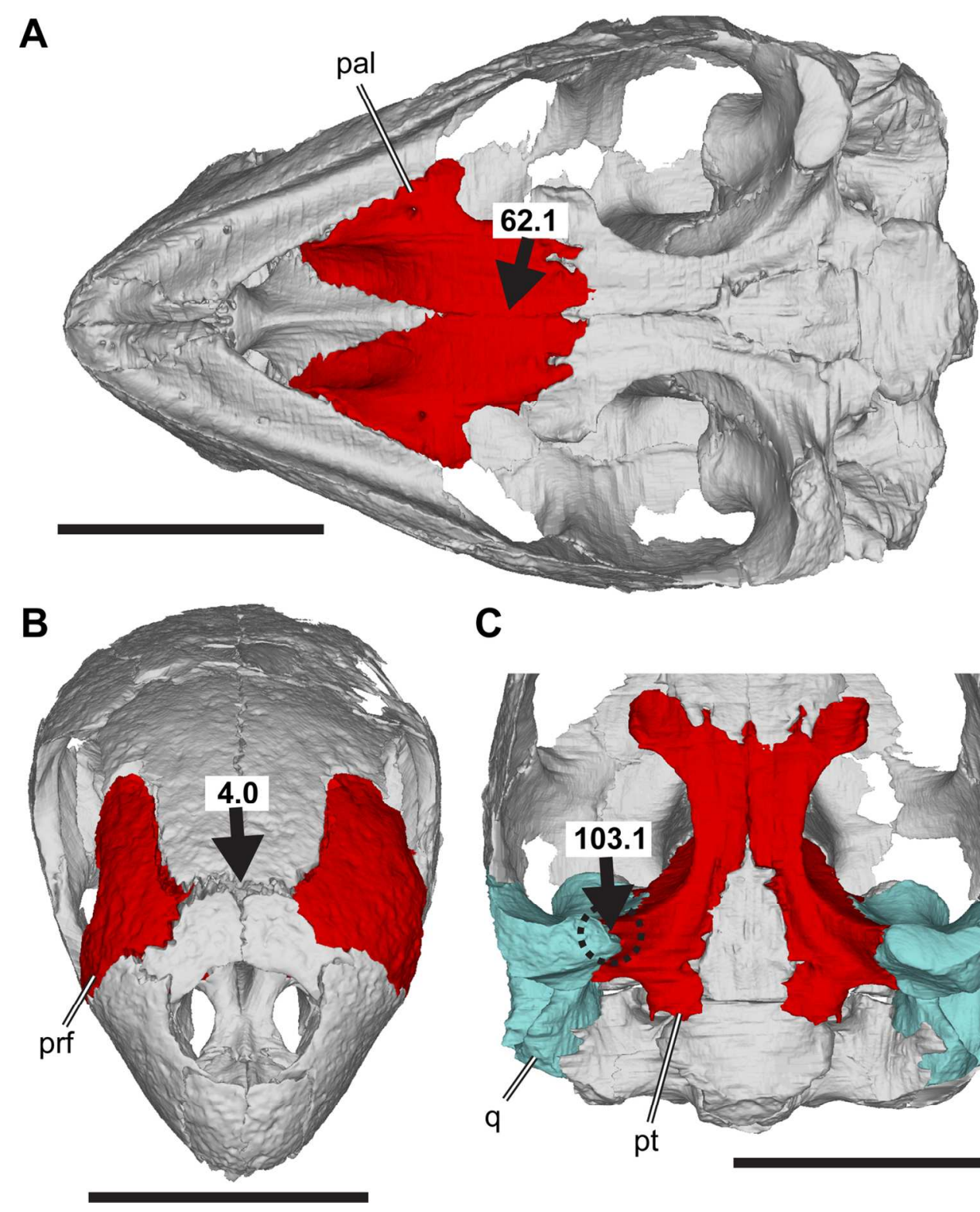

C

FIG. 10. Cranial synapomorphies of Protostegidae illustrated by renderings of 3D models generated using CT data. A, cranium of Rhinochelys pulchriceps (CAMSM B55783) in ventral view, showing the interpalatine contact (ch. 62.1); B, cranium of Rhinochelys pulchriceps (CAMSM B55783) in anterodorsal view, showing the lack of a medial contact between the prefrontals (ch. 4.0); C, posterior part of cranium of Rhinochelys pulchriceps (CAMSM B55783) in ventral view, showing the contact of the pterygoid with the mandibular articular surface of the quadrate (ch 103.1). Scale bars are $1 \mathrm{~mm}$. Abbreviations: pal, palatine; prf, prefrontal; pt, pterygoid; q, quadrate.

$127 \times 152 \mathrm{~mm}(300 \times 300 \mathrm{DPI})$ 
A

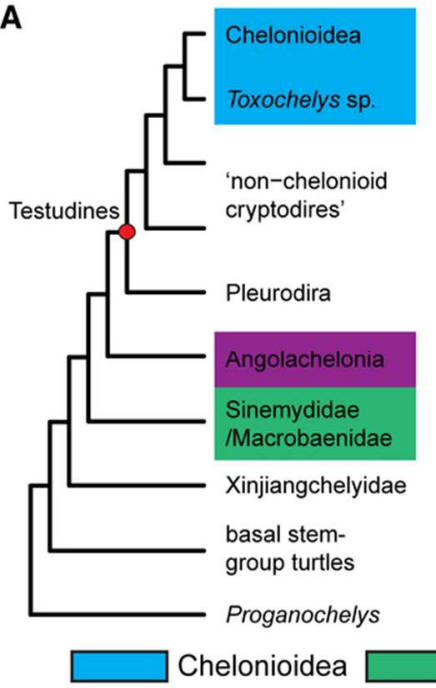

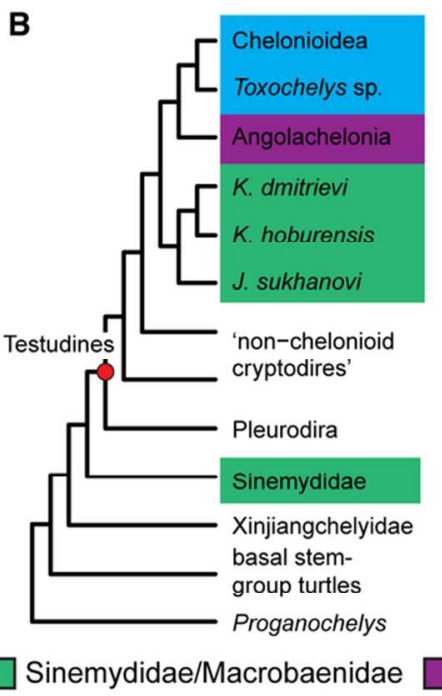

FIG. 11. Competing MPT topologies of our ordered analysis resulting in a large polytomy. A, topology supported by a subset of MPTs that is identical with results from the unordered analysis; B, topology supported by a subset of MPTs in which angolachelonians and macrobaenids are stem-group chelonioids; $C$, topology supported by a subset of MPTs in which angolachelonians, but not macrobaenids are stem-group chelonioids. Note that Ordosemys has been pruned from the MPTs, and that protostegids are included in Chelonioidea.

\section{$85 \times 45 \mathrm{~mm}(300 \times 300 \mathrm{DPI})$}




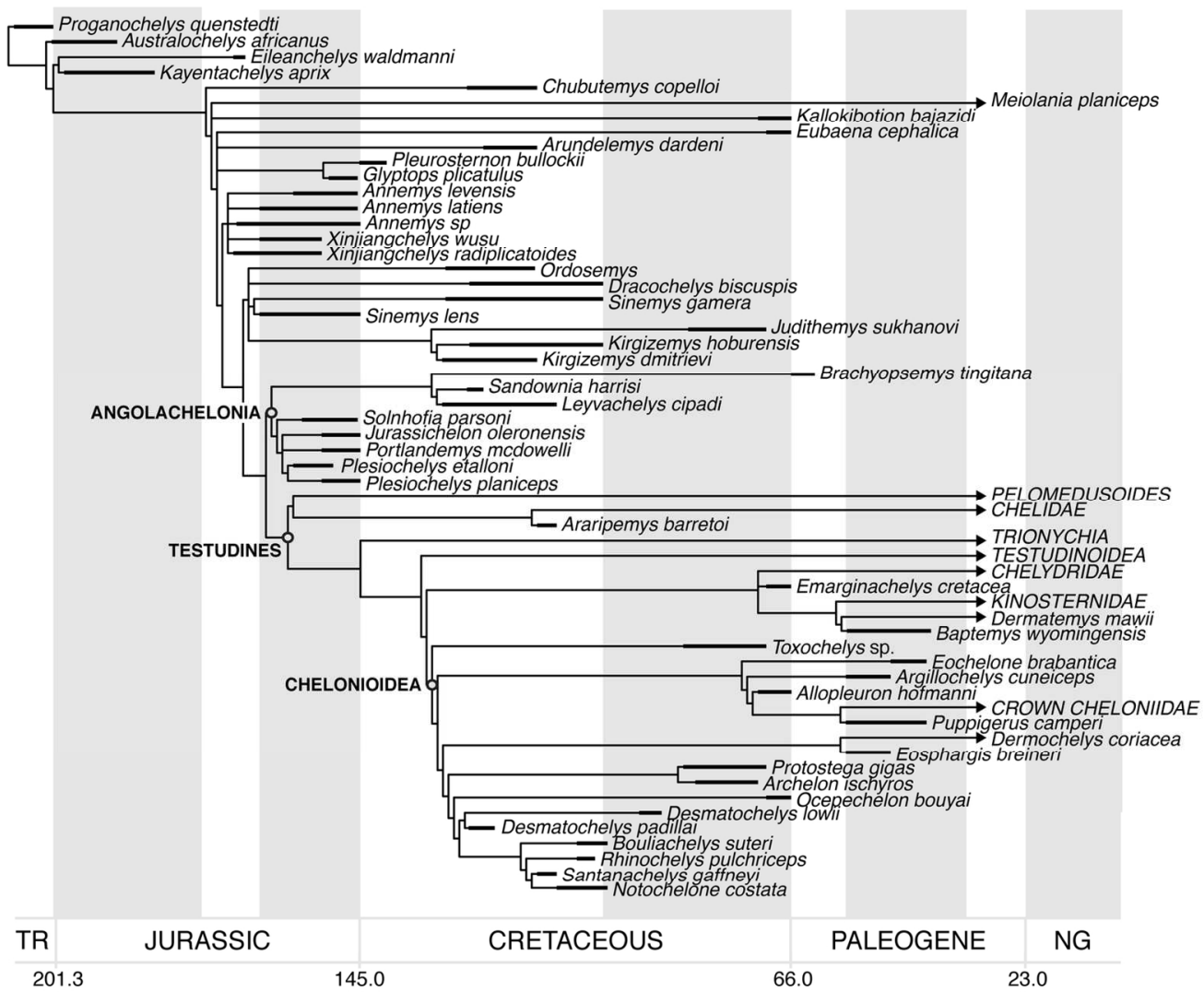

FIG. 12. Simplified phylogenetic tree scaled to geologic time using range data for turtles. $139 \times 117 \mathrm{~mm}(300 \times 300 \mathrm{DPI})$ 
A

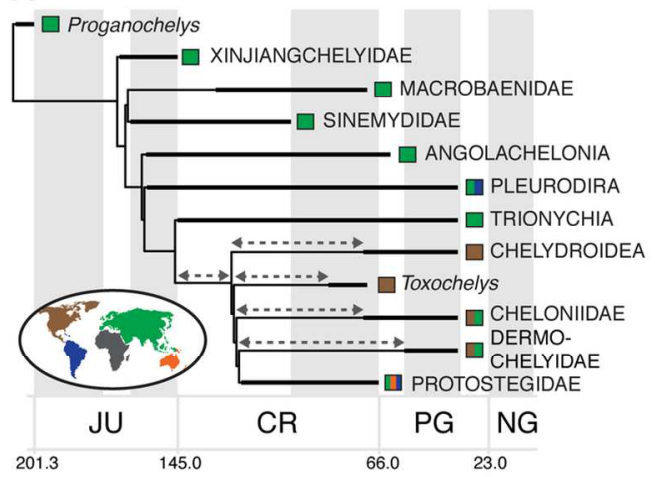

C

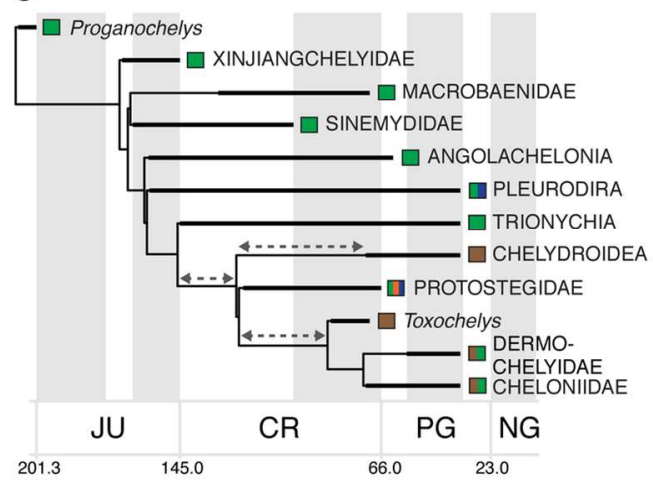

B

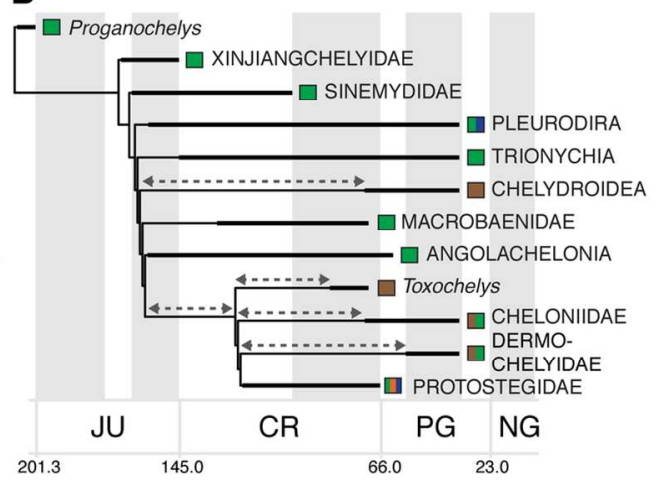

D

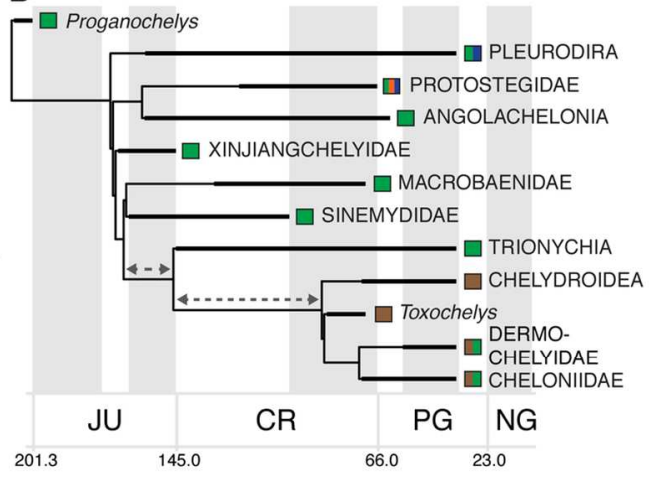

FIG. 13. Implications of alternative positions of Protostegidae for americhelydian ghost-lineages and biogeography illustrated by simplified calibrated trees. A, preferred hypothesis of this study, supported by unordered phylogenetic analysis; B, hypothesis placing Angolachelonia on the stem-group of chelonioids, supported by a subset of MPTs in the ordered analysis; $C$, hypothesis of protostegids being stem-group chelonioids, supported by a subset of our 'least specialised taxa analyses'; D, hypothesis following Joyce (2007) and other authors in placing protostegids in close relation to thalassochelydians and sandownids, and having an extended cryptodiran stem-lineage that further includes sinemydids/macrobaenids and xinjiangchelyids. Ghost lineages for americhelydian lineages are indicated by dashed arrows. Coloured squares indicate the distribution of earliest fossils according to continents.

$$
127 \times 102 \mathrm{~mm}(300 \times 300 \mathrm{DPI})
$$


Taxon

Allaeochelys libyca

Allopleuron hoffmanni

Annemys sp.

Annemys levensis

Annemys latiens

Apalone spinifera emoryi

Araripemys barretoi

Archelon ischyros

Argillochelys cuneiceps

Arundelemys dardeni

Australochelys africanus

Baptemys wyomingensis

Bouliachelys suteri

Brachyopsemys tingitana

Caretta caretta

Carettochelys insculpta

Chelodina oblonga

Chelodina longicollis*

Chelonia mydas

Chelonoidis sp.

Chelonoidis chilensis*

Chelus fimbriatus

Chelydra serpentina

Chrysemys picta

Chubutemys copelloi

Dermatemys mawii

Dermochelys coriacea

Desmatochelys lowii

Desmatochelys padillai

Dracochelys bicuspis

Eileanchelys waldmanni

Elseya dentata

Emarginachelys cretacea

Emys orbicularis

Eochelone brabantica

Eosphargis breineri

Eretmochelys imbricata

Eubaena cephalica

Geoclemys hamiltoni

Glyptops plicatulus

Gopherus polyphemus 
Judithemys sukhanovi

Jurassichelon oleronensis

Kallokibotion bajazidi

Kayentachelys aprix

Kinosternon suburum hippocrepis

Kinosternon flavescens*

Kirgizemys dmitrievi

Kirgizemys hoburensis

Lepidochelys kempii

Lepidochelys olivacea

Levyachelys cipadi

Lissemys punctata

Macrochelys temminckii

Meiolania platyceps

Natator depressus

Notochelone costata

Ocepechelon bouyai

Ordosemys sp.

Pelodiscus sinensis

Pelomedusa subrufa

Phrynops geoffranus

Platysternon megacephalum

Plesiochelys planicpes

Plesiochelys etalloni

Pleurosternon bullockii

Podocnemis unifilis

Podocnemis expansa*

Portlandemys mcdowelli

Proganochelys quenstedti

Protostega gigas

Puppigerus camperi

Rhinochelys pulchriceps

Sandownia harrisi

Sinemys gamera

Sinemys lens

Solnhofia parsoni

Staurotypus salvinii

Staurotypus triporcatus*

Sternotherus minor

Sternotherus odoratus*

Testudo marginata

Testudo hermanni*

Toxochelys sp.

Xinjiangchelys radiplicatoides 


\section{Xinjiangchelys wusu}

*Species indicated by asterisk wer

Bold specimen numbers indicate s/ 
Specimen(s) used for character scoring

BSPG 1991 II 130

NHMUK R4291; NHMM 000001

IVPP V18106

PIN 4636-4-2

PIN 4636-6-1

FMNH 22178

AMNH 30778

YPM 3000

NHMUK R38955; NHMUK R41636

USNM 497740

BP/1/4933

YPM 374, 3758; DMNH 511

QMF 31669

AMNH 30001; AMNH 30612

NHMUK 1938.1.9.1

NHMUK 1903.7.10.1

NHMUK 64.12.22

unknown (specimen number not given in Cadena \& Parham 2015)

NHMUK 1969.776

SMF 67582

unknown (specimen number not given in Cadena \& Parham 2015)

NHMUK 81.9.27.4

SMF 32846

NHMUK 76.1.31.19

MPEF-PV1236

SMF 59463

FMNH 171756; UMZC R3031

KUVP 1200

FCG-CBP 01, 13, 15, 39, 40; UCMP 38345, 382456

IVPP V4075; IVPP V12091

NMS.G.2004.31.15; NMS.G.2004.31.16a-f

NHMUK 76.5.19.77

KUVP 23488

WGJ1987a

NHMUK R37213

FUM-N-1450

FMNH 22242

DMNH 96004; AMNH 4948, 2602, 2604, 2606; YPM 1785

NHMUK 87.9.30.1

AMNH 336; YPM 1784, 4717, 5821

FMNH 211815 
TMP 87.2.1

PIMUZ AIII 514

NHMUK R4918; NHMUK R4921; NHMUK R4925

TMM 4370-2, 43653-1; MCZ 8914-8917; MNA V1558, V2664

FMNH 211711

unknown (specimen number not given in Cadena \& Parham 2015)

ZIN PH7/15

PIN 3334-4; PIN 3334-35; PIN 3334-36

M009/08

SMNS 11070

FCG-CBP-71; SMU 75377, 72852, 74982, 75327; FWMSH 93B-17

SMF 74141

FMNH 22111

NHMUK R682; specimens listed in Gaffney 1983

R112123

NHMUK R9590

OCPDEK/GE516

IVPP V12092

IW576-2

SMF 70504

SMF 45470

SMF 69684

OUMNH J1582

MNB 435

UMZC T1041

FMNH 45657

unknown (specimen number not given in Cadena \& Parham 2015)

NHMUK R2914

SMNS 15759, 16980

AMNH 1502, 1503; CMNH 1421; FMNH PR2, P27385

NHMUK R14375

CAMSM B55775, B55783, B55776; NHMUK R43980, R2226, R35197

MIWG 3480

IVPP V9532-11

IVPP V9533-1; IVPP V9533-3

TM 4023

NHMUK 1879.1.7.5

unknown (specimen number not given in Cadena \& Parham 2015)

FMNH 211696

unknown (specimen number not given in Cadena \& Parham 2015)

FMNH 51672

unknown (specimen number not given in Cadena \& Parham 2015)

AMNH1496, 5118; FMNH UR3; FMNH PR219, PR648

IVPP V9539-1 
PMOL-SGPA0100-1; PMOL-SGPA0100-3

z used only for postrcanial scores.

secimens for which CT scans were available.

10

11

12

13

14

15

16

17

18

19

20

21

22

23

24

25

26

27

28

29

30

31

32

33

34

35

36

37

38

39

40

41

42

43

44

45

46

47

48

49

50

51

52

53

54

55

56

57

58

59

60

Palaeontology 
References used for character scoring

Personal observation

of taxon

CT

Havlik et al. 2014

yes

yes

Mulder 2003

Brinkman et al. 2013

Shukanov 2000; Rabi et al. 2014

yes yes

Rabi et al. 2014

no additional references used

Meylan 1996; Gaffeny et al. 2011

no yes

Wieland 1896, 1900, 1902

no additional references used

Lipka et al. 2006

Gaffney \& Kitching 1995

Meylan \& Gaffney 1989; Knauss 2014

Kear \& Lee 2006

Tong \& Meylan 2013

no additional references used

no additional references used

no additional references used

Cadena \& Parham 2015

no additional references used

no additional references used

no

no

no no

Cadena \& Parham 2015

no additional references used

no additional references used

yes

yes

yes

yes

yes

no

yes

yes

no yes

yes

yes

no

yes

no yes

yes yes

yes yes

yes yes

yes yes

no no

yes yes

no yes

no additional references used

Gaffney et al. 2007; Sterli et al. 2015

no no

yes yes

no yes

yes yes

no additional references used

no no

no additional references used

no yes

no additional references used

yes

yes

Cadena \& Parham 2015

no yes

Gaffney \& Ye 1992; Brinkman 2001

no no

Anquetin 2010

no additional references used

no no

yes yes

yes yes

Whetstone 1978

no additional references used

no no

Casier 1968

no yes

yes yes

Nielsen 1959

no additional references used

yes no

Gaffney 1972, 1979; Gaffney 1982a, b

yes yes

no additional references used

no no

yes yes

Gaffney 1979

no no

no additional references used

yes

yes 
Parham \& Hutchinson 2003

$\begin{array}{cc}\text { no } & \text { no } \\ \text { yes } & \text { yes } \\ \text { yes } & \text { yes } \\ \text { no } & \text { yes } \\ \text { yes } & \text { yes }\end{array}$

Rieppel 1980

Gaffney \& Meylan 1992

Sterli \& Joyce 2007; Gaffney \& Jenkins 2010

no additional references used

no no

Cadena \& Parham 2015

no no

Danilov et al . 2006

no no

Jones et al . 2012

no yes

no additional references used

yes yes

Vineyard 2009; Cadena 2015

no additional references used

no additional references used

no

no

Gaffney 1983

Jones et al . 2012

no additional references used

no yes

yes yes

yes yes

no yes

Bardet et al . 2013

Brinkman \& Wu 1999

yes yes

no no

no additional references used

no yes

no additional references used

no yes

no additional references used

yes yes

no yes

no additional references used no yes

Gaffney 1975a; Gaffney 1976 yes yes

Gaffney 1975a; Gaffney1976 yes yes

Evans \& Kemp 1975

no additional references used

no yes

Cadena \& Parham 2015

yes yes

no additional references used

no no

Gaffney 1990

yes yes

Case 1897; Hay 1908

yes no

Moody 1974

no additional references used

Meylan et al . 2000

yes no

yes yes

yes yes

yes yes

Brinkman \& Peng 1993 no no

Brinkman \& Peng 1993 no no

Gaffney $1975 b$

no additional references used

yes yes

Cadena \& Parham 2015 no no

Bever 2009 yes yes

Cadena \& Parham 2015 no no

no additional references used yes yes

Cadena \& Parham 2015 no no

Hay 1896; Nicholls 1988 yes yes

Brinkman et al. 2013 no yes 
Taxon

First Appaearance Datum

Last Appearance Datum

Allopleuron hofmanni
Annemys latiens
Annemys levensis
Annemys sp.
Araripemys barretoi
Archelon ischyros
Argillochelys cuneiceps
Arundelemys dardeni
Australochelys africanus
Baptemys wyomingensis
Bouliachelys suteri
Brachyopsemys tingitana
Chubutemys copelloi
Desmatochelys lowii

(FAD)

(LAD)

72.1

66.0

163.5

145.5

157.3

145.5

167.7

145.0

112.6

109.0

83.6

72.1

56.0

47.8

122.46

112.6

201.6

189.6

55.8

40.4

105.3

99.7

66.043

61.7

125.45

112.6

93.9

89.8

Desmatochelys padillai

125.0

120.0

Dracochelys biscuspis

125.0

168.3

100.5

Eileanchelys waldmanni

70.6

166.1

Eubaena cephalica

70.6

66.043

Emarginachelys cretacea

47.8

66.043

Eochelone brabantica

56.0

41.2

Eosphargis breineri

150.8

47.8

Glyptops plicatulus

84.9

145.5

Judithemys sukhanovi

Jurassichelon oleronensis

152.1

70.6

Kallokibotion bajazidi

72.1

145.0

Kayentachelys aprix

199.3

66.0

Kirgizemys dmitrievi

130.0

182.7

Kirgizemys hoburensis

125.0

112.6

Leyvachelys cipadi

130.0

100.5

Notochelone costata

109.0

109.0

Ocepechelon bouyai

70.6

99.7

Ordosemys sp.

129.4

66.043

Plesiochelys etalloni

157.3

113.0

Plesiochelys planiceps

152.1

150.0

Pleurosternon bullockii

145.2

145.0

Portlandemys mcdowelli

152.1

140.2

Proganochelys quenstedti

208.5

145.0

Protostega gigas

85.8

201.3

70.6

Puppigerus camperi

41.2 
Rhinochelys pulchriceps

Sandownia harrisi

Santanachelys gaffneyi

Sinemys gamera

Sinemys lens

Solnhofia parsoni

Toxochelys latiremis

Xinjiangchelys radiplicatoides

Xinjiangchelys wusu
105.3

125.45

112.6

129.4

163.5

155.7

85.8

168.3

163.5
102.0

122.46

109.0

100.5

145.0

145.5

70.6

152.1

152.1 
Source

Janssen et al. 2013

Rabi et al. 2010

Rabi et al . 2010

PalaeoDB

PalaeoDB

Hirayama 1997

Weems \& Brown 2017

PalaeoDB

PalaeoDB

PalaeoDB

PalaeoDB

PalaeoDB

PalaeoDB

Hirayama 1997

Cadena \& Parham 2015

Rabi et al . 2010

Joyce et al. 2016b

PalaeoDB

PalaeoDB

Weems \& Brown 2017

Nielson 1959

PalaeoDB

PalaeoDB

Rieppel 1980; Anquetinet al. 2017

Joyce et al. 2016b

Joyce et al. $2016 b$

PalaeoDB

Rabi et al. 2010

PalaeoDB

PalaeoDB

PalaeoDB

Rabi et al . 2010

Anquetin et al . 2017

Anquetin et al . 2017

PalaeoDB

Anquetin et al. 2017

Joyce et al . 2016b

PalaeoDB

Weems \& Brown 2017 
PalaeoDB for FAD; LAD following Collins 1970

PalaeoDB

PalaeoDB

Rabi et al .2010

Rabi et al .2010

PalaeoDB; Joyce 2000

PalaeoDB; Weems \& Brown 2017

Rabi et al. 2010

PalaeoDB 
Taxon

\begin{tabular}{l} 
Chelonioidea (total-group) \\
Chelonioidea (crown-group) \\
Cheloniidae (total-group) \\
Dermochelyoidea \\
Dermochelyidae \\
Protostegidae \\
Angolachelonia \\
Sandownidae \\
Thalassochelydia \\
Sinemydidae/Macrobaenidae \\
Xinjiangchelyidae \\
\hline
\end{tabular}




\section{Unambiguous synapomorhies}

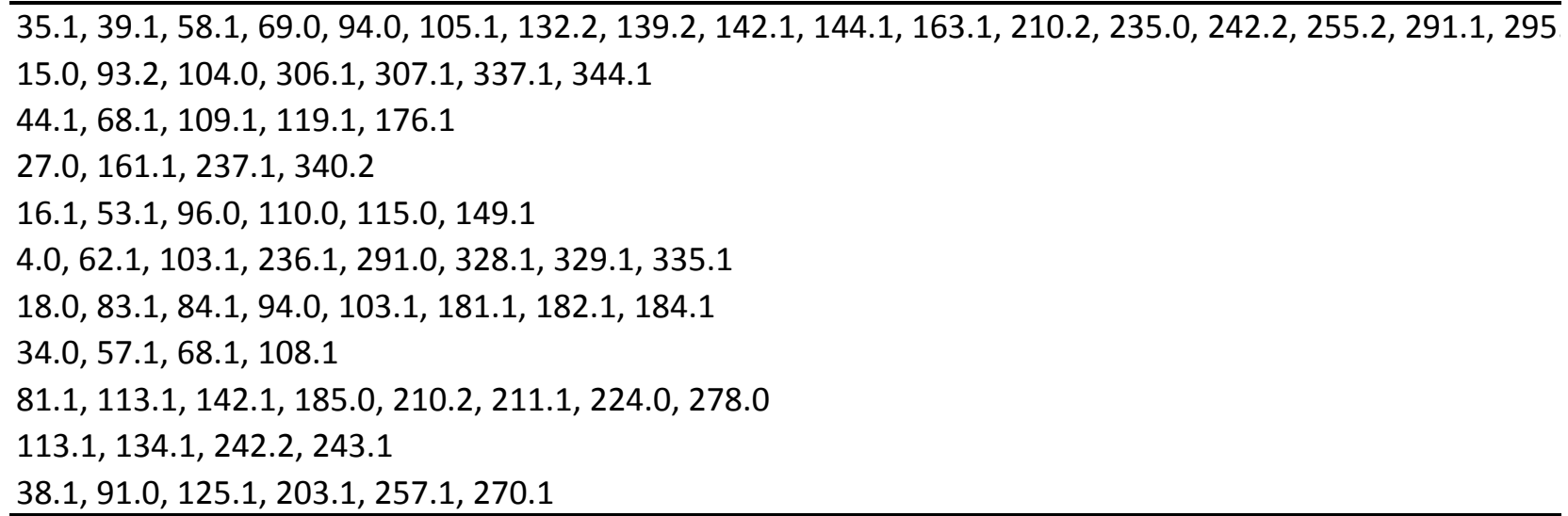




$\begin{array}{lc}1 & \\ 2 & \\ 3 & \text { Sum } \\ 4 & 21 \\ 5 & 7 \\ 6 & 5 \\ 7 & 4 \\ 8 & 6 \\ 9 & 8 \\ 10 & 8 \\ 11 & 4 \\ 12 & 8 \\ 13 & 4 \\ 14 & 6 \\ 15 & \\ 16 & \\ 17 & \end{array}$

18

19

20

21

22

24

25

26

27

28

29

30

31

32

33

34

35

36

37

39

40

41

42

43

44

45

46

47

48

49

50

5

52

53

54

55

56

57

58

59

60

Palaeontology 


\section{Constraint}

\begin{tabular}{|c|}
\hline All fossil unconstrained \\
\hline $\begin{array}{l}\text { Plesiochelys etallon i as a stem-group cryptodire } \\
\qquad \text { (Constraint } 1 \text { ) }\end{array}$ \\
\hline $\begin{array}{l}\text { Jurassichelon oleronensis as a stem-group } \\
\text { chelonioid (Constraint 2) }\end{array}$ \\
\hline $\begin{array}{l}\text { Jurassichelon oleronensis as a stem-group } \\
\text { cryptodire (Constraint } 3 \text { ) }\end{array}$ \\
\hline $\begin{array}{l}\text { Solnhofia parsoni as a stem-group cryptodire } \\
\text { (Constraint 4) }\end{array}$ \\
\hline $\begin{array}{l}\text { Solnhofia parsoni as a stem-group chelonioid } \\
\text { (Constraint 5) }\end{array}$ \\
\hline $\begin{array}{l}\text { Sandownia parsoni as a stem-group cryptodire } \\
\text { (Constraint 6) }\end{array}$ \\
\hline $\begin{array}{l}\text { Sandownia harrisi as a stem-group chelonioid } \\
\text { (Constraint 7) }\end{array}$ \\
\hline $\begin{array}{l}\text { Rhinochelys pulchriceps as a stem-group } \\
\text { cryptodire (Constraint } 8 \text { ) }\end{array}$ \\
\hline $\begin{array}{l}\text { Rhinochelys pulchriceps as a stem-group turtle } \\
\qquad \text { (Constraint 9) }\end{array}$ \\
\hline $\begin{array}{l}\text { Xinjiangchelys wusu as a stem-group cryptodire } \\
\text { (Constraint 10) }\end{array}$ \\
\hline $\begin{array}{l}\text { Sinemys lens as a stem-group cryptodire } \\
\text { (Constraint 11) }\end{array}$ \\
\hline $\begin{array}{l}\text { Judithemys sukhanovi as a stem-group cryptodire } \\
\text { (Constraint } 12 \text { ) }\end{array}$ \\
\hline $\begin{array}{l}\text { Protostega gigas as a stem-group cryptodire } \\
\text { (Constraint 13) }\end{array}$ \\
\hline $\begin{array}{l}\text { Protostega gigas as a stem-group turtle } \\
\text { (Constraint 14) }\end{array}$ \\
\hline $\begin{array}{l}\text { Xinjiangchelys wusu as a stem-group chelonioid } \\
\text { (Constraint 15) }\end{array}$ \\
\hline $\begin{array}{l}\text { Sinemys lens as a stem-group Chelonioid } \\
\text { (Constraint 16) }\end{array}$ \\
\hline $\begin{array}{l}\text { Judithemys sukhanovi as a stem-group chelonioid } \\
\text { (Constraint 17) }\end{array}$ \\
\hline $\begin{array}{l}\text { Santanachelys gaffneyi as a stem-group cryptodire } \\
\text { (Constraint 18) }\end{array}$ \\
\hline $\begin{array}{l}\text { Santanachelys gaffneyi as a stem-group turtle } \\
\text { (Constraint 19) }\end{array}$ \\
\hline $\begin{array}{l}\text { Santanachelys gaffneyi as a stem-group } \\
\text { chelonioid (Constraint 20) }\end{array}$ \\
\hline
\end{tabular}

${ }^{x}$ Indicates low $\mathrm{p}$-value due to small $\mathrm{N}$ 
${ }^{(*)}$ Indicates low p-values that we refer to as near-sig

*Denotes significant at $p<0.05$

**Denotes significant at $\mathrm{p}<0.01$

1

2

5

6

7

8

9

10

11

12

13

14

15

16

17

18

19

20

21

22

23

24

25

26

27

28

29

30

31

32

33

34

35

36

37

38

39

40

41

42

43

44

45

46

47

48

49

50

51

52

53

54

55

56

57

58

59

60

Palaeontology 
Topology as in Fig. 4A

Plesiochelyids are stem-group cryptodires

Plesiochelyids are stem-group chelonioids

Plesiochelyids are stem-group cryptodires

Thalassochelydia are stem-group cryptodires

Thalassochelydia are stem-group chelonioids

Sandownids are stem-group cryptodires

Sandownids are stem-group chelonioids

Protostegids are stem-group cryptodires

Protostegids are stem-group turtles

Xinjiangchelyids are stem-group cryptodires

Sinemydids are stem-group cryptodires

Macrobaenids are stem-group cryptodires

Protostegids are stem-group cryptodires

Protostegids are stem-group turtles

Xinjiangchelyids are stem-group chelonioids

Sinemydids are stem-group chelonioids

Macrobaenids are stem-group chelonioids

Protostegids are stem-group cryptodires

Protostegids are stem-group turtles

Protostegids are stem-group chelonioids
Maximum

Minimum

Maximum

Minimum

Maximum

Minimum

Maximum

Minimum

Maximum

Minimum

Maximum

Minimum

Maximum

Minimum

Maximum

Minimum

Maximum

Minimum

Maximum

Minimum

Maximum

Minimum

Maximum

Minimum

Maximum

Minimum

Maximum

Minimum

Maximum

Minimum

Maximum

Minimum

Maximum

Minimum

Maximum

Minimum

Maximum

Minimum

Maximum

Minimum
1532

1536

1536

1536

1536

1536

1536

1534

1548

1548

1538

1536

1536

1553

1553

1542

1537

1537

1548

1547

1534 
nificant in the main text 


\begin{tabular}{ccc} 
Test statistic & $\mathbf{N}$ & $\mathbf{P}$ \\
\hline- & - & - \\
-452.5 & 44 & 0.2918 \\
$-3,5$ & 6 & $0.0513^{\times}$ \\
-829.0 & 59 & 0.3196 \\
-103.5 & 22 & 0.1969 \\
-473.5 & 45 & 0.2928 \\
-3.5 & 6 & $0.0513^{\times}$ \\
-452.5 & 44 & 0.2018 \\
-3.5 & 6 & $0.0513^{\times}$ \\
-829.0 & 59 & 0.3196 \\
-103.5 & 22 & 0.1969 \\
-351.0 & 39 & 0.2686 \\
-3.5 & 6 & $0.05125^{\times}$ \\
-565.0 & 48 & 0.3952 \\
-162.0 & 26 & 0.3475 \\
-1538.5 & 86 & $\left.0.0536^{*}\right)$ \\
-966.5 & 70 & $0.0334^{*}$ \\
-1684.0 & 89 & $\left.0.0727^{*}\right)$ \\
-598.5 & 57 & $0.0195^{*}$ \\
-1088.5 & 68 & 0.2857 \\
-646.0 & 53 & 0.2535 \\
-829.0 & 59 & 0.3196 \\
-247.5 & 33 & 0.2525 \\
-829.0 & 59 & 0.3196 \\
-247.5 & 33 & 0.2525 \\
-1252.5 & 81 & $0.0153^{*}$ \\
-375.0 & 50 & $0.00195^{* *}$ \\
-1873.5 & 96 & $0.0315^{*}$ \\
-580.5 & 59 & $0.0047^{* *}$ \\
-855.0 & 63 & 0.1192 \\
-638.0 & 55 & 0.1074 \\
-870.0 & 61 & 0.2695 \\
-304.0 & 37 & 0.2056 \\
-870.0 & 61 & 0.2695 \\
-304.0 & 37 & 0.2056 \\
-1495.0 & 85 & $0.0495^{*}$ \\
-966.5 & 70 & $0.0334^{*}$ \\
-594.0 & 56 & $0.0309^{*}$ \\
-128.0 & 31 & $0.0036^{*}$ \\
-770.0 & 56 & 0.3981 \\
-115.0 & 22 & 0.3349 \\
\hline & & \\
\hline
\end{tabular}




\section{Character state}

Description

39.1

58.1

68.1

210.2

231.1

333.1

337.1

338.1

342.1 lose squamosal-quadrate articulation

maxillary triturating surface with labial and lingual ridge vomer contributing to upper triturating surface reduction of costal ossification presence of plastral fontanelle humerus longer than femur rigid articulations in first and second mandual digit rigid articulations in third through fifth manual digit flattening of carpal and tarsal elements 


\section{Synapomorphy}

total-group chelonioids; plesiochelyids

total-group chelonioids; plesiochelyids

cheloniids; sandownids

total-group chelonioids; thalassochelydians

total-group chelonioids

total-group chelonioids

crwon-group chelonioids

total-group chelonioids

total-group chelonioids
Functional relevance

?underwater hearing

feeding

secondary palate

functinal interpretation unclear

functinal interpretation unclear

swimming

swimming

swimming

swimming 